\title{
The Dynamics of Refugee Return: Syrian Refugees and Their Migration Intentions *
}

\author{
Ala' Alrababa'h ${ }^{1,2}$, Daniel Masterson ${ }^{2,3}$, Marine Casalis ${ }^{2}$, \\ Dominik Hangartner ${ }^{1,2,4}$, Jeremy Weinstein ${ }^{2,5}$
}

\author{
${ }^{1}$ Center for International and Comparative Studies, ETH Zurich \\ ${ }^{2}$ Immigration Policy Lab, Stanford University and ETH Zurich \\ ${ }^{3}$ Department of Political Science, University of California, Santa Barbara \\ ${ }^{4}$ Department of Government, London School of Economics and Political Science \\ ${ }^{5}$ Department of Political Science, Stanford University
}

\begin{abstract}
November 1, 2022
This version to appear in the British Journal of Political Science.
\end{abstract}

${ }^{*}$ The authors would like to thank Claire Adida, Stathis Kalyvas, Kelsey Norman, Stephanie Schwartz, Alexandra Siegel and workshop participants at the American University in Beirut, APSA 2019 and 2020, CaliWEPS III, EGAP 2019, and MESA 2019. We thank Nasser Yassin and AUB's Issam Fares Institute for hosting a research design workshop and providing input on several aspects of the research. We are grateful to Oxfam and Amel for their support with several parts of the project and to CARE for sharing some of their data on the return intentions of Syrians in Jordan with us. We also thank staff at Basmeh \& Zeitooneh, SMEX, IRC, DSP, and Human Rights Watch. Funding for this project was provided by the UK Foreign, Commonwealth \& Development Office awarded through Innovation for Poverty Action's Peace \& Recovery Program, the Swiss Network for International Studies, the Leverhulme Trust, a consortium of the Wellcome Trust, the Riksbankens Jubileumsfond, the Volkswagen Stiftung, and the Swiss Federal Department of Foreign Affairs. All analyses, unless otherwise noted, were pre-specified in EGAP registration 20190914AB. This project was reviewed and approved by the Stanford Human Subjects Committee under IRB protocol 49387 and by the Ethics Committee of ETH Zurich. 


\begin{abstract}
We study the drivers of refugees' decision-making about returning home using observational and experimental data from a survey of 3,003 Syrian refugees in Lebanon. We find that the conditions in refugee-hosting countries play a minor role. In contrast, conditions in a refugee's home country are the main drivers of return intentions. Even in the face of hostility and poor living conditions in host countries, refugees are unlikely to return unless the situation at home improves significantly. These results challenge traditional models of decision-making about migration where refugees weigh living conditions in the host and home countries ("push" and "pull" factors). We offer an alternative theoretical framework: a model of threshold-based decision-making whereby only once a basic threshold of safety at home is met do refugees compare other factors in the host and home country. We explore some empirical implications of this new perspective using qualitative interviews and quantitative survey data.
\end{abstract}




\section{Introduction}

Mass forced displacement has proven to be an enduring challenge in contemporary international politics. Forcibly displaced people face joblessness and food insecurity, lack legal status, and experience hostility and violence in host countries. Meanwhile, the governments of many hosting countries struggle to meet the additional demands that refugees place on public services and infrastructure (Verme et al., 2015). The consequences of forced migration are most acute in developing countries - where more than $85 \%$ of refugees reside - due to constrained government budgets, weak state capacity, and limited public infrastructure 1 Making matters worse, as of 2018-2019, 78\% of all refugees worldwide were in protracted refugee situations, living in exile for more than five consecutive years. The largest protracted refugee populations are Afghans, Syrians, and South Sudanese; the vast majority of these people reside in neighboring countries in the Middle East and North Africa and South Asia:2

Despite the significant challenges that refugee crises pose to refugees themselves, hosting countries, and international donors, effective responses are lacking. Each year over the last decade, less than $1 \%$ of refugees worldwide received citizenship in a hosting country and only 1-2\% were resettled ${ }^{3}$ Further, governments in hosting countries often restrict refugees' rights and prospects for integration in order to accelerate return (Janmyr, 2016). The vast majority of refugees remain in a state of limbo, neither able to integrate locally nor find a new home through resettlement.

How then do refugee crises come to an end? To answer this question, we need an understanding of whether, when, and why refugees return home. But this proves to be a challenging issue to explore empirically. Existing administrative data on refugee return is incomplete: in the past, many returns went unrecorded and the definition of return varied across organizations and across countries, making systematic analysis difficult. Moreover, data collection is especially challenging with mobile populations. The unpredictable timing of return means that it has been difficult to capture household return migration through surveys, especially in contexts of ongoing violence, which compound challenges related to data collection and sample attrition.

\footnotetext{
${ }^{1}$ UNHCR: https://tinyurl.com/unhcrglobaltrends2018wb

${ }^{2}$ UNHCR: https://tinyurl.com/unhcrprotractedwb UNHCR statistics do not include the 5.7 Palestinian refugees who are under UNRWA's mandate. If Palestinians were included the statistics would shift to 21.7 million people in protracted refugee situations, accounting for $83 \%$ of refugees worldwide.

${ }^{3}$ UNHCR: https://tinyurl.com/unhcrglobaltrends2018wb, pp. 28-33.
} 
We tackle the challenges of studying refugee return with original, cross-sectional survey data from a nationally representative sample of 3,003 Syrian refugee households in Lebanon. This constitutes the first important contribution of our paper. By supplying data on return intentions and preparations for refugees, as well as how intentions vary in the short- and long-term, our study provides novel and hard-to-collect descriptive data on how refugees think about return. We then use this data to examine predictors of return intentions and preparations, to explore the role of information, and to identify differences in the drivers of short- and long-term return intentions. We supplement analysis of observational data with a conjoint experiment in order to isolate the causal effect of conditions in Syria and Lebanon on return intentions and semi-structured interviews with Syrians living in Lebanon. Finally, we explore the generality of our findings using a second original survey of Syrian refugees in Jordan.

The Syrian refugee crisis in Lebanon provides a useful setting in which to examine the dynamics of refugee return. When we conducted data collection in mid- and late-2019, active conflict in Syria was diminishing and many governmental and humanitarian organizations had begun discussing and even facilitating returns. Conditions across Syria varied widelymany areas remained insecure, and overall prospects for safety, economic recovery, and service provision were uncertain. At the same time, Syrian refugees in Lebanon experienced highly differentiated living conditions, local government policies, and levels of community hostility. In some municipalities, local governments actively targeted refugees for harsh treatment and prominent politicians called for accelerating their return, while in others refugees were integrating both economically and socially. We leverage this variation in prospects in the country of origin and well-being in the host country to learn about the drivers of return intentions.

Our theoretical starting point is the "push" and "pull" framework, which suggests that refugees decide whether to return to their home country or stay in the host country based on a comparison of conditions in the two locations. This model draws its intellectual origins from the neoclassical economic model of migration (Borjas, 1987; Borjas and Bratsberg, 1996), and has long informed both research and policy discussions of return migration (e.g. Oxfam, 2018; El Asmar, Shawaf and Mikdashi, 2019; The World Bank, 2020). Our empirical results call into question the relevance of the push-pull framework for refugee decision-making. In particular, we find that on average, push factors in the hosting country have a small impact on refugee's aspirations to return. Across a range of potential drivers, conditions in Lebanon 
do not substantially shape return intentions, even though many Syrians confront extremely challenging living situations.

Before data collection for this project, we registered our research hypotheses (along with statistical models to test them), including our expectations that host-country conditions would shape return intentions. We expected host-country conditions to matter for a number of reasons. First, existing theoretical models of migration operate under a framework of comparing well-being in both the place of residence and potential destinations (Borjas, 1987 , Massey et al., 1993; Borjas and Bratsberg, 1996). Second, evidence from related studies of return among labor migrants and internally displaced populations find that conditions in the place of residence are important drivers of return choices (Constant and Massey, 2003. Dustmann and Weiss, 2007; Arias, Ibáñez and Querubin, 2014 Stefanovic, Loizides and Parsons, 2015). Further, governments in many refugee-hosting countries implement policies that undercut refugee well-being with the goal of pushing refugees to return (Janmyr, 2016). Advocacy organizations and media reports have repeatedly called attention to Lebanon's policy of refugee immiseration to coerce Syrians to return $5^{5}$

Instead, we find that conditions in the home country predict the return intentions of refugees. To explain these results, we propose an alternative framework for understanding refugee return. Specifically, our threshold model suggests that refugees do not trade safety in the country of origin for other goods, such as economic conditions and public service provision, as long as their safety concerns are not met. Only once safety in the country of origin passes a certain threshold do refugees begin to consider other factors. We provide qualitative and survey data that are consistent with this explanation. Overall, we find that despite having been displaced for nearly a decade and having little hope to return in the near future, people who have fled the violence and societal devastation of civil war generally want to return home when those threats dissipate.

This article contributes to an emerging body of work on the drivers of return among displaced populations. Much of the existing work focuses on internally displaced persons (IDPs), who face the question of whether to return to their place of origin after flight within their country Arias, Ibáñez and Querubin, 2014, Stefanovic, Loizides and Parsons, 2015. Camarena and Hagerdal, 2020; Weber and Hartman, 2022). A small but growing body of

\footnotetext{
${ }^{4}$ Pre-specified in EGAP registration 20190914AB.

${ }^{5}$ Advocacy groups: see, e.g., Amnesty International (https://tinyurl.com/amnesty2019) and Human Rights Watch (https://tinyurl.com/humanrightswatch2016). Media: see, e.g., Foreign Policy (https:// tinyurl.com/foreignpolicy2019) and Middle East Institute (https://tinyurl.com/mei-dagher-2021).
} 
research has begun to shed light on the return choices of refugees, people who flee their home country during conflict and as a result face choices and constraints distinct from those that IDPs confront (Beber, Roessler and Scacco, 2021; Ghosn et al., 2021; Beaman, Onder and Onder, 2022). This is important as refugees generally have fewer prospects for longterm settlement in their place of refuge than IDPs do as citizens in their home country, and refugees face distinct legal, political, and economic challenges in a foreign country from those that IDPs face. We also contribute to this work by providing evidence on the role of a comprehensive set of theoretically motivated drivers of return decisions. Building on recent studies such as Ghosn et al. (2021), which focuses on refugees' wartime experiences and psychological anchoring, we extend the scope and examine a broad range of factors including material well-being and future prospects. Finally, our detailed measurement of return intentions and preparations allows us to study the interrelated roles of timing and aspirations, building on recent work that focuses on observed migration behavior (see, e.g, Beaman, Onder and Onder, 2022; Camarena and Hagerdal, 2020). In light of the many constraints that refugees face, evidence on return intentions is important because focusing solely on migration behavior does not allow us to distinguish if someone stays in exile because they were unable to return, preferred to not do so, or both (Schewel, 2020).

More broadly, our research advances the literature on host country politics. Traditionally, research on immigrant-native dynamics focuses on host populations in the receiving country, examining the effect of immigration and refugees on local labor markets (e.g., Scheve and Slaughter, 2001), political attitudes and behavior (e.g., Hainmueller and Hopkins, 2014), and tensions, discrimination, and conflict (e.g., Adida, 2014). This paper explores the possibility that these host country dynamics may in turn shape choices about return. Importantly, despite the significant tensions with locals and active efforts to make host societies less hospitable, our results show that refugees may be willing to live with extreme hardship in the absence of a viable opportunity to return to their home country.

\section{When Do Refugees Return?}

We approach return migration through the lens of household decision-making - an approach that enables us to consider the impact of macro-level factors in a host country or the home country, sub-national processes including localized violence and anti-refugee sentiments, and micro-level measures of household experiences, beliefs, and resources. We define return as 
moving from a host country to one's home country with no immediate plans to depart again. Our focus is on the binary choice of whether to return to the home country, thereby setting aside other migration-related choices that refugees face such as internal migration within a host country, location choice within their home country after return, and formal or informal migration to a third country.

In identifying the factors that influence return, our starting point is the "push" and "pull" factors framework. The intellectual origins of this framework flow from neoclassical economic theories of migration (Borjas, 1987). Though developed to explain patterns of labor migration, these models provide a useful framework for understanding individual decisions to migrate based on the costs and benefits of living in different countries. From this perspective, potential migrants consider their long-term expected well-being in the country in which they live against conditions in possible destination countries, while accounting for the costs of travel, the challenges of adapting to a new labor market and culture, and any non-monetary costs or benefits of migration.

This framework is what underlies a focus in policy discussions on the relative importance of "push" and "pull" factors in the decisions of refugees about return. In this context, "push" refers to the conditions in the hosting country, while "pull" refers to the situation at home. For example, drawing on comparative experience, a recent World Bank report (2020) describes the "mobility calculus" of refugees in terms of a weighing of different structural conditionspeace, security, and protection; livelihoods and economic opportunities; housing, land, and property; and infrastructure and access to services - in the host and home countries. Recent NGO reports from the Middle East adopt a similar framing, arguing that refugees actively consider whether life will be better at home than in their host country. They also explicitly state that push factors may encourage refugees to return prematurely (e.g., Oxfam, 2018). But because conditions are often so difficult in both places, some argue that we need to think of these conditions as push factors in both settings (e.g., which is the better of two bad options) rather than push and pull factors (El Asmar, Shawaf and Mikdashi, 2019).

The logic of the push-pull framework has also informed Lebanon's response to the refugee crisis (Janmyr, 2016). Under the assumption that making life difficult for refugees will push them to return, the Lebanese government has long imposed significant restrictions on Syrian refugees. For instance, the Lebanese government has increased the difficulty and expense of obtaining residency permits for Syrian refugees. This effectively limits Syrians' access to education and healthcare and subjects them to detention and forcible return Amnesty 
International, 2015). A recent report by the Carnegie Endowment calls on the international community not only to stop forced return but also to reduce "factors in the host countries that push refugees to return home prematurely" (Yahya, 2018, p. 52).

Although one might question the value of rational choice models of migration in contexts of forced displacement, recent research on refugees and IDPs has found evidence that this framework provides important insights even in environments where initial decisions to move were influenced by violence. For example, a study of Lebanese Christians who were internally displaced during the country's civil war in the 1980s finds that, in the absence of attractive economic opportunities, people may not return to their home areas even if they have strong aspirations to do so (Camarena and Hagerdal, 2020). In the Colombian context, researchers found that, across a range of measures, IDPs were more likely to return home when their prospects were good (including land ownership, work opportunities, and social networks); conversely, they were less likely to return home when they could do better in their reception site (Arias, Ibáñez and Querubin, 2014).

Building on this framework, we hypothesize that refugees' choices about return are shaped by four key conditions: (1) the situation in the host country (2) the dynamics in the country of origin (3) the costs of movement and (4) the quality of information about the costs and benefits of return.

Conditions in the host country: When assessing their prospects in the host country, refugees evaluate their household well-being along multiple dimensions: are they employed, do they have access to humanitarian aid, are public services available, are they welcomed by their surrounding communities, and is there a path to formal legal status. These critical elements have been shown in previous work to be primary determinants of decisions to return. For example, Constant and Massey (2003) find that a lack of stable full-time employment roughly doubles the odds of return migration for foreign workers in Germany. Arias, Ibáñez and Querubin (2014) find that IDPs in Colombia are roughly four percentage points more likely to intend to return if the household head is unemployed. And Stefanovic, Loizides and Parsons (2015) find that integration into a new environment in western Turkey, measured by economic advancement and knowledge of Turkish, decreased return intentions among displaced Kurds from eastern Turkey. All else equal, we expect that improvement on any of these dimensions will increase the perceived value of remaining in the host country, making return less likely. Likewise, a worsening of the situation in the host country will increase the aspiration to return. Historically, host governments often apply intense pressures for 
refugees to return en masse (see, e.g., Janmyr, 2016, Schwartz, 2019), gradually ramping up anti-refugee rhetoric and undercutting refugees' legal residency and right to work. Often, the rationale behind such restrictions is that harsher living conditions will incentivize refugees to return home.

We expect conditions in the host country to play an important role in our study context. As we explain in the next section, the Lebanese government has long attempted to make life difficult for Syrian refugees, including through restrictions on the right to work and access to services Janmyr (2016). Furthermore, there is significant local variation in the levels of hostility toward Syrian refugees. Some Lebanese welcome Syrians because they perceive them to be escaping a brutal dictatorship and a violent civil war. Others view Syrians as a demographic threat to the country's sectarian balance. This variation in hostility is reflected in local government policies, with some municipalities imposing curfews targeting Syrians, as well as in discrimination by the local authorities and the host community.

Conditions in the home country: Decisions about return also depend on the environment in the home country. Refugees must consider both the current conditions in their country of origin and their expectations about how the situation will evolve. Economic prospects are one key part of the decision-making calculus, as refugees assess the quality of the post-war economy, access to public services, and the viability of meeting their family's basic needs. For example, in Colombia Arias, Ibáñez and Querubin (2014) show that people who own land or have prospects for employment in their place of origin have higher return intentions. Beber, Roessler and Scacco (2021) find that the South Sudanese residents of North Sudan who were least likely to return were the middle class for whom employment opportunities were scarce in the South. War may also impact people's economic prospects by generating disputes over public policy or property rights (Schwartz, 2019). In one example of such dynamics, Weber and Hartman (2022) demonstrate that displaced Iraqis were more likely to return if they had property at the place of origin only when they possessed written documentation of their rights and the property was not disputed or badly damaged.

Refugees also must consider the security situation at home. For example, will violence pick up again and would it affect the region they are from? Moreover, might they be at risk of targeted persecution or arrest upon return? As households assess their safety if they were to return, they may consider current levels of violence in their hometown, their connections or proximity to existing political divisions, and expectations about continued violence and persecution by the government or armed groups. Overall, we expect that better conditions 
in the home country will be associated with greater aspirations and preparation to return.

In addition, we expect networks of friends and family to predict return intentions. After over a decade of civil war, many refugees have not seen their relatives and friends in Syria for several years. As the regime regains broad control in Syria and fighting abates, reuniting with relatives and friends could provide a particularly important reason for people to return. Further, when people consider returning, networks in their places of origin can provide critical support by offering shelter and connections to opportunities. This argument is in line with Arias, Ibáñez and Querubin (2014), who find that social networks in people's places of origin (measured through membership in a peasant organization or collective land ownership) increase return intentions.

Mobility Costs: Households considering return migration also weigh the financial costs and physical risks associated with moving (Hunt and Mueller, 2004). Long-distance travel for refugees, in particular, may be expensive and require passage through unsafe territory. Returning refugees may also face the prospect of being stopped at checkpoints run by the state or armed groups that charge tolls or taxes, steal possessions, or detain, interrogate, or abuse travelers. Depending on people's legal status and relationship to the state and other actors, they may need to undertake costly or dangerous informal travel, using smugglers or traveling through remote territory to avoid authorities. Given these concerns, we expect that households facing higher mobility costs will be less likely to return.

Information: Finally, any effort to compare the prospects for household well-being in the host and home countries depends critically on the quality of information about conditions in the country of origin. Yet refugees fleeing violence may lack access to information about localized conditions in their home country. Social networks are often disrupted and those who remain behind may face strong disincentives to share information about local conditions, especially in repressive countries. Moreover, the situation on the ground can change often and differ even across small geographies. This makes it challenging for refugees to evaluate their potential well-being in the place of origin. In the absence of good information about conditions in their places of origin, we expect refugees to be less likely to return home.

\section{The Syrian Refugee Crisis in Lebanon}

To shed light on the drivers of refugee return intentions, we focus on the Syrian refugee crisis in Lebanon. (We later validate our findings using similar data from Jordan.) Given 
the diversity of localities in which Syrians have settled and the heterogeneity in conditions in Syria, this is a helpful case for examining the role of push and pull factors, mobility costs, and information in shaping return intentions. Lebanon, in particular, provides a critical test of the importance of push factors, given the documented hostility, discrimination, and violence that many Syrians have faced in Lebanon (Lehmann and Masterson, 2020). Advocacy groups have repeatedly reported that Lebanon's unlawful evictions, curfews, raids and arrests make life miserable for Syrian refugees, forcing many to return to Syria despite its dangerous conditions ${ }^{6}$ In addition, the context provides meaningful variation in prospects in Syria, mobility costs, and access to information. Syrians in Lebanon vary widely in their characteristics and backgrounds, originating from all of Syria's regions and spanning the country's pre-war socioeconomic spectrum.

What began in Syria in 2011 with street demonstrations and calls for political reforms collapsed into a devastating civil war, which caused an enormous refugee crisis, with millions of people fleeing to Lebanon, Jordan, Turkey, Iraq, Egypt and beyond. As of late 2019, when our study was conducted, more than five million Syrians had fled to neighboring countries and more than six million were displaced inside Syria. Approximately 930,000 Syrians lived in Lebanon, alongside 4.5 million native residents, in a small country with the smallest land area in continental Asia.7

One driving assumption behind Lebanon's national policy agenda for Syrian refugees is that exploitation, vulnerability, and material hardship will force Syrians to leave the country (Janmyr, 2016). Syrians in Lebanon face widespread hostility, confront significant restrictions on the right to work, and have only limited legal status in the host country. Most Syrians in Lebanon lack reliable access to education, healthcare, stable housing, and safe transportation (see, e.g., Mourad, 2017; Lehmann and Masterson, 2020). They live primarily in urban and peri-urban settings, with $15 \%$ in camps, informally managed by NGOs, as the UN did not establish official refugee camps in the country. The situation of Syrians in Lebanon is similar in many respects to the hardship that refugees worldwide face; notably, many governments restrict refugee rights in order to accelerate return and, worldwide, less than one third of the world's 26 million refugees live in camps.

\footnotetext{
${ }^{6}$ See, e.g., Amnesty International (https://tinyurl.com/amnesty2019).

${ }^{7}$ We use UN registration numbers, which provide a conservative estimate of displacement. Refugee population: UNHCR Operational Portal. https://data2.unhcr.org/en/situations/syria. IDP data: UNHCR Refugee Data Finder. https://www.unhcr.org/refugee-statistics/. And IDMC. https: //www. internal-displacement.org/countries/syria. Accessed November 15, 2019.
} 
As the Syrian government regains control of much of the country, tens of thousands of Syrians have begun returning home, even as violence continues to displace more people. State and non-state actors in Lebanon have begun taking steps to facilitate and push for the return of refugees, tensions between Lebanese and Syrians remain high, and discussions about the return of refugees are increasingly prominent in journalistic and policy circles. Looking to Syria, the war has devastated the country's infrastructure and public services, including water supply, electricity, schools, and healthcare. Many people fear the persecution and violence that may result from government retribution and collective punishment in the postwar period. Men aged 18-42 are subject to military conscription in Syria, and serving in the Syrian military is likely to put conscripts in violent situations for years to come. Even if the ultimate victor in the war is no longer in question, the specter of future violence remains.

\section{Research Design and Data}

\subsection{Survey Design}

We use original survey data from interviews with a nationally representative sample of 3,003 Syrian refugee households living in Lebanon.8 The survey measured a wide range of household characteristics, predictors of return, and migration intentions, and also included a conjoint experiment to identify drivers of return intentions. The research team contracted a Lebanese survey firm to conduct data collection, and participated in all stages of the research including enumerator training, survey piloting, and oversight of data collection. Data collection for the survey took place from August to October 2019.

To obtain a representative sample of Syrian households in Lebanon, we used stratified random sampling to ensure variation in Syrian and Lebanese demographics in localities and households sampled. A household head (either gender) served as survey respondent. Appendix Section 1 provides a detailed discussion of sampling protocols.

\footnotetext{
${ }^{8}$ Conducting research with Syrian refugees in Lebanon requires particular attention to the sensitive situation in which they live. See Appendix Section 8 for a full discussion of our study's ethical considerations and precautions.
} 


\subsection{Measuring Return Intentions}

Measuring return intentions is challenging, and survey instruments must account for the different time horizons across which households consider decisions in addition to the uncertainty that people face. Capturing intentions is also difficult in the absence of concrete behaviors consistent with stated intentions. As a result, we also measure preparations to return, as a self-reported but behavioral manifestation of return intentions. We asked respondents about their return intentions in three ways:

- Return intentions: "Do you plan to return to Syria in the next 12 months with the goal of staying there?"

- Return preparations: We asked a battery of binary questions about legal, financial, and logistical steps to prepare for return. Metrics of preparation include saving resources for return, collecting paperwork such as birth certificates or marriage documents, reaching out to Lebanese authorities and UNHCR about return, and taking scoping trips. We use these questions to calculate a preparations index with polychoric principal component analysis (PCA).

- Long-term return intentions: "Do you hope to move back to Syria and live there one day?"

The return intentions measures are binary variables, coded as 1 if the head of household plans to return within the specified time frame and 0 otherwise. $!^{9}$ It is worth noting that our key outcomes are stated intentions and self-reported preparations to return, not a retrospective measure of return behavior. Such forward-looking outcomes are an important quantity of interest as people consider whether to return and policymakers design and implement programs to address refugee situations. A foundational principle of return policy is ensuring its voluntary nature, which requires placing people's intentions to return at the center of planning (see, e.g., Mixed Migration Centre, 2019, p. 93).

\subsection{Measuring Drivers of Return}

We measure four key concepts that we hypothesize will drive return decisions: (1) well-being in Lebanon, (2) prospective well-being in Syria, (3) information, and (4) mobility costs. To

\footnotetext{
${ }^{9}$ Robustness tests using alternative coding for the outcome are included in Appendix Section 6.4.
} 
measure concepts 1-3, we draw on data from multiple survey questions and use PCA to construct indices to capture aspects of respondents' living situation in Lebanon, prospects in Syria, and access to information. We present the full set of PCA inputs in Appendix Sections 2 and $34^{10}$ In both Syria and Lebanon, we measure economic well-being, using data on assets and earning potential in each country, and current employment, earnings, and aid in Lebanon. We also examine the availability of services, including education, healthcare, water, and electricity, in Lebanon and Syria. We analyze the size of social networks and the number of friends and family in Lebanon and Syria. We measure people's ability to move freely and safely around Lebanon, and their integration in the country using the measures from the IPL-12 integration scale (Harder et al., 2018). To construct an index for the security situation in Syria, we focus on both general factors, such as whether there is still fighting, and personal factors, such as whether a family has any draft-aged men and whether the respondent personally experienced violence. The index on safety also includes an input about safety expectations in one year. The indices on economic conditions and services in Syria also include inputs that measure expectations about the future situation. We also construct an index for regime control, including detailed questions on which parties currently and formerly controlled a respondent's hometown 110 The index for information includes whether the respondent speaks regularly with family or friends in Syria about the situation as well as measures of people's confidence in the information they have about safety, jobs, services, and conscription in their hometown.

In addition to measuring people's confidence in information directly, we ask questions about the size of refugees' networks in the host and the home country. Family and friends may serve as important sources of information about the conditions in one's hometown. Networks of family and friends may also directly impact people's return choices independent of the information they provide, in the sense that many people want to live in the same place as others in their close network.

We study mobility costs using two metrics: travel distance to one's hometown and household size. We calculate travel distance from each survey respondent's town of residence in Lebanon to their hometown in Syria, via the Beirut-Damascus highway and border crossing, using the Google Maps API. Our fieldwork revealed that this was the only legal border

\footnotetext{
${ }^{10}$ Although PCA inputs were pre-specified, some survey questions were listed in the PAP for inclusion in two indices. We departed from the PAP in these cases in order to maintain mutually exclusive index inputs. Appendix Section 5 documents these changes.

${ }^{11}$ We deviated from the PAP to separately study the role of regime control and safety conditions in Syria.
} 
crossing open at the time of research and that a majority of Syrians moving back travel via official routes.

One potential concern with our survey is that affective biases may shape both people's self-reports of their situation and their return intentions, possibly leading to spurious correlations. To mitigate this threat, our metrics of well-being in Lebanon and prospects in Syria aim to measure objective facts rather than people's opinions. For instance, we ask respondents questions including "Did you work outside the home for money in the past 30 days?" and "Do you receive humanitarian aid through the UN cash assistance program?" (rather than about affect such as "How would you rate the quality of your life in Lebanon?").

\subsection{Conjoint Experiment}

We also present a conjoint analysis that experimentally manipulates potential drivers of return intentions ${ }^{12}$ This allows us to isolate the effects of conditions in Lebanon and Syria, individual circumstances, and social networks in shaping respondents' thinking about return. During the survey interview, enumerators read to respondents a sequence of five separate hypothetical vignettes, and after each one asked the respondents whether, under these conditions, they would you return to Syria. In the vignettes, each of the numbered attributes below was randomly given one of the lettered values, and the order of the attributes was randomized across respondents. The vignettes were presented as follows:

Imagine that one year from now, regarding the security situation in Syria, [INSERT FROM (1) BELOW]. It appears that in [INSERT HOMETOWN], [INSERT FROM (2)]. As for conscription, [INSERT FROM (3)]. In Lebanon, [INSERT FROM (4)]. Finally, regarding your friends and relatives, [INSERT FROM (5)]13

\footnotetext{
${ }^{12}$ See also, Ghosn et al. (2021) and Beaman, Onder and Onder $(2022)$.

${ }^{13}$ Two substantive areas - jobs and services - were included in one conjoint attribute in order to reduce length and increase respondent comprehension (which was important because many respondents had relatively low literacy levels. So the enumerators read the conjoint vignettes to all respondents and we wanted to ensure that the vignette remained short and comprehensible). We analyze these substantive areas separately by comparing possessing a good job against the reference category of lacking a good job and by comparing available and affordable public services against the reference category of unavailable and unaffordable public services.
} 
1. Safety in Syria: (a) Your hometown is quite safe; (b) Your hometown remains insecure; (c) All of Syria is quite safe

2. Economic conditions in Syria: (a) There are many job opportunities; (b) Public services, such as health centers and schools, are relatively easy to attain; (c) There are few job opportunities; (d) Public services, such as health centers and schools, are difficult to attain

3. Personal safety: (a) Military conscription has stopped; (b) Military conscription is still in place

4. Conditions in Lebanon: (a) You have a good job in Lebanon; (b) You do not have a good job in Lebanon; (c) Health centers and schools in Lebanon are available and affordable; (d) Health centers and schools in Lebanon are unavailable and unaffordable

5. Network effects: (a) Most of your friends and relatives are in Lebanon; (b) Most of your friends and relatives are in Syria; (c) Most of your friends and relatives are in Jordan, Turkey, and Iraq

\section{Results: Observational Data on Return Intentions}

We begin by describing our sample. Around 50\% of our 3,003 respondents reside in urban areas in Lebanon and $33 \%$ live in informal settlements. The median year of arrival for respondents was 2013. The majority, 80\%, are registered or recorded with UNHCR. In terms of education levels, $49 \%$ had an education level less than completing primary school, $39 \%$ completed primary school, and $12 \%$ had a secondary education or higher. As for aid, $48 \%$ of respondents received cash transfers, $62 \%$ received food vouchers, and $32 \%$ received both. Discrimination toward refugees in Lebanon is quite high but far from universal. 37\% of respondents reported living in towns that had curfews in the past two years (which usually target refugees) and $40 \%$ reported facing discrimination when searching for housing. Finally, when it comes to conditions in Syria, $67 \%$ of respondents reported that protests occurred in their hometown during the revolution and $96 \%$ said that there was heavy fighting in their hometown at some point during the war. By the time the survey was conducted, $66 \%$ of respondents said that their hometowns were controlled by the government. 


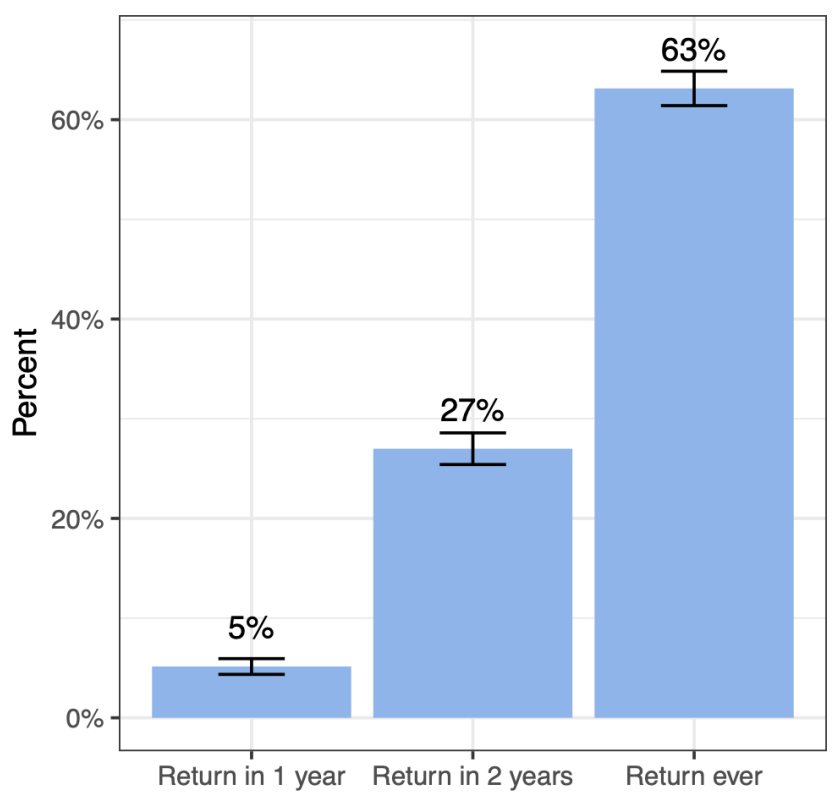

Figure 1: Return Intentions (Short, medium, and long-term)

We examine the distribution of return intentions in Figure 1. We find that return intentions are increasing with the time horizon. Only 5\% of Syrians plan to return in the next 12 months, that is, before approximately September 2020, and about a quarter of Syrians anticipate returning before September 2021. $63 \%$ plan to return at some point in the future ${ }^{14}$ To put these numbers in context, the median year of arrival for respondents was 2013, meaning that the median respondent had been displaced for more than six years at the time of data collection.

To study how cross-sectional differences shape return intentions, we examine the predictive power of a range of potential drivers of refugee return described above. We estimate the following regression model:

$$
Y_{i}=\alpha+\beta T_{i}+\gamma X_{i}+\epsilon_{i}
$$

for each outcome $Y$ and a vector of indices $T$. Each index is the first principal component from a PCA analysis of the measures detailed in Section 4.3. We also adjust for a range of control variables, $X$, including household-level covariates and locality-level fixed effects.

\footnotetext{
${ }^{14}$ We impute missing values in our data using multivariate imputation by chained equations, discussed in Appendix Section 3.
} 
Control variables were defined in the pre-analysis plan and are presented in full in Appendix Section 2.3. Finally, $\epsilon$ is a mean-zero error term. We also run a series of regression models similar to Equation 1) but where the vector of indices $T$ is replaced with each respective index in one model 15

\subsection{Drivers of Return Intentions}

We present results for the drivers of return intentions in Figure 2. Each dot represents the point estimate for the relationship between a given index, labeled on the y-axis, and a metric of return, labeled at the top of each panel. Circles represent point estimates drawn from our main model in Equation 1, and triangles represent point estimates drawn from models with each respective index in a separate regression. The independent variables are grouped into four categories: people's prospective situation in Syria, people's living situation in Lebanon, mobility costs to return to Syria, and people's confidence in the information they possess about Syria. The horizontal line around each point estimate shows the $90 \%$ and 95\% confidence intervals (dark and light, respectively). Standard errors are clustered at the locality level, following from the sampling strategy. Indices are normalized to have mean zero and standard deviation one, and the point estimates present the change in the probability of return intentions that corresponds to a one standard deviation shift in an index. As shown in the Appendix Section 6.5, results are robust to using additive indices rather than PCA indices and using alternative control sets.

Figure 2 provides strong evidence for a relationship between conditions in Syria and intentions to return within 12 months (first panel). We see that safety in Syria, economic prospects in Syria, the availability of public services in one's hometown, and respondents' family and friend networks in Syria are positively and significantly associated with return. For each of these indices, we see that a one standard deviation shift in the index corresponds with about a 2 percentage point increase in return intentions. In light of the small fraction of refugees (only 5\%) who plan to return in the next year, this constitutes a large increase in return intentions in percentage terms (roughly 40\%). Control by the Syrian government correlates negatively with intentions to return, although we cannot rule out a null relationship at either the $90 \%$ or $95 \%$ level.

The relationship between conditions in Syria and preparations for return (second panel)

\footnotetext{
${ }^{15}$ Figure 2 involves two deviations from the PAP due to multicollinearity, discussed in Appendix Section 5 .
} 


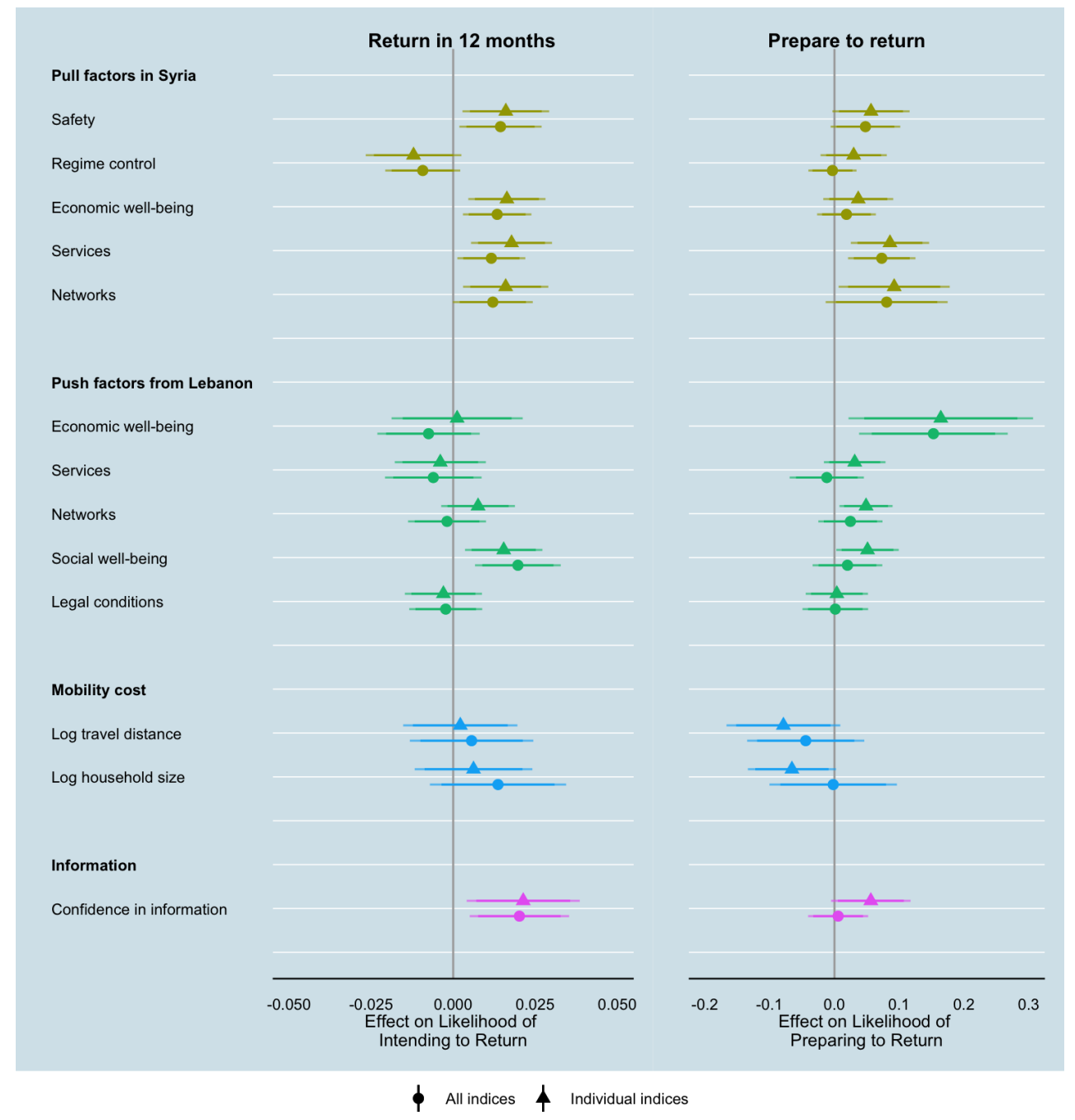

Figure 2: Index Results -Effects on Return Intentions and Preparations. Each dot represents the effect on return intentions (left panel) and return preparations (right panel) presented with its corresponding 95\% (thick lines) and 90\% (thin lines) confidence intervals. The triangles represent the regression that includes each index alone as well as demographic controls. The circles represent the regression that includes all the indices in the same regression as well as demographic controls.

is less clear but points in the same direction. Point estimates are consistently positive, but only the availability of services and the size of social networks are statistically significant. Security in Syria and economic prospects predict preparations to return but the results are not statistically significant. Regime control has no detectable relationship with preparations to return. 
The results on push factors in Lebanon are quite different. First, looking at the left panel, we do not find a clear correlation between well-being in Lebanon and return intentions. We cannot rule out a zero association for most of the indices. The one index that demonstrates a statistically significant association with return intentions is social well-being. In contrast to the lack of evidence for a role of push factors in shaping return intentions, the second panel reveals evidence for an association between conditions in Lebanon and return preparations. We find that higher levels of economic well-being, networks, and social well-being in Lebanon exhibit a detectable positive correlation with having taken steps to prepare to return to Syria in at least one specification. The direction of the relationship is not what we expected ex ante, based on a theory of preparations being driven by a simple utility comparison between conditions in Lebanon and prospects in Syria. The finding highlights that the theory's focus on migration costs and incentives may have overlooked migration capacities. Indeed, return is a complex and daunting process, and people with more financial and social resources may be better able to undertake a safe voluntary return.

Looking at the next group of drivers, we see in the first panel that the results do not provide evidence of a relationship between mobility costs and return intentions. In the second panel, we find a negative association between mobility costs and preparations for return, significant at the $10 \%$ level, when we consider indices separately. Looking at the bottom row of Figure 2, we see that confidence in information about one's hometown is positively associated with both intentions and preparations. Information access may both have a direct effect on return intentions and play a moderating role. We examine this possibility in Appendix Section 6.6, where we test whether conditions in Syria have a larger effect on people's intentions when they have high levels of confidence in their information about the situation in Syria. Results provide evidence that the relationship between conditions in Syria and return intentions and preparations is shaped by respondents' confidence in their information sources.

As one additional test of the findings in Figure 2, we fit predictive models based on homecountry factors and host-country factors using 10-fold cross validation. We present the results in Appendix Section 6.7, and find that models based on conditions in Syria consistently demonstrate higher predictive power than models based on conditions in Lebanon.

In light of our theoretical priors, what explains the limited impact of host-country conditions on return intentions? One possible explanation could be that there is insufficient variation in the conditions of refugees in Lebanon. We do not find evidence in the ob- 
servational data consistent with this possibility. For example, in Appendix Section 3.1, the descriptive statistics demonstrate wide variation in the living conditions of Syrians in Lebanon. In Appendix Section 6.3, we re-run all models that controlled for Lebanese locality level fixed effects, but without adjusting for locality. Our findings are robust to this alternative specification, suggesting that our null findings for the role of factors in Lebanon are not driven by a lack of variation in living conditions within localities. In Appendix Section 6.8, we examine this further by producing a map of Lebanon that shows the variation in respondents' conditions by district using an index of all the components used to measure conditions in Lebanon. The map shows significant variation across districts - the difference in the index between the district with the, on average, worst and the best conditions for respondents is about 2.4 standard deviations. Of course, we cannot rule out the fact that host-country conditions might matter if our sample included a greater diversity of host countries (e.g., Western Europe, the U.S., Canada, etc.). But given that most refugees are hosted in the Global South by neighboring countries, our observational analysis suggests that host-country conditions may not be very important determinants of decision-making in these contexts. In the next section, we provide evidence based on even wider variation in home and host country conditions by leveraging a conjoint survey experiment.

\section{Results: Conjoint Experiment}

The analysis of observational data strongly suggests that pull factors are more predictive of return intentions than push factors. Yet, despite our extensive set of control variables, our correlational estimates might be affected by other factors not included in the model. In this section, we present the results of a conjoint experiment designed to provide greater leverage on the causal effects of these drivers on return intentions. We follow a standard approach for analyzing conjoint experiments, using OLS regressions to estimate the Average Marginal Component Effect (AMCE) for each attribute (Hainmueller, Hopkins and Yamamoto, 2014). Figure 4 displays the effects on respondents' answers to the question: "Under these conditions, would you be willing to return to Syria?"

The main findings from the conjoint experiment are consistent with our analysis of the observational data. On average, conditions in Syria play a more important role in shaping people's return intentions than conditions in Lebanon. Results suggest that safety is the most powerful driver of return, with security in one's hometown increasing return intentions by 
35 percentage points and nationwide security increasing return intentions by 42 percentage points. The fact that safety in one's hometown has nearly as large of an effect as nationwide safety, suggests that the majority of variation in people's consideration of security is driven by conditions in their hometown, highlighting the local nature of security concerns in postwar environments. An end to military conscription also plays an important role in shaping people's return intentions, and increases the likelihood of return by 18 percentage points. In comparison, the availability of jobs and public services in Syria has a more modest effect: both increase return intentions by 8 percentage points.

Both access to a good job and public services in Lebanon play a small, negative role in people's return intentions. Someone with a good job in Lebanon is 2 percentage points less likely to return, and if someone has access to public services they are 3 percentage points less likely to return. Despite the statistical significance of these estimates, the differences in magnitudes between push and pull factors is substantial.

At the bottom of the figure, we see the effect of networks on people's responses. People were nearly 5 percentage points more likely to say that they would return to Syria if they have family and friends there (compared to having people outside of Syria and Lebanon). In contrast, we see a precisely estimated null effect for having family and friends in Lebanon on people's return intentions. These network results align with our earlier findings about the relative importance of the conditions in the home country compared to the hosting country.

\section{Beyond Lebanon: Return Intentions in Jordan}

Syrian refugees migrated to numerous countries, including three primary hosting countries: Lebanon, Jordan, and Turkey. In order to ascertain whether our results are driven by unique circumstances among Syrians in Lebanon, we ran a separate survey with 1,286 Syrian refugees in Jordan. These data offer a test of the external validity of our findings to the broader population of Syrian refugees. Our sampling strategy selected individuals from the four metropolitan areas in Jordan with the largest refugee populations: Amman, Irbid, Mafraq and Zarqa (including Azraq town). In the summer of 2019, enumerators interviewed a random sample of Syrians who received services from the NGO CARE during the study period. The participants were recruited from Syrian refugees living outside of camps, as do more than $80 \%$ of Syrians in Jordan (Verme et al., 2015, p. 40).

The two cases make for a valuable comparison given some key similarities and critical 


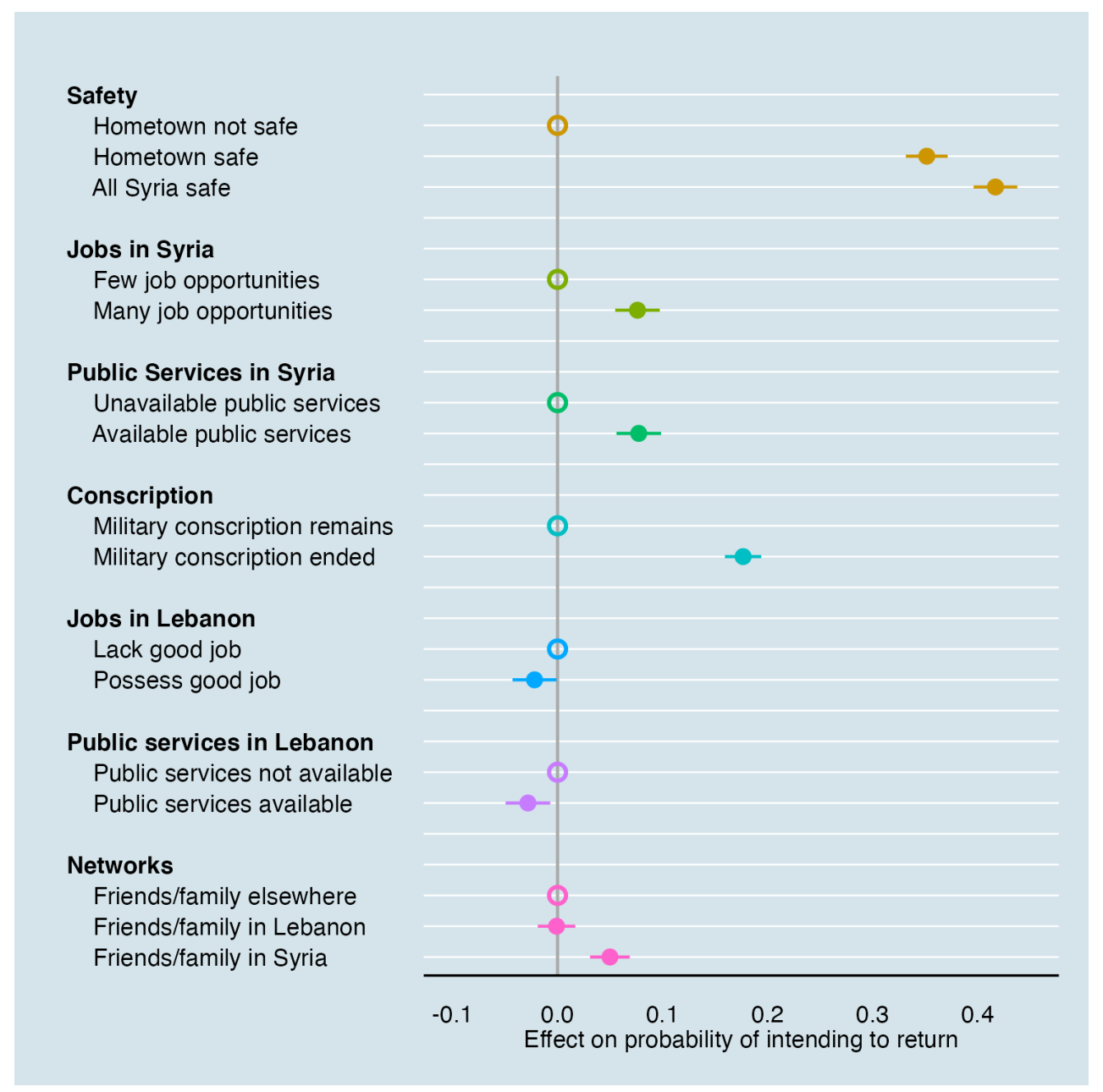

Figure 3: Conjoint Experiment Results. Each dot represents the effect on the probability that respondents would return to Syria in a given hypothetical situation, presented with its corresponding $95 \%$ confidence interval. The empty circles indicate reference categories. We cluster standard errors at the respondent level.

differences. Similar to Lebanon, Jordan hosts a large number of Syrian refugees relative to its population, and public discourse in the country widely frames refugees as having large negative economic and fiscal impacts. Unlike Lebanon, national political discourse in Jordan at the time of the survey was not pushing aggressively for Syrians to return. Further, the baseline rate of return intentions for Syrians in Jordan is very low. When we asked Syrian refugees in Jordan if they plan to ever return to Syria, we find that a large majority of respondents (around 75\%) reported that they never want to return to Syria. Therefore, the data enable us to examine whether our results from Lebanon pertain only to a context with 
major pressure to return and where a large share of people hope to return home someday.

The difference in baseline return intentions between our samples in Lebanon and Jordan is likely driven by different selection into displacement to the countries. Similar to Lichtenheld (2020)'s theory of assortative displacement, we can imagine that refugees sort into host countries based on a range of personal characteristics, including their relationship to a war's armed groups in the country of origin, and these views may influence the return decision. First, we see a difference between the two samples in self-reported level of security in respondents' hometowns. As of summer 2019, $51 \%$ of the sample in Jordan said that their place of origin continues to be very dangerous. In contrast, only $28 \%$ of respondents in Lebanon said so, when we conducted our survey there a few months later in August-October 2019. Second, our fieldwork suggests that the political attitudes of Syrians living in Jordan tend to be more anti-regime whereas the Syrian population in Lebanon is more divided in its views toward the Syrian government, which aligns with public opinion surveys on the topic (Corstange, 2018).

Using our data from Jordan, we construct indices for dimensions of people's well-being in Jordan and prospective well-being in Syria. We then regress return intentions on the indices, as defined in the "individual indices" specification of Equation 1, to estimate the impact of each factor on peoples' stated plans to ever return to Syria. ${ }^{16}$

Figure 4 presents results from analysis of the Jordan data. Despite the sizeable difference in baseline return intentions and the political climate, the drivers of return intentions in Jordan are strikingly similar to Lebanon. First, prospective conditions in Syria play an important role. We see that conditions in respondents' place of origin in Syria - specifically safety, economic prospects, and public services - are positively correlated with return intentions. Also, having family and friend networks in Syria is positively correlated with return intentions.

Second, in line with results from Lebanon, we do not find strong evidence that conditions in Jordan drive return intentions. First, we see in Figure 4 that economic conditions, access to public services, social well-being, and legal conditions are not strongly associated with return intentions. Networks is the one dimension of conditions in Jordan where we find a relationship with return intentions. This contrasts with results from Lebanon, where social well-being is the only push factor that consistently predicts return intentions.

Finally, looking at the impact of information, we do not find evidence of a relationship

\footnotetext{
${ }^{16}$ The list of questions used in each index are included in Appendix Section 3.
} 


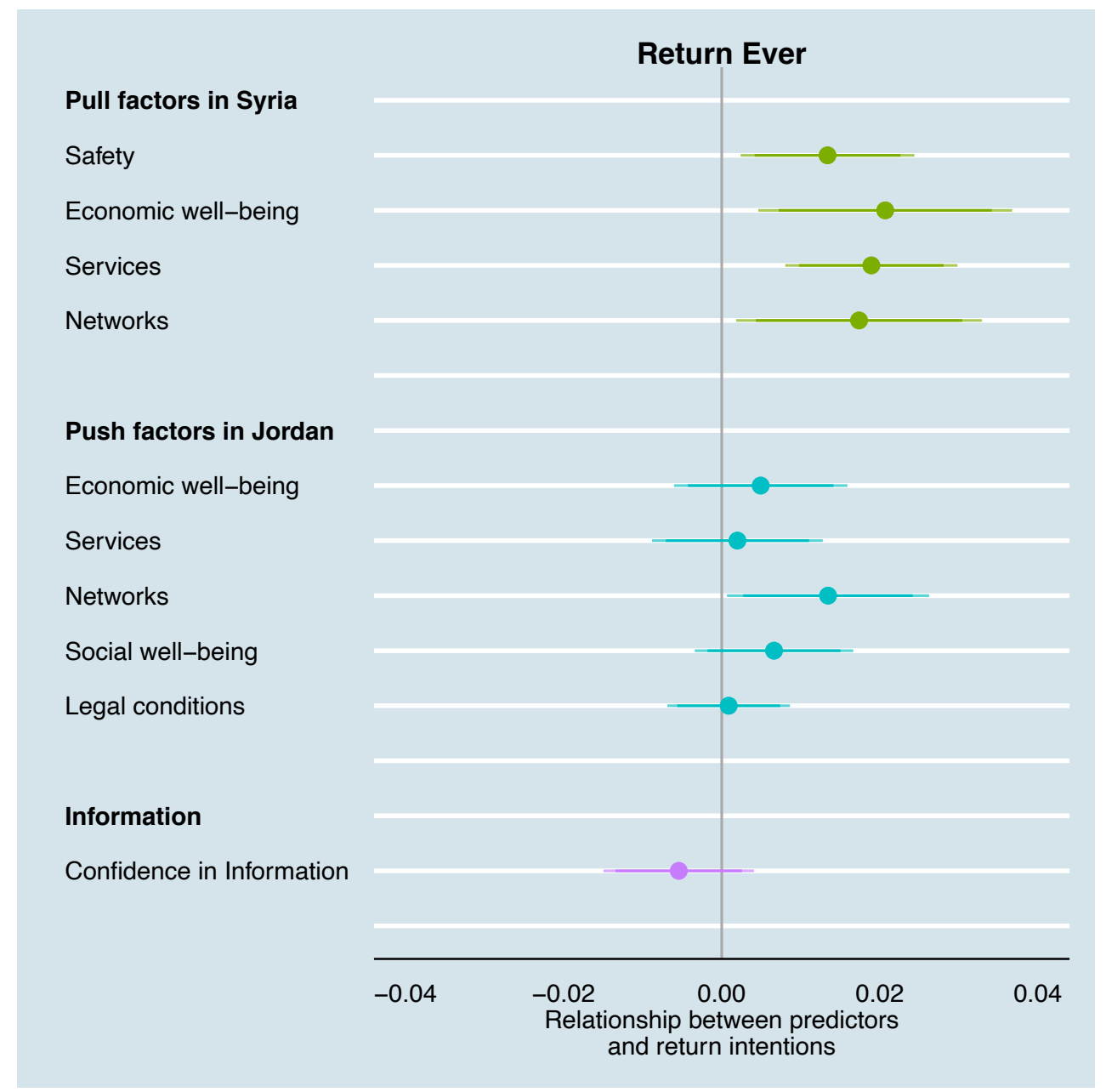

Figure 4: Index Results-Effects on Plans to Ever Return in Jordan. Each dot represents the effect on return intentions presented with its corresponding 95\% (thick lines) and 90\% (thin lines) confidence intervals. We control for gender, age, household size, education, female headed households, as well as place of origin in Syria and locality in Jordan. Missing values were imputed using mean imputation.

between information quality and return intentions in Jordan. This contrasts with the evidence we found in Lebanon for the importance of information for Syrians' decision-making about return.17

\footnotetext{
${ }^{17}$ We were not able to ask respondents in Jordan for the name of their hometown or district in Syria, preventing analysis of mobility cost.
} 


\section{Towards an Alternative Framework for Understanding Refugee Return}

In contrast to our predictions, we find that host-country conditions have little bearing on refugees' decision-making about return. At least in this context, the "push" and "pull" framework, informed by traditional models of labor migration, has less explanatory power than anticipated. The empirical results challenge us to reconsider whether a model of migration developed for people weighing how to improve their economic situation applies to the return choices of people who have fled war to neighboring countries in the Global South. While we accept that any binary distinction between different categories of international movers, i.e., "labor migrants" and "refugees," is often too simplistic, even problematic, to stand alone as an explanation (see, e.g., Abdelaaty and Hamlin, 2022), our intuition is that the conditions that drive people's initial departure from their home country will structure their decisionmaking about return in important ways. We highlight two features of wartime displacement that are particularly relevant for our context and discuss their implications for an alternative theoretical framework for understanding return.

First, when people flee violence and other consequences of war, they may depart based on a sense that they have no other choice in order to find safety and security. In general, these may not be households that would have chosen migration in the absence of conflict and violence at home. Second, the destination choices of refugees are often highly constrained. This is distinct from international movers who choose a destination country based on an opportunity to increase their income or achieve a related economic goal. Many refugees have to flee quickly to a subset of immediately accessible neighboring countries in search of safety.

As a result, we may need an alternative framework to understand refugees' decisions about whether or not to return. A different starting point is that if refugees flee their homes to avoid violence, destruction, and military service, living conditions in the home country may need to exceed a certain threshold before refugees are willing to return. If refugees flee to accessible host countries for the sake of safety rather than optimizing their income, then challenging conditions in the host country may be unlikely to increase the probability of return before conditions at home have improved. This framework suggests a different set of predictions than those implied in the push-pull model: (i) return only occurs when safety conditions at home improve beyond certain thresholds; and (ii) as long as these conditions are not met and refugees remain safe(r) in the host country, the difficulties they face there, 
as well as non-safety factors at home, will have a minimal impact on return.

One way to conceptualize the non-compensatory decision-making process underlying this alternative framework is to allow that (some) refugees do not trade-off safety for other goods (such as income, access to services, etc.) as long as their safety concerns are not met. This conception of hierarchical preferences (see, e.g. Marshall, 1949; Scott, 2002) over safety lies somewhere on the following continuum: On one end, we have the assumption of perfect substitutability of all kinds of goods embedded in standard choice models - a class of models which encompasses neoclassical economic theories of migration, the theoretical foundation for the push-pull model. On the other end, we have strict lexicographic ordering, which in this context implies that refugees maximize safety without regard to other goods. In contrast, this alternative framework assumes that refugees set a target (threshold) for safety that must be reached before other goods and factors are considered. As long as the safety conditions are not met, no amount of other goods will make the refugee indifferent between returning and not doing so 18 While other factors such as risk-aversion are likely correlated with the safety threshold that any individual household might apply, for the moment we treat the threshold as exogenous, though recognize that it may vary across refugees.

Theories of hierarchical preferences and non-compensatory decision-making have a rich tradition in psychology and economics, which includes the satisficing theory of Simon (1966), the 'elimination by aspect' model of Tversky (1972), and lexicographic trade-off structures such as those considered by Luce (1978), among others. Research in psychology has provided ample experimental evidence that individuals indeed use such non-compensatory decisionmaking in a range of choice situations, both with low and high stakes (e.g., Payne, Bettman and Johnson, 1993; Gigerenzer and Todd, 1999).

To explore the plausibility of this alternative framework for understanding refugee return, we look for suggestive evidence with two sources of complementary data: 36 qualitative interviews with Syrian refugees living in Lebanon and a re-analysis of the conjoint experiment discussed above. The qualitative, semi-structured interviews were conducted with a separate sample of Syrian refugees living in Lebanon between February 2020 and June 2021 by a

\footnotetext{
${ }^{18}$ To fix ideas, assume that refugees value two goods, safety $(S)$ and income $(I)$. The threshold model implies that refugees prefer any amount of $S$ to any amount of $I$ as long as $S$ is below the safety threshold $s_{0}$. Only once $S>s_{0}$ does the refugee start trading off $S$ and $I$. Thus, the threshold model nests both the standard choice model assuming perfect substitutability (if $s_{0}=0$ ) and strictly lexicographic preferences (if $s_{0}=\infty$ ) as special cases.
} 
member of the research team.19 The semi-structured interviews took place one-on-one in Syrian Arabic over encrypted WhatsApp calls. The discussions focus on people's migration histories, migration intentions and aspirations, and their process of decision-making about the future. We analyze the qualitative data to provide an interpretative understanding of Syrian refugees' lived experiences of return decision-making. Appendix Section 9 offers a detailed presentation of the qualitative data collection as well as an ethics discussion.

The qualitative data support the proposition that people are waiting for the security and safety situation in Syria to improve before returning. Many respondents emphasized that while they want to return to Syria at some point, they would only do so after certain conditions are met. One respondent told us that "if the war ended in Syria, I'd think about returning, but as long as the war continues and the security situation isn't good, I won't return.'20 Another respondent echoed the same sentiment, saying "we can only return to our region when there is no longer war there.'21 Even when people strongly desired to return in order to reconnect with family or, in one case, to attend a father's funeral, many respondents said they couldn't return because of how difficult the situation had become. ${ }^{22}$ Another respondent explained that she never expected to stay in Lebanon as long as she did, but she remained because the war continued. "I said to myself we'd stay in Lebanon until the situation gets better in Syria, then we'd return. I thought that we'd stay for just a short period then we'd return, but we're still here.'23

The threshold model also implies that host-country conditions have little effect on return as long as safety concerns in the home country are not addressed. The qualitative data reconciles this prediction with the reality that harsh conditions in Lebanon cause real suffering for the people experiencing them. Respondents explained that while they are very unhappy with their circumstances in Lebanon, they feel like the conditions in Syria simply preclude the option of return. One respondent said that "Lebanon is a prison" but he would return to Syria only "once the crisis ends," referring to the ongoing civil war.24 Another respondent

\footnotetext{
${ }^{19}$ The qualitative interviews were conducted after approval by [Universities Redacted] IRB numbers [Redacted]. The following analyses are not pre-registered. For these interviews, we oversampled Syrians who said they intended to return to Syria in the near future. Due to Covid-19-related travel restrictions, all qualitative interviews took place remotely, rather than in person as originally planned.

${ }^{20}$ Respondent 2 , Interview 1.

${ }^{21}$ Respondent 6 , Interview 2 .

${ }^{22}$ Respondent 3 , Interview 1.

${ }^{23}$ Respondent 10, Interview 1.

${ }^{24}$ Respondent 15, Interview 1.
} 
explained that she cannot afford rent in Lebanon, saying that "there's nothing available" for her or her family in Lebanon, but she still refuses to return to Syria without a significant improvement there, in particular noting the military draft requirement for her husband.25 Another respondent explained that even extreme hardship in Lebanon will not push them to return to a country at war: “[My husband] can't work very much. His health isn't good right now. He works a little, but it's not enough for a living. [...] In the beginning, when I came here in 2012 and 2013, [the UN] gave me food aid. They gave me a card and food supplies, but eventually they stopped. I was very dependent on that card. It was about $50 \%$ of our food supply, but they stopped all that aid three years ago. [...] My homeland is at war. So, I can't return. But here [in Lebanon] I can't live.'26

We can also use data from our conjoint experiment to assess whether refugees' response behavior is consistent with predictions from the threshold model. As outlined above, the threshold model has two (testable) implications: if safety conditions are not met, return is unlikely. And other push and pull factors only begin to play a role in refugees' decisionmaking once safety exceeds the minimal threshold. Both the observational and experimental evidence supports the first prediction that, on average, safety concerns - and in particular the security situation in the hometown or country and the ongoing policy of military conscription in Syria - figure prominently in refugees' return decisions.

To explore the second prediction, we re-analyse the conjoint experiment from Figure 3 , but subset the sample of the conjoint vignettes to those where conditions at home are described as safe (i.e., vignettes in which either the hometown or all of Syria is described as safe and in which military conscription has ended) or unsafe (i.e., hometown is described as unsafe and military conscription remains) ${ }^{27}$

Focusing on the vignettes that describe conditions in Syria as unsafe, the left panel of Figure 5 shows the effects of other push and pull factors. In line with the second prediction, we find precisely estimated null effects for the availability of jobs and public services in Lebanon. We also document null effects for the same conditions in Syria. The only factors that have significant, albeit small, positive effects are social networks in Lebanon, and, slightly larger, networks in Syria. The right panel shows the effects for the same factors

\footnotetext{
${ }^{25}$ Respondent 8, Interview 1.

${ }^{26}$ Respondent 2, Interview 1.

${ }^{27}$ Based on this contrast, we can calculate a simple summary measure of the importance of safety: When conditions at home are described as safe, choosing return makes up for $58.4 \%$ of the responses. This figure drops to a mere $4.7 \%$ for vignettes when conditions are described as unsafe.
} 


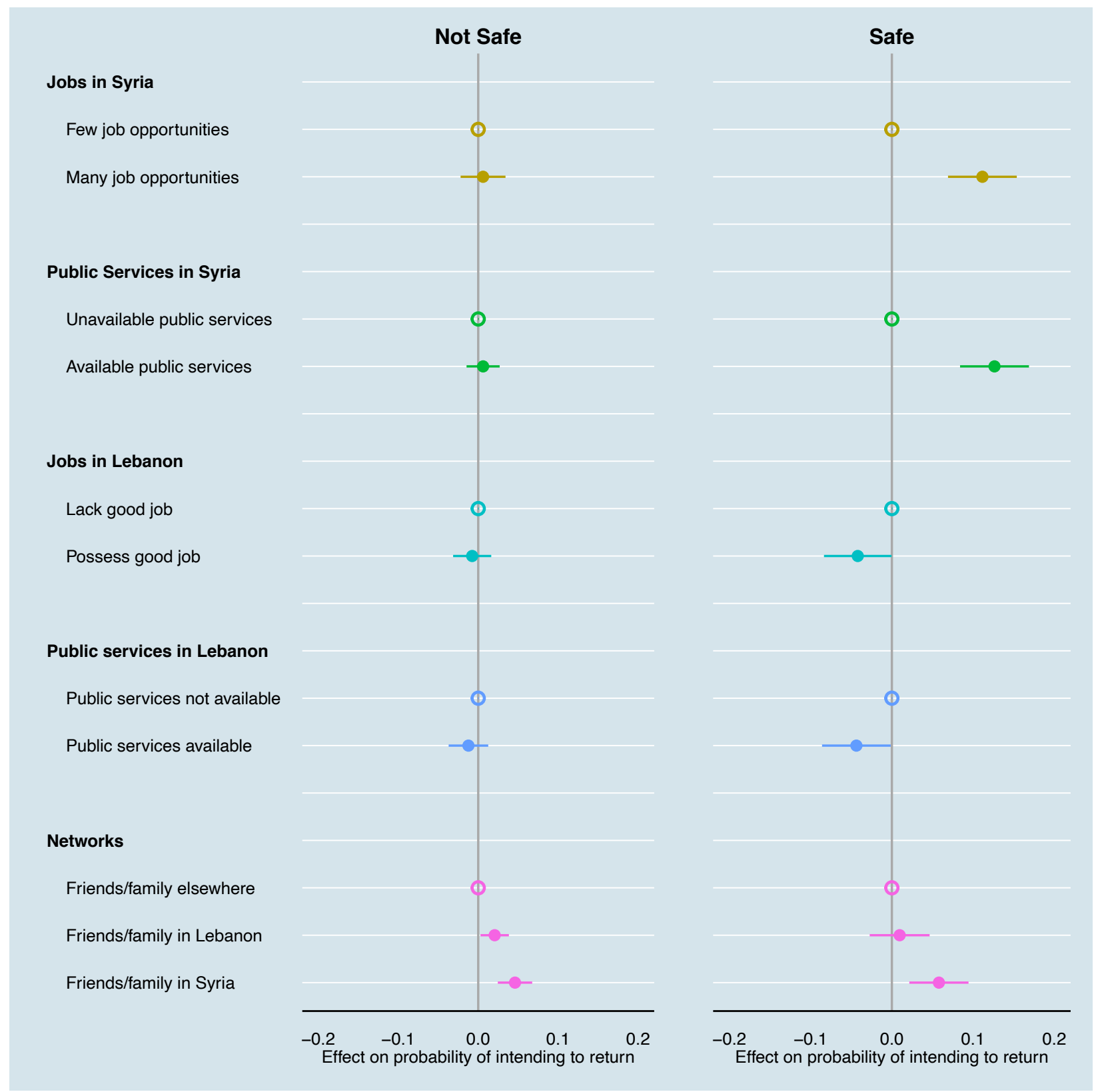

Figure 5: Conjoint experiment results by whether the hypothetical vignette mentioned that respondents' hometowns are unsafe and military conscription remains (left) or that their hometowns/all of Syria are safe and military conscription has ended (right). Each dot represents the effect on the probability that respondents would return to Syria in a given hypothetical situation, presented with its corresponding $95 \%$ confidence interval. The empty circles indicate the reference categories. We cluster standard errors at the respondent level. 
but subsets to those vignettes that describe conditions as safe. In contrast to the previous estimates, we find that once safety concerns are addressed, the availability of jobs and public services in Lebanon reduces return intentions, while the availability of the jobs and public services in Syria increases return. These results are consistent with the threshold model, but also suggest an important qualification to our main result based on the entire sample of vignettes: It is not the case that conditions in the host country do not factor into refugee's decision-making about return. Push factors matter too, but only if return is a safe option.

It is important to note that both the conjoint results and qualitative data, while consistent with and parsimoniously explained by the threshold model, cannot provide definitive tests against the standard choice model underlying the push-pull framework (Lancsar and Louviere, 2006).28 We offer suggestions for how to design future research to more directly test the threshold model in the next section.

\section{Conclusion}

We begin this paper by presenting novel evidence about the return plans in the short- and long-term of refugees using a representative survey of Syrians in Lebanon. We show that while a minority of refugees want to return in the short term, most refugees hope to return at some point in the future. We also advance understanding of the dynamics of refugee return by examining four major drivers of return at the household level: host country conditions, home country conditions, the cost of mobility, and the role of information. These initial hypotheses reflect the dominant model of decision-making in the refugee context, which emphasizes how refugees weigh possible outcomes at home versus where they live now. We test our hypotheses in the context of the Syrian refugee crisis, one of the largest refugee crises in the past century, in Lebanon using observational and experimental survey data from a representative sample of refugees and explore the external validity of our results with

\footnotetext{
${ }^{28}$ Without restrictive assumption on individual's decision rules and tailored experimental designs, it is generally not possible to dispositively test a single decision rule from discrete choice experiments and conjoint analysis (Lancsar and Louviere, 2006). However, for standard choice models to generate the estimates reported in Figure 5, it is not enough to simply put very large weights - larger than the sum of the weights of all other push and pull factors embedded in the vignette - on safety. In order to explain that other factors matter if and only if return is deemed safe, one would also have to assume a particular, multiplicative decision rule decision rule that leads to the observed pattern of a negative interaction effect between safety and push factors, and a positive interaction effect between safety and pull factors.
} 
a second survey in Jordan.

Our findings challenge the conventional view that refugees make return decisions by evaluating whether they can do better at home than in their hosting country. In particular, we find strong evidence that conditions at home matter most. By contrast, the dynamics in the hosting country do not have large effects, on average, on the return intentions of Syrian refugees. This finding, which stands in contrast to our registered expectations, is important because governments often restrict refugee rights based on the view that doing so will accelerate return (Janmyr, 2016). To explain these results, we propose an alternative framework for understanding refugee return. A threshold model suggests that refugees do not trade safety in the country of origin for other goods, such as economic conditions and public service provision as long as their safety concerns are not met. We find in evidence for this alternative framework in both qualitative and quantitative data.

While these findings challenge the "push" and "pull" models that dominate discussions of return in policy contexts, we cannot evaluate the generality of our findings to contexts outside of a warring country's neighbors in the Global South. Results may differ in countries with robust social welfare systems or with clear pathways to citizenship (although we note, a study on the drivers of return migration for Syrians in Germany did not find conditions in Germany to drive decisions (Kaya and Orchard, 2020). While this is an important scope condition for our findings, our results nonetheless speak to a significant proportion of the global refugee population. Worldwide, $85 \%$ of refugees live in developing countries and $90 \%$ live in countries neighboring their home country.

The paper also raises a number of important questions for a growing research agenda on refugee crises and the dynamics of return. First, further work is needed to develop and validate the threshold model proposed in the paper. Valuable extensions could explore direct questions and survey experiments to elicit refugees' thresholds, and what safety and security mean to them. In particular, more fine-grained levels for the safety attribute will allow researchers to narrow in on the thresholds refugees apply. Further, exploring variation in thresholds across individuals - and even for a given individual over time - may prove fruitful. These correlates could include refugees' psychological traits, such as risk-aversion and time preferences, socio-demographic variables, such as ethnic and religious identity, or political affiliation, as well as past experiences of violence and conflict.

Second, although previous research explores why refugees seek out information about potential destinations (Holland and Peters, 2020), little is understood about how refugees 
acquire and assess information about the situation at home. It is intuitive that high-quality information will condition migration choices, especially given the potential negative consequences of returning prematurely to a dangerous context. But theories accounting for risk aversion would predict that the uncertainty that refugees have about the situation at home may lead them to underweight outcomes in the home country relative to those in the host country (see, e.g., Kahneman and Tversky, 1979). Given the complexity of our findings on information and the absence of a well-identified causal effect, further research is needed on how information quality influences return decisions.

Third, future research should explore the degree to which return intentions predict people's subsequent migration choices. Recent studies of labor migration with direct measurement of both migration intentions and behavior find that intentions are strong predictors of future emigration (see, e.g., Van Dalen and Henkens, 2013; Docquier, Peri and Ruyssen, 2014: Tjaden, Auer and Laczko, 2019). Future work should explore the conditions under which refugees' return intentions do and do not translate into behavior.

We conclude with two key takeaways for policymakers and humanitarian organizations. First, many refugees intend to return to their home country when threats to their physical, economic, and social well-being have decreased, and when they feel that they possess credible information. We find that more than two thirds of Syrians in Lebanon want to return home, and prospects for a good job and access to public services in Lebanon do not influence people's likelihood of staying. The findings also suggest that, at least while a home country remains unsafe, humanitarian agencies can support refugee well-being without undermining the goal of safe voluntary return. Efforts to deliver humanitarian assistance and provide broader economic opportunities appear unlikely to substantially change the calculus of refugees in the absence of improving conditions at home. Thus continuing support and the provision of economic opportunities to the displaced can benefit both refugees and host societies, without exacerbating the long-term challenges of hosting governments. 


\section{References}

Abdelaaty, Lamis and Rebecca Hamlin. 2022. "Introduction: The Politics of the Migrant/Refugee Binary." Journal of Immigrant $\&$ Refugee Studies 20(2):233-239.

Adida, Claire L. 2014. Immigrant exclusion and insecurity in Africa. Cambridge University Press.

Amnesty International. 2015. "Pushed to the Edge: Syrian Refugees Face Increased Restrictions in Lebanon.".

Arias, María Alejandra, Ana María Ibáñez and Pablo Querubin. 2014. "The desire to return during civil war: Evidence for internally displaced populations in Colombia." Peace Economics, Peace Science and Public Policy 20(1):209-233.

Beaman, Lori, Harun Onder and Stefanie Onder. 2022. "When do refugees return home? Evidence from Syrian displacement in Mashreq." Journal of Development Economics 155:102802.

Beber, Bernd, Philip Roessler and Alexandra Scacco. 2021. "Coping with Partition: Wealth, Security, and Migration in Post-Separation Sudan." Working paper .

Borjas, George J. 1987. "Self-Selection and the Earnings of Immigrants." American Economic Review 4(77):531-55.

Borjas, George J and Bernt Bratsberg. 1996. "Who leaves? The outmigration of the foreignborn." The Review of Economics and Statistics 78(1):165-76.

Camarena, Kara Ross and Nils Hagerdal. 2020. "When Do Displaced Persons Return? Postwar Migration among Christians in Mount Lebanon." American Journal of Political Science 64(2):223-239.

Constant, Amelie and Douglas S Massey. 2003. "Self-selection, earnings, and out-migration: A longitudinal study of immigrants to Germany." Journal of Population Economics $16(4): 631-653$.

Corstange, Daniel. 2018. "The Syrian Conflict and Public Opinion Among Syrians in Lebanon." British Journal of Middle Eastern Studies 46(1):178-200. 
Docquier, Frédéric, Giovanni Peri and Ilse Ruyssen. 2014. "The cross-country determinants of potential and actual migration." International Migration Review 48(1):37-99.

Dustmann, Christian and Yoram Weiss. 2007. "Return migration: theory and empirical evidence from the UK." British Journal of Industrial Relations 45(2):236-256.

El Asmar, Francesca, Nour Shawaf and Dalia Mikdashi. 2019. "No One Asked: Amplifying the voices of Syrian refugee women in Lebanon on their power to decide." Oxfam .

Ghosn, Faten, Tiffany S Chu, Miranda Simon, Alex Braithwaite, Michael Frith and Joanna Jandali. 2021. "The Journey Home: Violence, Anchoring, and Refugee Decisions to Return." American Political Science Review .

Gigerenzer, Gerd and Peter M Todd. 1999. Fast and frugal heuristics: The adaptive toolbox. In Simple heuristics that make us smart. Oxford University Press pp. 3-34.

Hainmueller, J., D.J. Hopkins and T. Yamamoto. 2014. "Causal inference in conjoint analysis: Understanding multidimensional choices via stated preference experiments." Political Analysis 22(1):1-30.

Hainmueller, Jens and Daniel J. Hopkins. 2014. "Public Attitudes Toward Immigration." Annual Review of Political Science 17(1):225-249.

Harder, Niklas, Lucila Figueroa, Rachel M Gillum, Dominik Hangartner, David D Laitin and Jens Hainmueller. 2018. "Multidimensional measure of immigrant integration." Proceedings of the National Academy of Sciences 115(45):11483-11488.

Holland, Alisha C and Margaret E. Peters. 2020. "Explaining Migration Timing: Political Information and Opportunities." International Organization 74(3):560-583.

Hunt, Gary L and Richard E Mueller. 2004. "North American migration: returns to skill, border effects, and mobility costs." Review of Economics and Statistics 86(4):988-1007.

Janmyr, Maja. 2016. "Precarity in Exile: The Legal Status of Syrian Refugees in Lebanon." Refugee Survey Quarterly 35(4):58-78.

Kahneman, D and A Tversky. 1979. "Prospect theory: An analysis of decision under risk." Econometrica 47(2):263-291. 
Kaya, Serdar and Phil Orchard. 2020. "Prospects of return: The case of Syrian refugees in Germany." Journal of Immigrant Refugee Studies 18(1):95-112.

Lancsar, Emily and Jordan Louviere. 2006. "Deleting 'irrational' responses from discrete choice experiments: a case of investigating or imposing preferences?" Health economics 15(8):797-811.

Lehmann, M Christian and Daniel T R Masterson. 2020. "Does aid reduce anti-refugee violence? evidence from Syrian refugees in lebanon." American Political Science Review 114(4):1335-1342.

Lichtenheld, Adam G. 2020. "Explaining Population Displacement Strategies in Civil Wars: A Cross-National Analysis." International Organization 74(2):253-294.

Luce, R Duncan. 1978. "Lexicographic tradeoff structures." Theory and Decision 9(2):187.

Marshall, Alfred. 1949. Principles of economics. Cosimo, Inc.

Massey, Douglas S, Joaquin Arango, Graeme Hugo, Ali Kouaouci, Adela Pellegrino and J Edward Taylor. 1993. "Theories of International Migration: A Review and Appraisal." Population and Development Review 19(3):431-466.

Mixed Migration Centre, The. 2019. "Mixed Migration Review 2019.”.

Mourad, Lama. 2017. "“Standoffish" Policy-making: Inaction and Change in the Lebanese Response to the Syrian Displacement Crisis." Middle East Law and Governance 9(3):249266.

Oxfam. 2018. "Pushing Bank on Push Factors.".

Payne, John William, James R Bettman and Eric J Johnson. 1993. The adaptive decision maker. Cambridge university press.

Scheve, Kenneth F. and Matthew J. Slaughter. 2001. "Labor Market Competition and Individual Preferences Over Immigration Policy." Review of Economics and Statistics $83(1): 133-145$.

Schewel, Kerilyn. 2020. "Understanding immobility: Moving beyond the mobility bias in migration studies." International Migration Review 54(2):328-355. 
Schwartz, Stephanie. 2019. "Home, Again: Refugee Return and Post-Conflict Violence in Burundi." International Security 44(2):110-145.

Scott, Anthony. 2002. "Identifying and analysing dominant preferences in discrete choice experiments: an application in health care." Journal of economic Psychology 23(3):383398.

Simon, Herbert A. 1966. Theories of decision-making in economics and behavioural science. In Surveys of economic theory. Springer pp. 1-28.

Stefanovic, Djordje, Neophytos Loizides and Samantha Parsons. 2015. "Home is where the heart is? Forced migration and voluntary return in Turkey's Kurdish regions." Journal of Refugee Studies 28(2):276-296.

The World Bank. 2020. The mobility of displaced Syrians: an economic and social analysis. The World Bank.

Tjaden, Jasper, Daniel Auer and Frank Laczko. 2019. "Linking migration intentions with flows: Evidence and potential use." International Migration 57(1):36-57.

Tversky, Amos. 1972. "Elimination by aspects: A theory of choice." Psychological review $79(4): 281$.

Van Dalen, Hendrik P and Kène Henkens. 2013. "Explaining emigration intentions and behaviour in the Netherlands, 2005-10." Population Studies 67(2):225-241.

Verme, Paolo, Chiara Gigliarano, Christina Wieser, Kerren Hedlund, Marc Petzoldt and Marco Santacroce. 2015. The welfare of Syrian refugees: evidence from Jordan and Lebanon. World Bank Publications.

Weber, Sigrid and Alexandra Hartman. 2022. "Property Rights and Post-Conflict Recovery: Theory and Evidence from IDP Return Movements in Iraq." Working paper.

Yahya, Maha. 2018. "Unheard Voices: What Syrian Refugees Need to Return Home." Carnegie Middle East Center, and Carnegie Endowment for International Peace . 


\title{
Appendix
}

\author{
The Dynamics of Refugee Return: \\ Syrian Refugees and Their Migration Intentions* \\ Ala Alrababah ${ }^{1,2}$, Daniel Masterson ${ }^{2,3}$, Marine Casalis ${ }^{2}$, \\ Dominik Hangartner ${ }^{1,2,4}$, Jeremy Weinstein ${ }^{2,5}$ \\ ${ }^{1}$ Center for International and Comparative Studies, ETH Zurich \\ ${ }^{2}$ Immigration Policy Lab, Stanford University and ETH Zurich \\ ${ }^{3}$ Department of Political Science, University of California, Santa Barbara \\ ${ }^{4}$ Department of Government, London School of Economics and Political Science \\ ${ }^{5}$ Department of Political Science, Stanford University
}

October 31, 2022

\section{Contents}

$1 \quad$ Sampling Strategy 1

2 Survey questions 3

2.1 Dependent variables . . . . . . . . . . . . . . . . . . . . . . . . . . . . . . . . 3

2.2 Independent variables . . . . . . . . . . . . . . . . . . . . . . . . . . . . . . . . . . . 4

2.2 .1 Push factors from Lebanon . . . . . . . . . . . . . . . . . . . . . . . . . . . . 4

2.2 .2 Pull factors in Syria . . . . . . . . . . . . . . . . . . . . . . . . . . . 5

2.2 .3 Confidence in information and mobility . . . . . . . . . . . . . . . . . . . . . 7

2.3 Control variables . . . . . . . . . . . . . . . . . . . . . . . . . . . . . . 8

3 Index construction and descriptives

3.1 Push factors from Lebanon . . . . . . . . . . . . . . . . . . . . . . . . . . . . . . 10

3.2 Pull factors in Syria . . . . . . . . . . . . . . . . . . . . . . . . . . . . . . . . . . 11

${ }^{*}$ All analyses, unless otherwise noted, were pre-specified in EGAP registration 20190914AB. This project was reviewed and approved by the Stanford Human Subjects Committee under IRB protocol 49387 and by the Ethics Committee of ETH Zurich and the Human Subjects Committee of the University of California, Santa Barbara. 
3.3 Confidence in information . . . . . . . . . . . . . . . . . . 13

3.4 Mobility . . . . . . . . . . . . . . . . . . . . . . . . . . . 13

3.5 Preparation to return $\ldots \ldots \ldots \ldots \ldots \ldots$

3.6 Covariates $\ldots \ldots \ldots \ldots \ldots \ldots$

\begin{tabular}{|lll}
4 & Scree plots for principal component analysis & 14
\end{tabular}

4.1 Push factors from Lebanon . . . . . . . . . . . . . . . . . . . . . . . . 14

4.2 Pull factors in Syria $\ldots \ldots \ldots \ldots \ldots$

4.3 Confidence in information $\ldots \ldots \ldots \ldots$

4.4 Preparation for return $\ldots \ldots \ldots \ldots \ldots \ldots$

$\begin{array}{llr}5 \text { Deviations from PAP } & 20\end{array}$

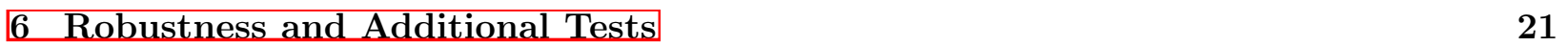

6.1 Return in two years and ever . . . . . . . . . . . . . . . . . . . . 22

6.2 Safety, services, and additional covariates $\ldots \ldots \ldots \ldots \ldots . \ldots \ldots$

6.3 Excluding locality fixed effects . . . . . . . . . . . . . . . . . . . . . . . . 23

6.4 Return plans for household members and uncertainty about return . . . . . . . . . 23

6.5 Additive indices . . . . . . . . . . . . . . . . . . . . . . . . . . 24

6.6 Information and return intentions $\ldots \ldots \ldots \ldots \ldots \ldots$

6.7 Testing the models' predictive power . . . . . . . . . . . . . . . . 27

6.8 Map of conditions in Lebanon $\ldots \ldots \ldots \ldots$

6.9 Conjoint results $\ldots \ldots \ldots \ldots \ldots \ldots$

\begin{tabular}{|lr}
\hline 7 & Jordan survey \\
\hline
\end{tabular}

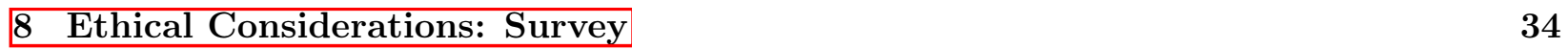

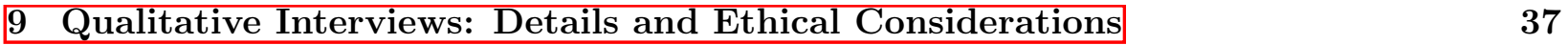




\section{Sampling Strategy}

We conducted stratified multistage sampling. In the first stage, we selected localities based on two dimensions: the prevalence of Syrians and the majority sect. We drew Syrian population data from UNHCR registration records and Lebanese population data from voter registration records, since there is no current census available. In the second stage, we used a random walk procedure to select households within each locality. In the third stage, we selected a head of household - defined as a person regardless of gender who plays a large role in household decision-making.

For this study, we wanted to draw inferences about all individuals from Syria in Lebanon as of the study's start date irrespective of their legal status and access to services and support. Thus, this study includes Syrian citizens regardless of whether they registered with UNHCR, and also Palestinian refugee from Syria (PRS), regardless of whether they registered with UNRWA.

\section{First sampling stage: Locality selection}

The sampling frame for the first stage is the list of localities published by the Lebanese Council for Development and Reconstruction (CDR) in 2018 and the 2018 UNHCR data on the number of registered Syrians by locality. Each locality is identified by way of its administrative affiliationKaza and Mohafza.

The localities were sorted into nine strata depending on their prevalence of Syrian population and the majority Lebanese sectarian group, as follows:

- Dimension 1: Prevalence of Syrian refugees

- Low prevalence: where the Syrian population accounted for less than $20 \%$ of the total population.

- Medium prevalence: where the Syrian population is between $20 \%$ and $50 \%$ of the total population.

- High prevalence: where the Syrian population accounted for over $50 \%$ of the total population.

- Dimension 2: Sectarian component of the non-Syrian population

- Sunni non-Syria majority: More than $50 \%$ of the documented non-Syrian population of the village is Sunni.

- Non-Sunni non-Syrian majority: More than 50\% of the documented non-Syrian population of the village is of a single non-Sunni sectarian group. 
- Mixed: No single sectarian group makes up more than $50 \%$ of the village population.

In the first stage sample we selected 150 Lebanese localities with replacement, leading to 93 unique localities. We then randomly sampled people in each locality. Our goal is to say something about the drivers of return in the overall population. Hence, in our main analysis, we cluster standard errors by locality, since there are localities in the population of interest beyond those captured in the sample (Abadie et al. 2017).

The distribution of the sample of 150 localities into strata faced the classical dilemma of whether doing it in proportion to the population of the strata or rather selecting the same number of localities in each stratum. Since both are important considerations for our study, and we want to study subnational variation while also making nationwide claims, we followed a first-stage sampling distribution in accordance to Markward's rule (also known as the '50/50 equal/proportional allocation' rule), which is generally considered a good compromise between the two extremes. Given the small number of mixed localities in the pure PPS sample, the 50/50 equal/proportional allocation has an additional desirable feature of avoiding any bins with a very small number of localities.

\section{Second-stage sampling}

Enumerators interviewed 20 households for each sample. In order to capture all Syrians and not only registered refugees, we opted for a random walk strategy rather than sampling from UNHCR's registration database. To do so, team leaders initially met with local key informants (such as the head of the municipal government) and had a map print out of the locality. The local key informant was asked to draw boundaries around the neighborhoods that include Syrians and the rough proportion of Syrians in each part of the town. The team leader then assigned enumerators in proportion to Syrians across the towns and provided them with a starting direction (N, NE, E, SE, S, SW, W, NW) for the day. Given that streets limit the direction of movement, the enumerator were asked to proceed along the street that is closest to the starting direction indicated in the enumerator schedule. The enumerators were told to interview a household in every third building.

\section{Third-stage sampling: Respondent Selection}

Enumerators interviewed a head of household - a person with primary decision-making responsibility in the household. An eligible 'head of household' should know the details of the household, its economic situation, and important household decisions. If a household had multiple adults who share decision-making responsibility, this classifies as there being multiple heads of household, in which case enumerators would interview whichever head of household was at home. 


\section{Response Rate}

The team leaders recorded the total number of doors they knocked on each day and kept track of refusal to participate as well as non-answers. Out of 3,882 interview attempts, enumerators conducted 3,003 interviews. This resulted in a response rate of $77 \%$.

\section{Replacement}

We needed to drop one research site in the Baalbek area from our sample because a shawish refused us entry to the informal settlement. We returned to our original sampling methodology and drew another town in order to replace this site.

\section{Survey questions}

\subsection{Dependent variables}

Our outcome of interest is intention to return. The survey included multiple questions about stated short-term and long-term return intentions as well as return preparations. Table A1 shows the list of questions used to measure these concepts.

\begin{tabular}{|l|l|l|}
\hline Short term return intentions & Long term return intentions & Return preparations \\
\hline $\begin{array}{l}\text { Do you (the respondent) plan to return to } \\
\text { Syria in the next } 12 \text { months? }\end{array}$ & $\begin{array}{l}\text { Two years from now, where do you } \\
\text { expect to actually be living? }\end{array}$ & $\begin{array}{l}\text { Have you or your immediate family been } \\
\text { saving resources in order to prepare for } \\
\text { your return to Syria? }\end{array}$ \\
\hline $\begin{array}{l}\text { Are other members of your household } \\
\text { planning to return in the next } 12 \text { months? }\end{array}$ & $\begin{array}{l}\text { Do you hope to move back to Syria } \\
\text { and live there one day? }\end{array}$ & $\begin{array}{l}\text { Have you or your immediate family } \\
\text { prepared any legal paperwork, such as } \\
\text { marriage documents, birth certificates, or } \\
\text { proofs of property to prepare for your return } \\
\text { to Syria? }\end{array}$ \\
\hline & $\begin{array}{l}\text { Would you say it is correct that you } \\
\text { don't want to return no matter what } \\
\text { happens? }\end{array}$ & $\begin{array}{l}\text { Have you or your immediate family reached } \\
\text { out to Lebanese authorities to discuss } \\
\text { returning to Syria? }\end{array}$ \\
\hline & $\begin{array}{l}\text { Have you or your immediate family reached } \\
\text { out to UNHCR to discuss returning to Syria? }\end{array}$ \\
\hline & $\begin{array}{l}\text { Have you or anyone in your immediate family } \\
\text { made a scoping trip back to Syria to learn } \\
\text { about the situation there? }\end{array}$ \\
\hline
\end{tabular}

Table A1: Questions about return intentions and preparations 


\subsection{Independent variables}

\subsubsection{Push factors from Lebanon}

We use several measures of push factors in Lebanon. Table A2 shows questions used to build the economic well-being and access to services in Lebanon indices. Table A3 shows the indices that measure social well-being, legal conditions, and networks in Lebanon.

\begin{tabular}{|c|c|}
\hline Economic well-being in Lebanon & Services in Lebanon \\
\hline $\begin{array}{l}\text { Do you possess the status that allows you to work legally in Lebanon (do you } \\
\text { currently possess a work permit or Lebanese residency)? }\end{array}$ & $\begin{array}{l}\text { Have you been sick in the past } 6 \text { months to the point of requiring medical } \\
\text { treatment? (To enumerator: this does not mean that they actually saw a doctor, } \\
\text { just that they needed to be treated. This includes chronic illnesses but not } \\
\text { common illnesses like cold) }\end{array}$ \\
\hline $\begin{array}{l}\text { During the past } 4 \text { weeks, how many days did you work outside home to make } \\
\text { money? (If they did not work, enter } 0 \text {.) }\end{array}$ & $\begin{array}{l}\text { (If yes) Were you able to see a doctor? (To Enumerator: Going to a pharmacy } \\
\text { does not count as seeing a doctor) }\end{array}$ \\
\hline $\begin{array}{l}\text { (If worked) On the days that you worked during the past } 4 \text { weeks, how many } \\
\text { hours did you usually work per day? }\end{array}$ & $\begin{array}{l}\text { (For each household member) Has (household member) has been sick in the past } \\
6 \text { months to the point of needing medical treatment? (To enumerator: this does } \\
\text { not mean that they actually saw a doctor, just that they needed to be treated. This } \\
\text { includes chronic illnesses but not common illnesses like cold) }\end{array}$ \\
\hline (If worked) During the past 4 weeks, how much money did you make in total? & $\begin{array}{l}\text { (If yes) Was (household member) able to see a doctor? (To Enumerator: Going to } \\
\text { a pharmacy does not count as seeing a doctor) }\end{array}$ \\
\hline $\begin{array}{l}\text { Can you please tell me which sources your household normally receives } \\
\text { income from? By household we mean people who are family members or } \\
\text { close relatives and who live under the same roof and share meals with you: Aid } \\
\text { or assistance from other organizations (such as the United Nations, other } \\
\text { international NGOs, local Lebanese charities, etc.) }\end{array}$ & $\begin{array}{l}\text { In Lebanon, how difficult or easy would it be for you to do each of the following? } \\
\text { See a doctor (aside from the cost) }\end{array}$ \\
\hline $\begin{array}{l}\text { In the last month, how much money did your household withdraw in total } \\
\text { using cards from humanitarian organizations? To clarify, I do not mean using a } \\
\text { card to buy from certain shops. I mean using a card to go to and ATM and } \\
\text { withdraw cash. (This includes the } 260 \text { and other cash aid.) Enumerator: enter } \\
\text { the sum of all cash aid used by household members in the last month. }\end{array}$ & $\begin{array}{l}\text { Do you think it is hard for your or your family to access healthcare in Lebanon } \\
\text { because you are Syrian? (To enumerator: if hard but not because they are Syrians, } \\
\text { select "Not hard because we are Syrians") }\end{array}$ \\
\hline $\begin{array}{l}\text { In the last month, how much money did your household spend in total using } \\
\text { WFP (World Food Program) support, that is, using a card to buy food only } \\
\text { from certain shops? (We are referring to the taghziye program.) Enumerator: } \\
\text { enter the sum of all food card aid used by household members in the last month. }\end{array}$ & $\begin{array}{l}\text { Need school: Whether any children between ages of } 6 \text { and } 18 \text { never studied OR } \\
\text { (did not finish primary school and are above } 10 \text { years old) OR (are not currently } \\
\text { attending school) }\end{array}$ \\
\hline $\begin{array}{l}\text { To enumerator: This question is written in colloquial Arabic. Read it loud as it } \\
\text { is and do not try to summarize it. If you had to live solely on your remaining } \\
\text { savings and assets, without any income or debt, approximately how many } \\
\text { months of expenses and spending would your savings and assets support you? } \\
\text { Note that we're talking about the assets and savings of your household in } \\
\text { Lebanon. }\end{array}$ & $\begin{array}{l}\text { Now we would like you to think about all the areas you have lived since moving } \\
\text { to Lebanon since you arrived here in (insert year). How many different towns } \\
\text { have you lived in Lebanon (including this place) since you came here in (insert } \\
\text { year)? (To measure stability in Lebanon, if always in the same town, the variable } \\
\text { gets a value of } 3 \text { (most stable). If lived in two towns, the variable gets a value of } \\
\text { 2. If lived in more than two towns, the variable gets a value of } 1 \text { (least stable)) }\end{array}$ \\
\hline $\begin{array}{l}\text { Does this dwelling have the following items that you are able to use? } \\
\text { Refrigerator, Washing Machine, Oven, Desktop or Laptop computer at home, } \\
\text { Car, Microwave oven, Television, Internet connection at home (other than } \\
\text { through a smartphone, not through a neighbor but owned at home), Indoor } \\
\text { toilet, Central heating }\end{array}$ & $\begin{array}{l}\text { Which year did you start living in in this area (neighborhood or town)? (To code } \\
\text { stability in current town, we subtracted answer from } 2019 \text { to find number of years } \\
\text { in this town then we cut the answers into quantiles) }\end{array}$ \\
\hline $\begin{array}{l}\text { How does the aid that you're currently receiving compare to the amount of aid } \\
\text { that you were receiving a year ago? (Enumerator: Here we are referring to cash } \\
\text { and all other aid.) }\end{array}$ & $\begin{array}{l}\text { (If age of a child }<18 \text { AND child not currently attending school) Why is (child) } \\
\text { not attending school? (Do not read options. Let respondent answer and select all } \\
\text { that apply). }\end{array}$ \\
\hline $\begin{array}{l}\text { To enumerator: This question is written in colloquial Arabic. Read it loud as it } \\
\text { is and do not try to summarize it. Then read all the answer options. In a typical } \\
\text { month, what share of your household's monthly expenses and spending needs } \\
\text { you are you able to satisfy from household members' income? }\end{array}$ & $\begin{array}{l}\text { In Lebanon, how difficult or easy would it be for you to do each of the following? } \\
\text { Get help with legal problems }\end{array}$ \\
\hline $\begin{array}{l}\text { What is the approximate total value of assets and cash that you possessed when } \\
\text { you first came to Lebanon? Note that we're talking about the assets and savings } \\
\text { of your household in Lebanon and not anything you left in Syria. }\end{array}$ & $\begin{array}{l}\text { Does this dwelling have the following items that you are able to use? Running } \\
\text { water }\end{array}$ \\
\hline \multicolumn{2}{|l|}{ Does your household income vary from month to month? } \\
\hline \multicolumn{2}{|l|}{ Did you or anyone in your household work in Lebanon before $2011 ?$} \\
\hline $\begin{array}{l}\text { What was your total household income in the past month? By } \\
\text { household we mean people who are family members or close } \\
\text { relatives and who lived under the same roof and share meals } \\
\text { with you. Enumerator: This does not include income from aid. }\end{array}$ & \\
\hline
\end{tabular}

Table A2: Push factors: Economic well-being and access to services in Lebanon 


\begin{tabular}{|c|c|c|}
\hline Social well-being in Lebanon & Legal conditions in Lebanon & Networks in Lebanon \\
\hline $\begin{array}{l}\text { How would you describe your relationship } \\
\text { with Lebanese people? }\end{array}$ & $\begin{array}{l}\text { Do you possess the status that allows you } \\
\text { to work legally in Lebanon (does } \\
\text { (respondent) currently possess a work } \\
\text { permit or Lebanese residency))? }\end{array}$ & $\begin{array}{l}\text { How many of (original household members } \\
\text { from Syria) (excluding yourself) are living } \\
\text { in Lebanon now? }\end{array}$ \\
\hline $\begin{array}{l}\text { Have you been detained by Lebanese } \\
\text { authorities since arriving to Lebanon? Please } \\
\text { note that we will not share this information. }\end{array}$ & $\begin{array}{l}\text { What is your status with UNHCR? Please } \\
\text { note that we will not share this information } \\
\text { with anyone (Enumerator: If the respondent } \\
\text { says registered or recorded, please ask to see } \\
\text { the UNHCR registration file with names of } \\
\text { registered individuals). }\end{array}$ & $\begin{array}{l}\text { Please think about the Lebanese people in } \\
\text { your phone contacts. With how many of them } \\
\text { did you have a conversation-either by phone, } \\
\text { messenger chat, face-to-face, or text exchange } \\
\text {-in the last week? Note that this does not } \\
\text { include service provides such as the United } \\
\text { Nations or NGOs }\end{array}$ \\
\hline $\begin{array}{l}\text { Do you think it is hard for you or your family } \\
\text { to get housing in Lebanon because you are } \\
\text { Syrian? To enumerator: if hard but not because } \\
\text { they are Syrians, select "Not hard because we } \\
\text { are Syrians" }\end{array}$ & $\begin{array}{l}\text { (If this person is a Palestinian from Syria) } \\
\text { What is your status with UNRWA? Please } \\
\text { note that we will not share this information } \\
\text { with anyone. }\end{array}$ & $\begin{array}{l}\text { Please think about the Syrians in Lebanon in } \\
\text { your phone contacts. With how many of them } \\
\text { did you have a conversation-either by phone, } \\
\text { messenger chat, face-to-face, or text exchange } \\
\text {-in the last week? }\end{array}$ \\
\hline $\begin{array}{l}\text { In your personal experiences, How friendly or } \\
\text { hostile would you describe your personal } \\
\text { experiences with Lebanese authorities in this } \\
\text { area (town/neighborhood)? }\end{array}$ & & $\begin{array}{l}\text { Outside of your household, do you have any } \\
\text { close Lebanese relatives in this area or } \\
\text { elsewhere in the country? }\end{array}$ \\
\hline $\begin{array}{l}\text { In your personal experiences, how friendly or } \\
\text { hostile would you describe your personal } \\
\text { experiences with the Lebanese public in this } \\
\text { area (town/neighborhood)? We are asking } \\
\text { about the Lebanese general public, not } \\
\text { authorities. }\end{array}$ & & $\begin{array}{l}\text { In the last } 12 \text { months, how often did you share } \\
\text { a meal with Lebanese people who are not part } \\
\text { of your family? (To enumerator: Those do not } \\
\text { need to be friends. They can be people at work } \\
\text { or other people.) }\end{array}$ \\
\hline \multicolumn{3}{|l|}{$\begin{array}{l}\text { How well do you understand the important } \\
\text { issues facing Lebanon? }\end{array}$} \\
\hline \multicolumn{3}{|l|}{$\begin{array}{l}\text { In the last } 12 \text { months, how often did you } \\
\text { typically discuss major issues facing } \\
\text { Lebanon with others? }\end{array}$} \\
\hline \multicolumn{3}{|l|}{$\begin{array}{l}\text { In Lebanon, how difficult or easy would it } \\
\text { be for you to do each of the following? } \\
\text { Search for a job }\end{array}$} \\
\hline \multicolumn{3}{|l|}{$\begin{array}{l}\text { Which year did you move to Lebanon to } \\
\text { stay here until now? }\end{array}$} \\
\hline \multicolumn{3}{|l|}{$\begin{array}{l}\text { Does this town currently have curfews for } \\
\text { Syrians? }\end{array}$} \\
\hline \multicolumn{3}{|l|}{$\begin{array}{l}\text { (If no) Has this town had curfews for Syrians } \\
\text { in the last two years? }\end{array}$} \\
\hline \multicolumn{3}{|l|}{$\begin{array}{l}\text { How often do you feel like an outsider in } \\
\text { Lebanon? }\end{array}$} \\
\hline \multicolumn{3}{|l|}{$\begin{array}{l}\text { (To enumerator) Did the respondent speak } \\
\text { Arabic well? }\end{array}$} \\
\hline \multicolumn{3}{|l|}{$\begin{array}{l}\text { What is the highest level of education you } \\
\text { have completed? }\end{array}$} \\
\hline \multicolumn{3}{|l|}{ How well can you read and write? } \\
\hline \multicolumn{3}{|l|}{$\begin{array}{l}\text { How often are you personally able to travel } \\
\text { freely and safely around this area of Lebanon? }\end{array}$} \\
\hline $\begin{array}{l}\text { Are all your household members able to move } \\
\text { freely in this town? }\end{array}$ & & \\
\hline
\end{tabular}

Table A3: Push factors: Social well-being, legal conditions, and networks in Lebanon

\subsubsection{Pull factors in Syria}

For pull factors in Syria, Table A4 shows questions used to build the safety, control, and economic well-being in Syria indices. Table A5 shows the indices that measure services and networks in Syria. 


\begin{tabular}{|c|c|c|}
\hline Safety in Syria & Control in Syria & Economic well-being in Syria \\
\hline $\begin{array}{l}\text { How would you describe the current } \\
\text { risk to civilians' physical safety in } \\
\text { (place of origin)? }\end{array}$ & $\begin{array}{l}\text { Who mainly controlled (place of } \\
\text { origin) in the month before you } \\
\text { left? Syrian army; Opposition } \\
\text { forces such as the FSA; Jabhat } \\
\text { al-Nusra; ISIS; Kurdish forces; } \\
\text { Russian forces; Turkish forces; } \\
\text { It was contested }\end{array}$ & $\begin{array}{l}\text { How would you describe the current } \\
\text { availability of jobs at present in } \\
\text { (place of origin) currently? }\end{array}$ \\
\hline $\begin{array}{l}\text { To measure sympathy with opposition, } \\
\text { we examine difference between trusting } \\
\text { two anti-regime media (Al-Jazeera and } \\
\text { Al-Arabiya) and two pro-regime media } \\
\text { (Al-Mayadeen and Al-Manar) using the } \\
\text { question: How trustworthy would you } \\
\text { say each of the following news sources } \\
\text { is? }\end{array}$ & $\begin{array}{l}\text { Who mainly controls (place of } \\
\text { origin) currently? [Same options] }\end{array}$ & $\begin{array}{l}\text { What is the total amount of outstanding } \\
\text { debts you currently have in Syria? This } \\
\text { includes any debts on unpaid electricity, } \\
\text { water, or other bills while you were } \\
\text { away }\end{array}$ \\
\hline $\begin{array}{l}\text { Were there anti-regime protests in } \\
\text { (place of origin) in } 2011 \text { and } 2012 ?\end{array}$ & $\begin{array}{l}\text { Did ISIS control (place of origin) } \\
\text { at all during the conflict? }\end{array}$ & $\begin{array}{l}\text { Did you or your immediate family own } \\
\text { (not rent) the following items in Syria? } \\
\text { (ask for each): House (not an apartment); } \\
\text { Apartment (other than their house, if they } \\
\text { owned a house); Land }\end{array}$ \\
\hline $\begin{array}{l}\text { Have you suffered physical or } \\
\text { psychological harm because of violence } \\
\text { in Syria? }\end{array}$ & & $\begin{array}{l}\text { (If they stated that they own land in } \\
\text { previous question) Do you think you } \\
\text { would be able to continue as owner and } \\
\text { operator of this land if you returned to } \\
\text { Syria? }\end{array}$ \\
\hline $\begin{array}{l}\text { How do you expect the safety situation to } \\
\text { be in (place of origin) one year from } \\
\text { now? }\end{array}$ & & $\begin{array}{l}\text { (If owned house/apartment/land) Do you } \\
\text { or your immediate family have property } \\
\text { documents that prove you are the owner? }\end{array}$ \\
\hline $\begin{array}{l}\text { Conscription: To examine if someone in } \\
\text { household is of/near conscription age, we } \\
\text { saw if household includes any males born } \\
\text { between } 1977 \text { and } 2003 .\end{array}$ & & \\
\hline
\end{tabular}

Table A4: Pull factors: Safety, control, and economic well-being in Syria 


\begin{tabular}{|l|l|}
\hline Services in Syria & Networks in Syria \\
\hline $\begin{array}{l}\text { As far as you know, how many hours per day } \\
\text { is there electricity in (place of origin) currently? }\end{array}$ & $\begin{array}{l}\text { How many of (household members from Syria } \\
\text { before leaving) are living in Syria now? }\end{array}$ \\
\hline $\begin{array}{l}\text { As far as you know, how many hours per day is } \\
\text { there running water in (place of origin) } \\
\text { currently? }\end{array}$ & $\begin{array}{l}\text { Approximately how many Syrian relatives or } \\
\text { friends who have lived in Lebanon have gone } \\
\text { back to Syria with the goal of staying there? }\end{array}$ \\
\hline $\begin{array}{l}\text { As far as you know, are schools operating in } \\
\text { (place of origin) during the school year? }\end{array}$ & $\begin{array}{l}\text { Next, think about your Syrian friends and relatives } \\
\text { from (place of origin) who have lived in Lebanon. } \\
\text { Approximately how many of them have gone back } \\
\text { to (place of origin)? }\end{array}$ \\
\hline $\begin{array}{l}\text { As far as you know, are health centers operating } \\
\text { in (place of origin) currently? }\end{array}$ & $\begin{array}{l}\text { How many people who were in your household in } \\
\text { Lebanon at some point since 2011 have gone back } \\
\text { to Syria, regardless of where they are now? }\end{array}$ \\
\hline $\begin{array}{l}\text { How good do you think that public service } \\
\text { provision in (place of origin) (such as health } \\
\text { centers, schools, infrastructure) will be one year } \\
\text { from now? }\end{array}$ & \multicolumn{2}{|l}{} \\
\hline
\end{tabular}

Table A5: Pull factors: Services and networks in Syria

\subsubsection{Confidence in information and mobility}

Table A6 describes our measures of confidence in information and mobility costs. 


\begin{tabular}{|c|c|}
\hline Confidence in information & Mobility cost \\
\hline $\begin{array}{l}\text { To enumerator: This question is written in colloquial Arabic. Read it } \\
\text { loud as it is and do not try to summarize. Then read all the answer } \\
\text { options. When thinking of your knowledge about the safety situation } \\
\text { in (place of origin), would you say that... : I know enough to be } \\
\text { confident I understand the situation (1); I don't know enough, and I } \\
\text { want to know more (0); I don't know much but do not feel the need } \\
\text { to know }(0)\end{array}$ & $\begin{array}{l}\text { We calculate travel distance from each survey respondent's } \\
\text { town of residence in Lebanon to their hometown in Syria, } \\
\text { via the Beirut-Damascus highway and border crossing. } \\
\text { Travel routes were calculated using the Google Maps API. } \\
\text { We used the R package mapsapi and commands } \\
\text { mp_directions() and mp_get_routes(). }\end{array}$ \\
\hline $\begin{array}{l}\text { To enumerator: This question is written in colloquial Arabic. Read it } \\
\text { loud as it is and do not try to summarize. Then read all the answer } \\
\text { options. When thinking of your knowledge about employment } \\
\text { opportunities in (place of origin), would you say that... : (same } \\
\text { options as above) }\end{array}$ & The log of household size \\
\hline $\begin{array}{l}\text { To enumerator: This question is written in colloquial Arabic. Read it } \\
\text { loud as it is and do not try to summarize. Then read all the answer } \\
\text { options. When thinking of your knowledge about the availability of } \\
\text { public services (such as health centers, schools, or water) in (place of } \\
\text { origin), would you say that... : (same options as above) }\end{array}$ & \\
\hline $\begin{array}{l}\text { To enumerator: This question is written in colloquial Arabic. Read it } \\
\text { loud as it is and do not try to summarize. Then read all the answer } \\
\text { options. When thinking of your knowledge about the conscription } \\
\text { requirements by the Syrian military, would you say that... : (same } \\
\text { options as above) }\end{array}$ & \\
\hline $\begin{array}{l}\text { Now, please think about the person you communicate with the most } \\
\text { who is currently living in Syria. (If respondent answers: I don't } \\
\text { communicate with anyone in Syria, this is coded as } 0 \text {, otherwise } 1 \text { ) }\end{array}$ & \\
\hline $\begin{array}{l}\text { In general, how often do you communicate with people in (place of } \\
\text { origin)? }\end{array}$ & \\
\hline
\end{tabular}

Table A6: Confidence in information and mobility costs

\subsection{Control variables}

We also adjust for a range of control variables in Equation 1 in the paper, including householdlevel covariates and locality-level fixed effects. As defined in the pre-analysis plan, the control set includes the following: indicators for being from an urban area in Syria, living in an informal (tented) settlement, a household member being seriously ill, the head of household having finished secondary school or higher, a toddler household member, an elderly household member, femaleheaded household, whether an area is a Hizbullah-controlled area, and Syrian governorate of origin and Lebanese district of residence. All variables come from the survey data except the final covariate. Data for Hizbullah control is coded based on whether a Hizbullah-aligned candidate won a seat in the 2018 parliamentary elections, using Lebanese Ministry of Interior data released by the Data Liberation Project. In regressions including travel distance on the right-hand side, we drop controls for location in Lebanon and hometown in Syria, since travel distance is a deterministic function of these variables. 


\section{Index construction and descriptives}

We measured four key concepts with multiple independent variables using the first principal component.

1. Well-being in Lebanon

2. Expected well-being in Syria

3. Confidence in information

4. Preparation to return

The component variables are mentioned in Section 2. For the first three independent variables, we have many input variables. Note that all results for the survey in Lebanon impute missing values using multivariate imputation by chained equations. We specify 10 imputations and use random forest to predict missing values using the mice() package in R. We use Rubin's rules (Rubin, 1987) when pooling estimates across imputations.

Our primary analysis was based on regression models with indices constructed using polychoric PCA unless any variable in the index had too many categories (above 8 categories, in which case we used Pearson correlations) (Hainmueller, Hangartner and Pietrantuono, 2017). Scales for individual questions were reversed as necessary to simplify interpretation (to make sure they were all in the same positive direction). In addition to the indices constructed using the first principal components, we ran mean effects indices (aka z-scores) as a robustness check (Kling, Liebman and Katz, 2007). We constructed those indices by standardizing each variable (demeaning and dividing it by the standard deviation). We then summed the standardized variables and then standardized the sum again.

This section shows the component variables of each of the indices as well as descriptive statistics for these variables. We also show descriptive statistics for the control variables we included in the main regressions. 


\subsection{Push factors from Lebanon}

\section{Economic well-being in Lebanon}

\begin{tabular}{|c|c|c|c|c|c|c|c|}
\hline Variable & Weighted.Mean & Unweighted.Mean & Std.Dev & Min & Median & Max & Pct.Missing \\
\hline Aid: atm card & 0.63 & 0.58 & 1.39 & 0.00 & 0.00 & 7.00 & $0.30 \%$ \\
\hline Aid change from last year & 1.49 & 1.48 & 0.56 & 1.00 & 1.00 & 3.00 & $9.16 \%$ \\
\hline Aid: wfp card & 1.12 & 1.02 & 1.68 & 0.00 & 0.00 & 7.00 & $0.13 \%$ \\
\hline Assets: months left & 0.13 & 0.15 & 0.62 & 0.00 & 0.00 & 12.00 & $0.00 \%$ \\
\hline Assets: value upon arrival & 0.62 & 0.70 & 2.26 & 0.00 & 0.00 & 16.00 & $0.27 \%$ \\
\hline Ability to cover expenses & 2.78 & 2.88 & 1.26 & 1.00 & 3.00 & 5.00 & $0.17 \%$ \\
\hline Income & 1.75 & 1.90 & 3.07 & 0.00 & 0.00 & 13.00 & $0.10 \%$ \\
\hline Work days past 4 weeks & 5.82 & 6.25 & 9.91 & 0.00 & 0.00 & 28.00 & $0.00 \%$ \\
\hline Work hours past 4 weeks & 2.92 & 3.13 & 4.74 & 0.00 & 0.00 & 24.00 & $0.00 \%$ \\
\hline Able to work legally & 0.10 & 0.11 & 0.31 & 0.00 & 0.00 & 1.00 & $0.03 \%$ \\
\hline Income source: aid & 0.36 & 0.33 & 0.47 & 0.00 & 0.00 & 1.00 & $0.03 \%$ \\
\hline Stable household income & 0.81 & 0.79 & 0.71 & 0.00 & 1.00 & 2.00 & $0.20 \%$ \\
\hline Household income & 4.36 & 4.72 & 3.50 & 0.00 & 5.00 & 17.00 & $0.93 \%$ \\
\hline HH worked in Leb. before 2011 & 0.23 & 0.24 & 0.43 & 0.00 & 0.00 & 1.00 & $0.00 \%$ \\
\hline Own refrigerator & 0.80 & 0.81 & 0.39 & 0.00 & 1.00 & 1.00 & $0.00 \%$ \\
\hline Have indoor toilet & 0.83 & 0.83 & 0.37 & 0.00 & 1.00 & 1.00 & $0.00 \%$ \\
\hline Have central heating & 0.05 & 0.05 & 0.22 & 0.00 & 0.00 & 1.00 & $0.13 \%$ \\
\hline Own washing machine & 0.68 & 0.67 & 0.47 & 0.00 & 1.00 & 1.00 & $0.00 \%$ \\
\hline Own oven/stove & 0.79 & 0.79 & 0.41 & 0.00 & 1.00 & 1.00 & $0.00 \%$ \\
\hline Own computer & 0.02 & 0.02 & 0.13 & 0.00 & 0.00 & 1.00 & $0.00 \%$ \\
\hline Own car & 0.02 & 0.02 & 0.14 & 0.00 & 0.00 & 1.00 & $0.00 \%$ \\
\hline Own microwave oven & 0.04 & 0.05 & 0.21 & 0.00 & 0.00 & 1.00 & $0.00 \%$ \\
\hline Own television & 0.78 & 0.79 & 0.41 & 0.00 & 1.00 & 1.00 & $0.00 \%$ \\
\hline Have internet & 0.24 & 0.25 & 0.44 & 0.00 & 0.00 & 1.00 & $0.07 \%$ \\
\hline
\end{tabular}

Table A7: Summary statistics of variables included in constructing the economic well-being in Lebanon index

\section{Social well-being in Lebanon}

\begin{tabular}{|c|c|c|c|c|c|c|c|}
\hline Variable & Weighted.Mean & Unweighted.Mean & Std.Dev & Min & Median & Max & Pct.Missing \\
\hline Never had curfews & 0.65 & 0.63 & 0.48 & 0.00 & 1.00 & 1.00 & $0.93 \%$ \\
\hline Authorities discrimination (higher is less) & 2.71 & 2.73 & 0.74 & 1.00 & 3.00 & 4.00 & $15.38 \%$ \\
\hline Ease of mobility & 3.16 & 3.16 & 1.09 & 1.00 & 4.00 & 4.00 & $0.13 \%$ \\
\hline Ease of mobility for household & 2.38 & 2.39 & 0.78 & 1.00 & 3.00 & 3.00 & $0.53 \%$ \\
\hline Public discrimination (higher is less) & 2.97 & 2.98 & 0.68 & 1.00 & 3.00 & 4.00 & $1.60 \%$ \\
\hline Arabic speaking ability & 2.87 & 2.87 & 0.34 & 1.00 & 3.00 & 3.00 & $1.27 \%$ \\
\hline Relation with Lebanese & 3.66 & 3.68 & 0.95 & 1.00 & 4.00 & 5.00 & $0.33 \%$ \\
\hline Discuss Lebanese politics & 1.35 & 1.38 & 0.94 & 1.00 & 1.00 & 5.00 & $0.47 \%$ \\
\hline Ease job search & 1.59 & 1.61 & 1.02 & 1.00 & 1.00 & 5.00 & $0.83 \%$ \\
\hline Literacy level & 2.10 & 2.09 & 0.72 & 1.00 & 2.00 & 3.00 & $0.00 \%$ \\
\hline Feeling outsider (higher is less) & 2.95 & 2.96 & 1.29 & 1.00 & 3.00 & 5.00 & $0.03 \%$ \\
\hline Know Lebanese politics & 2.33 & 2.33 & 1.24 & 1.00 & 2.00 & 5.00 & $0.83 \%$ \\
\hline Time in Lebanon & 5.52 & 5.46 & 2.05 & 0.00 & 6.00 & 9.00 & $0.07 \%$ \\
\hline No curfew now & 0.75 & 0.73 & 0.45 & 0.00 & 1.00 & 1.00 & $0.50 \%$ \\
\hline Housing discrimination (higher is less) & 2.48 & 2.49 & 0.69 & 1.00 & 3.00 & 3.00 & $0.33 \%$ \\
\hline Never detained & 0.94 & 0.94 & 0.23 & 0.00 & 1.00 & 1.00 & $0.20 \%$ \\
\hline
\end{tabular}

Table A8: Summary statistics of variables included in constructing the social well-being in Lebanon index 
Services in Lebanon

\begin{tabular}{|c|c|c|c|c|c|c|c|}
\hline Variable & Weighted.Mean & Unweighted.Mean & Std.Dev & Min & Median & Max & Pct.Missing \\
\hline Can access legal services & 1.66 & 1.66 & 1.07 & 1.00 & 1.00 & 5.00 & $2.73 \%$ \\
\hline No healthcare discrimination & 2.37 & 2.37 & 0.73 & 1.00 & 3.00 & 3.00 & $0.47 \%$ \\
\hline Not sick & 0.83 & 0.83 & 0.38 & 0.00 & 1.00 & 1.00 & $0.07 \%$ \\
\hline Received treatment (if sick) & 0.94 & 0.95 & 0.23 & 0.00 & 1.00 & 1.00 & $0.00 \%$ \\
\hline Can access doctor & 2.80 & 2.87 & 1.66 & 1.00 & 3.00 & 5.00 & $0.70 \%$ \\
\hline No Kids need school & 0.59 & 0.59 & 0.49 & 0.00 & 1.00 & 1.00 & $0.03 \%$ \\
\hline Have running water & 0.80 & 0.81 & 0.39 & 0.00 & 1.00 & 1.00 & $0.00 \%$ \\
\hline No HH member sick & 0.78 & 0.79 & 0.41 & 0.00 & 1.00 & 1.00 & $0.17 \%$ \\
\hline $\mathrm{HH}$ members treated if sick & 0.91 & 0.91 & 0.28 & 0.00 & 1.00 & 1.00 & $0.03 \%$ \\
\hline School not preventive & 0.96 & 0.96 & 0.20 & 0.00 & 1.00 & 1.00 & $0.07 \%$ \\
\hline Period in current town & 2.39 & 2.37 & 1.16 & 1.00 & 2.00 & 4.00 & $0.10 \%$ \\
\hline Towns lived in Lebanon & 2.64 & 2.65 & 0.63 & 1.00 & 3.00 & 3.00 & $0.10 \%$ \\
\hline
\end{tabular}

Table A9: Summary statistics of variables included in constructing the services in Lebanon index

\section{Legal situation in Lebanon}

\begin{tabular}{|c|c|c|c|c|c|c|c|}
\hline Variable & Weighted.Mean & Unweighted.Mean & Std.Dev & Min & Median & Max & Pct.Missing \\
\hline Registered with UNHCR/UNRWA (or resident) & 0.81 & 0.80 & 0.40 & 0.00 & 1.00 & 1.00 & $0.00 \%$ \\
\hline Legal resident in Lebanon & 0.04 & 0.05 & 0.21 & 0.00 & 0.00 & 1.00 & $0.00 \%$ \\
\hline
\end{tabular}

Table A10: Summary statistics of variables included in constructing the legal situation in Lebanon index

\section{Networks in Lebanon}

\begin{tabular}{|c|c|c|c|c|c|c|c|}
\hline Variable & Weighted.Mean & Unweighted.Mean & Std.Dev & Min & Median & Max & Pct.Missing \\
\hline Syria HH members living in Leb. now & 4.58 & 4.45 & 3.51 & 0.00 & 4.00 & 15.00 & $0.00 \%$ \\
\hline Lebanese phone contacts & 1.71 & 1.71 & 1.11 & 1.00 & 1.00 & 5.00 & $0.53 \%$ \\
\hline Share meals with Lebanese & 1.51 & 1.53 & 1.08 & 1.00 & 1.00 & 5.00 & $0.17 \%$ \\
\hline Syrian phone contacts & 3.22 & 3.20 & 1.37 & 1.00 & 3.00 & 5.00 & $0.30 \%$ \\
\hline Lebanese relatives & 0.22 & 0.22 & 0.55 & 0.00 & 0.00 & 2.00 & $0.10 \%$ \\
\hline
\end{tabular}

Table A11: Summary statistics of variables included in constructing the networks in Lebanon index

\subsection{Pull factors in Syria}

\section{Safety in Syria}

\begin{tabular}{|c|c|c|c|c|c|c|c|}
\hline Variable & Weighted.Mean & Unweighted.Mean & Std.Dev & Min & Median & Max & Pct.Missing \\
\hline HH male at conscription age & 0.80 & 0.81 & 0.39 & 0.00 & 1.00 & 1.00 & $0.00 \%$ \\
\hline Exposed to violence & 0.28 & 0.27 & 0.45 & 0.00 & 0.00 & 1.00 & $0.03 \%$ \\
\hline Follow anti-regime media more than pro-regime media & 0.20 & 0.21 & 0.41 & 0.00 & 0.00 & 1.00 & $0.00 \%$ \\
\hline Hometown had protests & 0.67 & 0.67 & 0.47 & 0.00 & 1.00 & 1.00 & $2.40 \%$ \\
\hline Expect hometown to be safe & 2.54 & 2.53 & 0.86 & 1.00 & 3.00 & 4.00 & $18.81 \%$ \\
\hline Current safety in hometown & 2.05 & 2.06 & 0.88 & 1.00 & 2.00 & 4.00 & $7.13 \%$ \\
\hline
\end{tabular}

Table A12: Summary statistics of variables included in constructing the safety in Syria index. Respondents were coded as following anti-regime media more than pro-regime media if they reported following Al-Jazeera or Al-Arabiya (anti-regime) more than Manar/Mayadeen (pro-regime). 


\section{Control in Syria}

\begin{tabular}{|c|c|c|c|c|c|c|c|}
\hline Variable & Weighted.Mean & Unweighted.Mean & Std.Dev & Min & Median & Max & Pct.Missing \\
\hline Contested Now & 0.05 & 0.05 & 0.22 & 0.00 & 0.00 & 1.00 & $5.16 \%$ \\
\hline Contested before leaving & 0.15 & 0.15 & 0.36 & 0.00 & 0.00 & 1.00 & $3.06 \%$ \\
\hline Controlled by Kurds now & 0.13 & 0.14 & 0.35 & 0.00 & 0.00 & 1.00 & $5.16 \%$ \\
\hline Controlled by oppsn/FSA now & 0.09 & 0.09 & 0.29 & 0.00 & 0.00 & 1.00 & $5.16 \%$ \\
\hline Controlled by regime now & 0.69 & 0.67 & 0.47 & 0.00 & 1.00 & 1.00 & $5.16 \%$ \\
\hline Controlled by Russia now & 0.00 & 0.01 & 0.08 & 0.00 & 0.00 & 1.00 & $5.16 \%$ \\
\hline Controlled by Turkey now & 0.01 & 0.02 & 0.12 & 0.00 & 0.00 & 1.00 & $5.16 \%$ \\
\hline Controlled by Kurds before leaving & 0.02 & 0.03 & 0.17 & 0.00 & 0.00 & 1.00 & $3.06 \%$ \\
\hline Controlled by oppsn/FSA before leaving & 0.28 & 0.29 & 0.45 & 0.00 & 0.00 & 1.00 & $3.06 \%$ \\
\hline Controlled by regime before leaving & 0.38 & 0.36 & 0.48 & 0.00 & 0.00 & 1.00 & $3.06 \%$ \\
\hline Controlled by Russia before leaving & 0.00 & 0.00 & 0.06 & 0.00 & 0.00 & 1.00 & $3.06 \%$ \\
\hline Controlled by Turkey before leaving & 0.00 & 0.00 & 0.05 & 0.00 & 0.00 & 1.00 & $3.06 \%$ \\
\hline Controlled by ISIS at some point & 0.37 & 0.39 & 0.49 & 0.00 & 0.00 & 1.00 & $5.13 \%$ \\
\hline
\end{tabular}

Table A13: Summary statistics of variables included in constructing the control in Syria index

\section{Economic well-being in Syria}

\begin{tabular}{|c|c|c|c|c|c|c|c|}
\hline Variable & Weighted.Mean & Unweighted.Mean & Std.Dev & Min & Median & Max & Pct.Missing \\
\hline Debt in Syria & 0.31 & 0.32 & 0.66 & 0.00 & 0.00 & 2.00 & $4.96 \%$ \\
\hline Job situation in origin & 1.55 & 1.54 & 0.70 & 1.00 & 1.00 & 4.00 & $9.62 \%$ \\
\hline Home ownership docs ( 1 for some, 2 for everything) & 0.58 & 0.62 & 0.91 & 0.00 & 0.00 & 2.00 & $1.90 \%$ \\
\hline Can operate land in future & 0.12 & 0.13 & 0.33 & 0.00 & 0.00 & 1.00 & $2.33 \%$ \\
\hline Own house in Syria & 0.62 & 0.64 & 0.48 & 0.00 & 1.00 & 1.00 & $0.30 \%$ \\
\hline Own apt in Syria & 0.07 & 0.07 & 0.25 & 0.00 & 0.00 & 1.00 & $0.37 \%$ \\
\hline Own land in Syria & 0.21 & 0.21 & 0.41 & 0.00 & 0.00 & 1.00 & $0.63 \%$ \\
\hline
\end{tabular}

Table A14: Summary statistics of variables included in constructing the economic well-being in Syria index

\section{Services in Syria}

\begin{tabular}{|c|c|c|c|c|c|c|c|}
\hline Variable & Weighted.Mean & Unweighted.Mean & Std.Dev & Min & Median & Max & Pct.Missing \\
\hline Electricity in origin & 2.51 & 2.51 & 1.27 & 1.00 & 3.00 & 5.00 & $15.25 \%$ \\
\hline Health services in origin & 0.36 & 0.36 & 0.48 & 0.00 & 0.00 & 1.00 & $19.21 \%$ \\
\hline Expect services to improve in 1 year & 2.43 & 2.42 & 0.84 & 1.00 & 3.00 & 4.00 & $17.82 \%$ \\
\hline Schools in origin & 0.34 & 0.34 & 0.47 & 0.00 & 0.00 & 1.00 & $19.28 \%$ \\
\hline Running water in origin & 2.47 & 2.46 & 1.23 & 1.00 & 3.00 & 5.00 & $14.72 \%$ \\
\hline
\end{tabular}

Table A15: Summary statistics of variables included in constructing the services in Syria index

\section{Services in Syria}

\begin{tabular}{|c|c|c|c|c|c|c|c|}
\hline Variable & Weighted.Mean & Unweighted.Mean & Std.Dev & Min & Median & $\operatorname{Max}$ & Pct.Missing \\
\hline Electricity in origin & 2.51 & 2.51 & 1.27 & 1.00 & 3.00 & 5.00 & $15.25 \%$ \\
\hline Health services in origin & 0.36 & 0.36 & 0.48 & 0.00 & 0.00 & 1.00 & $19.21 \%$ \\
\hline Expect services to improve in 1 year & 2.43 & 2.42 & 0.84 & 1.00 & 3.00 & 4.00 & $17.82 \%$ \\
\hline Schools in origin & 0.34 & 0.34 & 0.47 & 0.00 & 0.00 & 1.00 & $19.28 \%$ \\
\hline Running water in origin & 2.47 & 2.46 & 1.23 & 1.00 & 3.00 & 5.00 & $14.72 \%$ \\
\hline
\end{tabular}

Table A16: Summary statistics of variables included in constructing the services in Syria index 
Networks in Syria

\begin{tabular}{|c|c|c|c|c|c|c|c|}
\hline Variable & Weighted.Mean & Unweighted.Mean & Std.Dev & Min & Median & Max & Pct.Missing \\
\hline No. HH members returned to Syria & 0.10 & 0.11 & 0.65 & 0.00 & 0.00 & 5.00 & $0.27 \%$ \\
\hline Relatives permanently return to Syria & 0.97 & 1.05 & 2.99 & 0.00 & 0.00 & 15.00 & $1.40 \%$ \\
\hline Relatives return to origin & 0.53 & 0.60 & 2.44 & 0.00 & 0.00 & 15.00 & $1.17 \%$ \\
\hline Syria HH members living in Syria now & 1.86 & 2.00 & 3.36 & 0.00 & 0.00 & 15.00 & $0.10 \%$ \\
\hline
\end{tabular}

Table A17: Summary statistics of variables included in constructing the networks in Syria index

\subsection{Confidence in information}

\begin{tabular}{|c|c|c|c|c|c|c|c|}
\hline Variable & Weighted.Mean & Unweighted.Mean & Std.Dev & Min & Median & Max & Pct.Missing \\
\hline Know Syr. conscription policy & 0.28 & 0.30 & 0.46 & 0.00 & 0.00 & 1.00 & $0.23 \%$ \\
\hline Know employment in origin & 0.27 & 0.29 & 0.46 & 0.00 & 0.00 & 1.00 & $0.13 \%$ \\
\hline Know safety in origin & 0.26 & 0.27 & 0.45 & 0.00 & 0.00 & 1.00 & $0.10 \%$ \\
\hline Know services in origin & 0.25 & 0.27 & 0.44 & 0.00 & 0.00 & 1.00 & $0.20 \%$ \\
\hline Communication freq. with origin & 2.39 & 2.45 & 1.69 & 1.00 & 2.00 & 6.00 & $0.03 \%$ \\
\hline Communication with someone in Syria & 0.61 & 0.62 & 0.49 & 0.00 & 1.00 & 1.00 & $0.03 \%$ \\
\hline
\end{tabular}

Table A18: Summary statistics of variables included in constructing the confidence in information index

\subsection{Mobility}

\begin{tabular}{|c|c|c|c|c|c|c|c|}
\hline Variable & Weighted.Mean & Unweighted.Mean & Std.Dev & Min & Median & Max & Pct.Missing \\
\hline household size (logged) & 1.50 & 1.48 & 0.56 & 0.00 & 1.61 & 2.89 & $0.00 \%$ \\
\hline travel distance (logged) & 12.83 & 12.85 & 0.52 & 11.13 & 12.98 & 15.63 & $0.37 \%$ \\
\hline
\end{tabular}

Table A19: Summary statistics of variables to measure mobility

\subsection{Preparation to return}

\begin{tabular}{|c|c|c|c|c|c|c|c|}
\hline Variable & Weighted.Mean & Unweighted.Mean & Std.Dev & Min & Median & Max & Pct.Missing \\
\hline Planned to return but aborted & 0.03 & 0.03 & 0.17 & 0.00 & 0.00 & 1.00 & $0.27 \%$ \\
\hline Reached to Leb. authorities about return & 0.01 & 0.01 & 0.08 & 0.00 & 0.00 & 1.00 & $0.13 \%$ \\
\hline Prepared docs for return & 0.02 & 0.03 & 0.17 & 0.00 & 0.00 & 1.00 & $0.10 \%$ \\
\hline Saved resources for return & 0.02 & 0.02 & 0.15 & 0.00 & 0.00 & 1.00 & $0.10 \%$ \\
\hline Conducting scoping trip to Syria & 0.03 & 0.03 & 0.17 & 0.00 & 0.00 & 1.00 & $0.10 \%$ \\
\hline Reached to UNHCR about return & 0.01 & 0.01 & 0.09 & 0.00 & 0.00 & 1.00 & $0.17 \%$ \\
\hline
\end{tabular}

Table A20: Summary statistics of variables included in constructing the preparation to return index

\subsection{Covariates}

The following covariates are included in the regressions. When including fixed effects, we also add locality fixed effects in Lebanon and Syria. 


\begin{tabular}{|c|c|c|c|c|c|c|c|}
\hline Variable & Weighted.Mean & Unweighted.Mean & Std.Dev & Min & Median & Max & Pct.Missing \\
\hline Household includes elderly & 0.04 & 0.04 & 0.19 & 0.00 & 0.00 & 1.00 & $0.00 \%$ \\
\hline Female headed single-parent household & 0.11 & 0.10 & 0.30 & 0.00 & 0.00 & 1.00 & $0.03 \%$ \\
\hline High school graduate & 0.11 & 0.12 & 0.32 & 0.00 & 0.00 & 1.00 & $0.03 \%$ \\
\hline Hezbollah controlled area & 0.16 & 0.17 & 0.38 & 0.00 & 0.00 & 1.00 & $0.00 \%$ \\
\hline Location: Tental settlement & 0.35 & 0.33 & 0.47 & 0.00 & 0.00 & 1.00 & $0.00 \%$ \\
\hline Sick required medical treatment & 0.30 & 0.30 & 0.46 & 0.00 & 0.00 & 1.00 & $0.23 \%$ \\
\hline Syria origin: urban & 0.23 & 0.23 & 0.42 & 0.00 & 0.00 & 1.00 & $0.20 \%$ \\
\hline Household includes toddler & 0.45 & 0.44 & 0.50 & 0.00 & 0.00 & 1.00 & $0.00 \%$ \\
\hline
\end{tabular}

Table A21: Summary statistics of variables included as controls in the regressions

\section{Scree plots for principal component analysis}

The following figures display how eigenvalues change with each additional component for the indices we created using PCA. Throughout the analysis, we used the first principal component.

\subsection{Push factors from Lebanon}

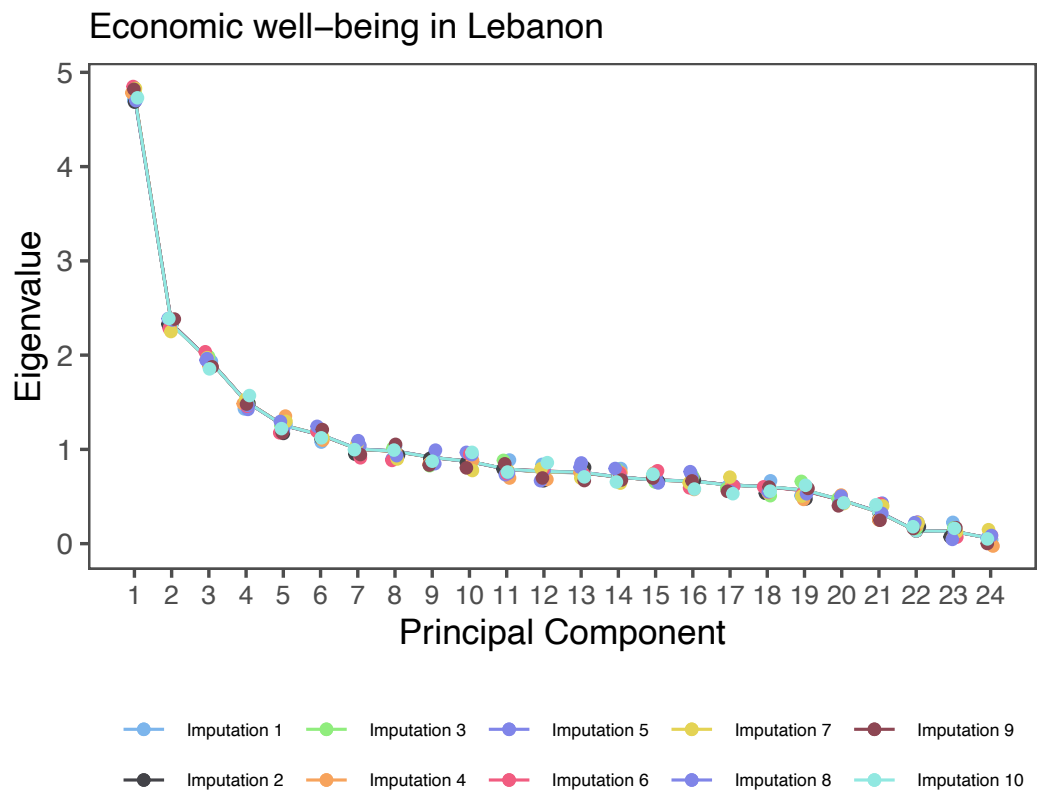

Figure A1: Screeplot for the economic well-being in Lebanon index 


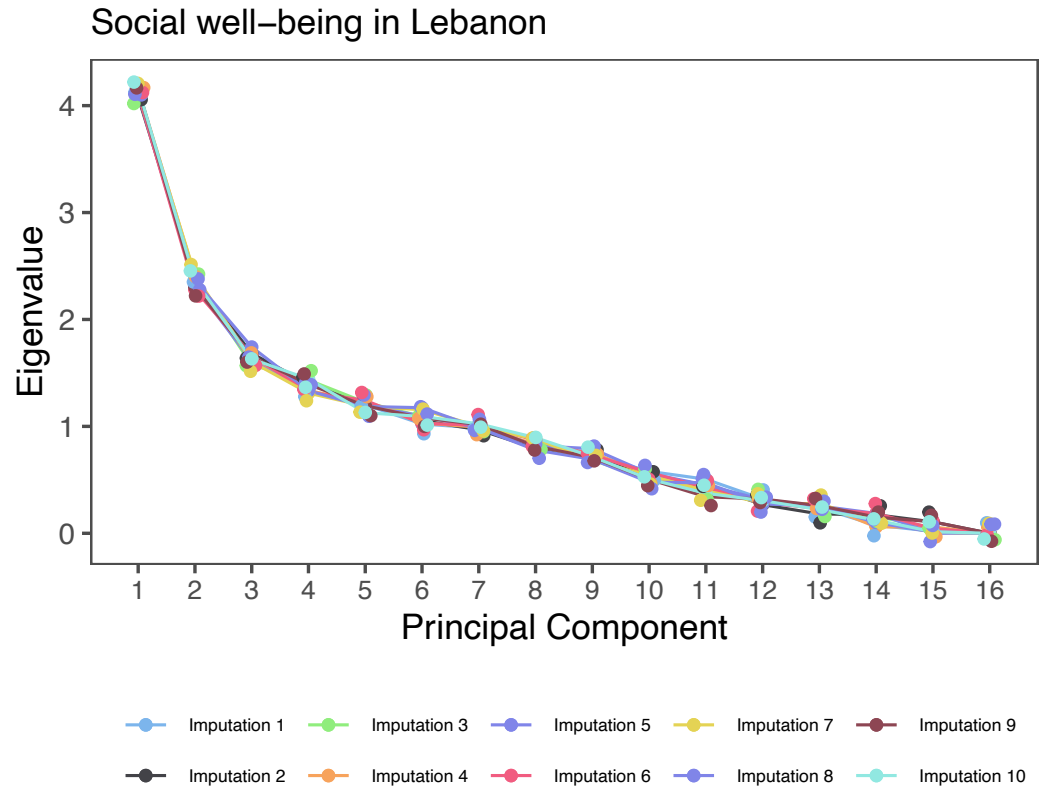

Figure A2: Screeplot for the social well-being in Lebanon index

\section{Services in Lebanon}

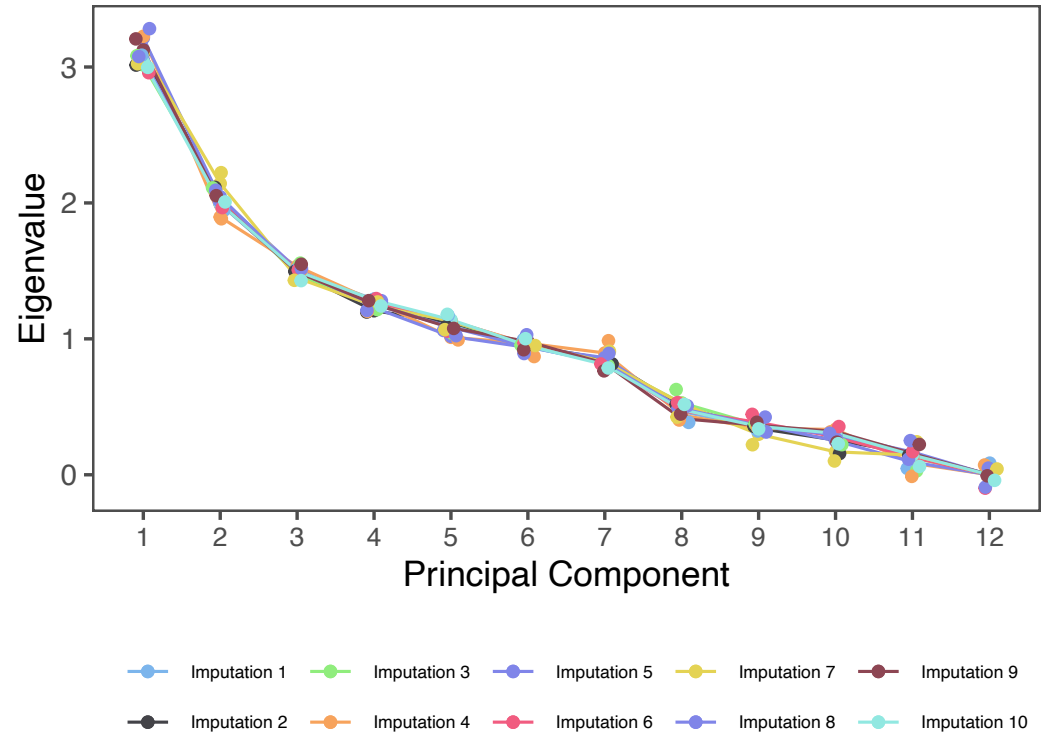

Figure A3: Screeplot for the services in Lebanon index 


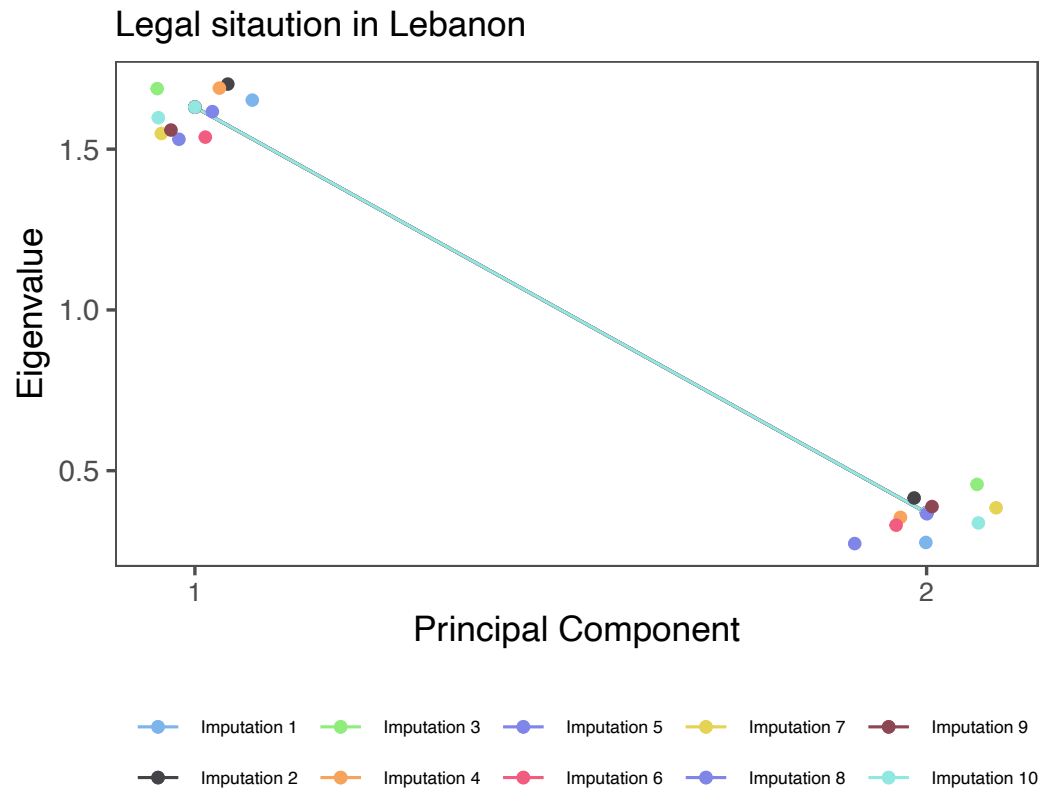

Figure A4: Screeplot for the legal situation in Lebanon index

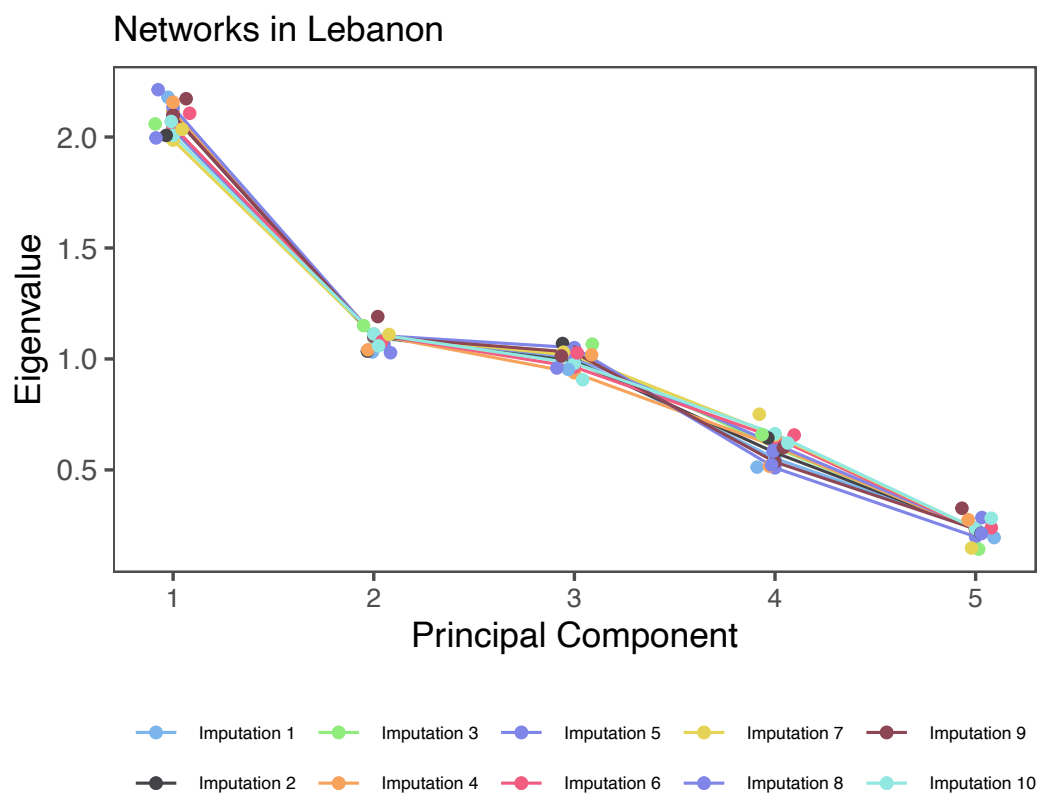

Figure A5: Screeplot for the networks in Lebanon index 


\subsection{Pull factors in Syria}

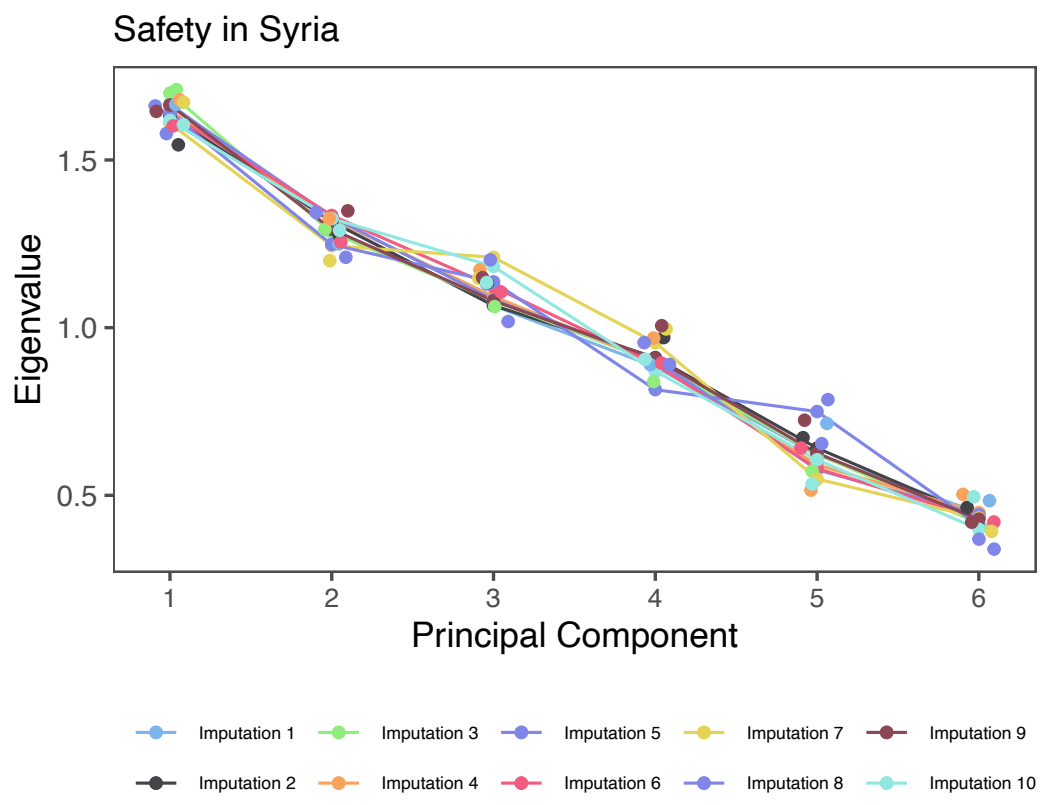

Figure A6: Screeplot for the safety in Syria index

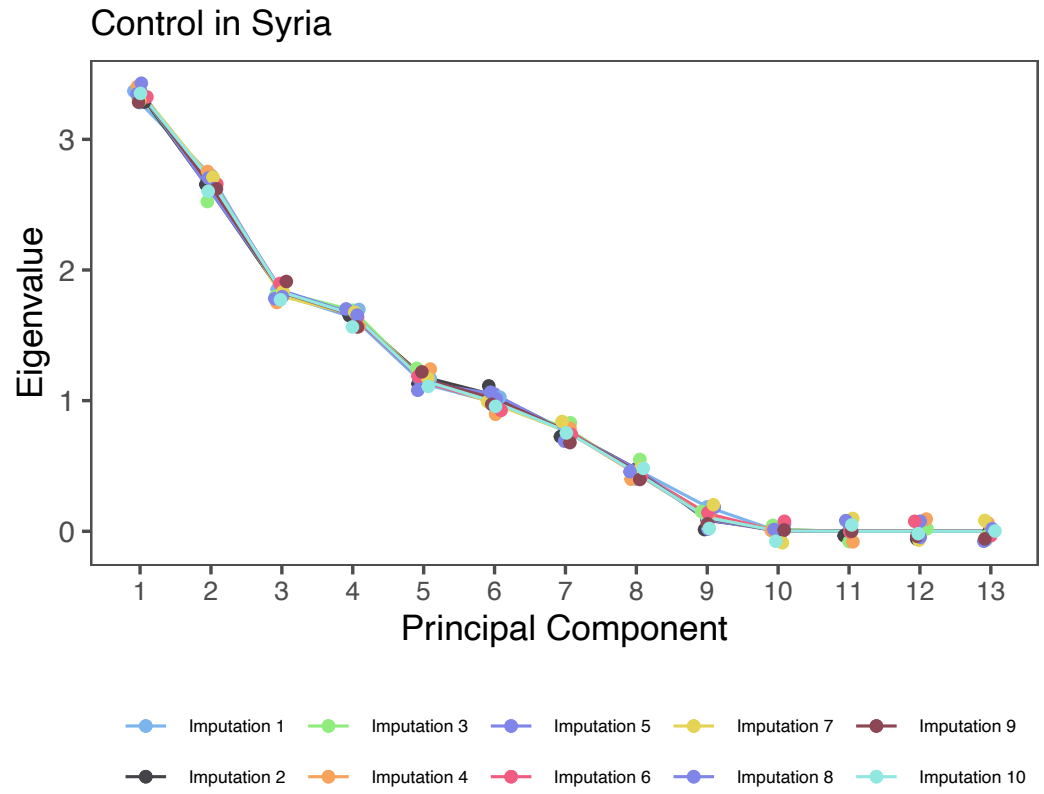

Figure A7: Screeplot for the control in Syria index 


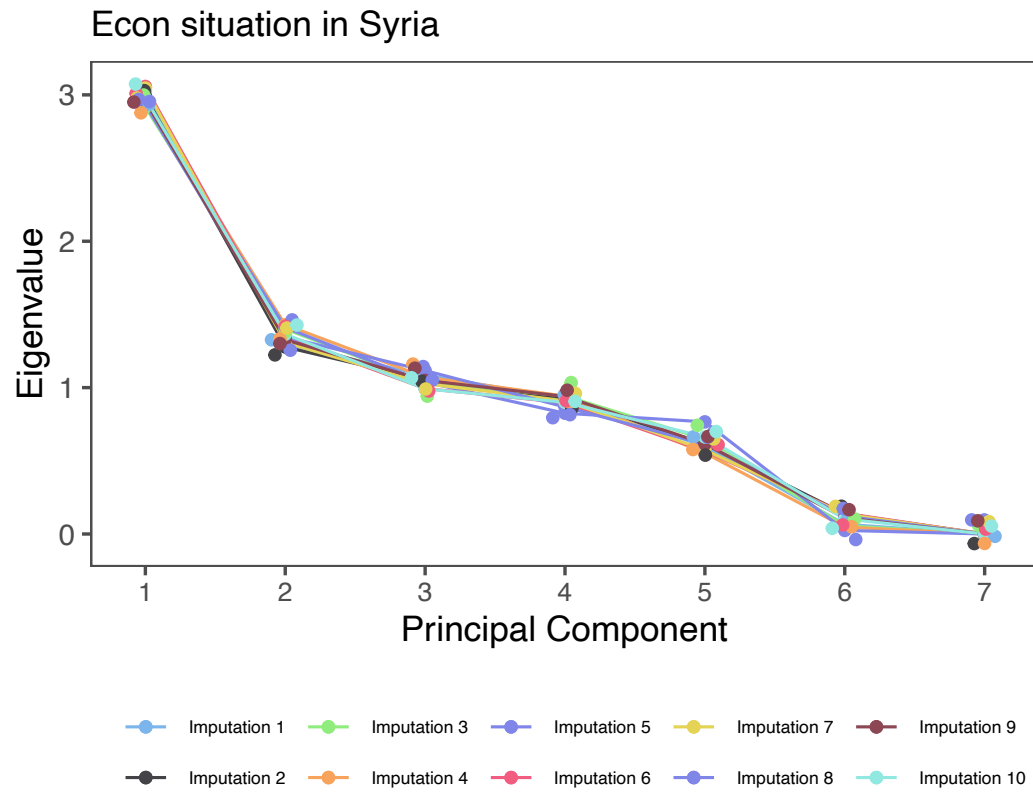

Figure A8: Screeplot for the economic well-being in Syria index

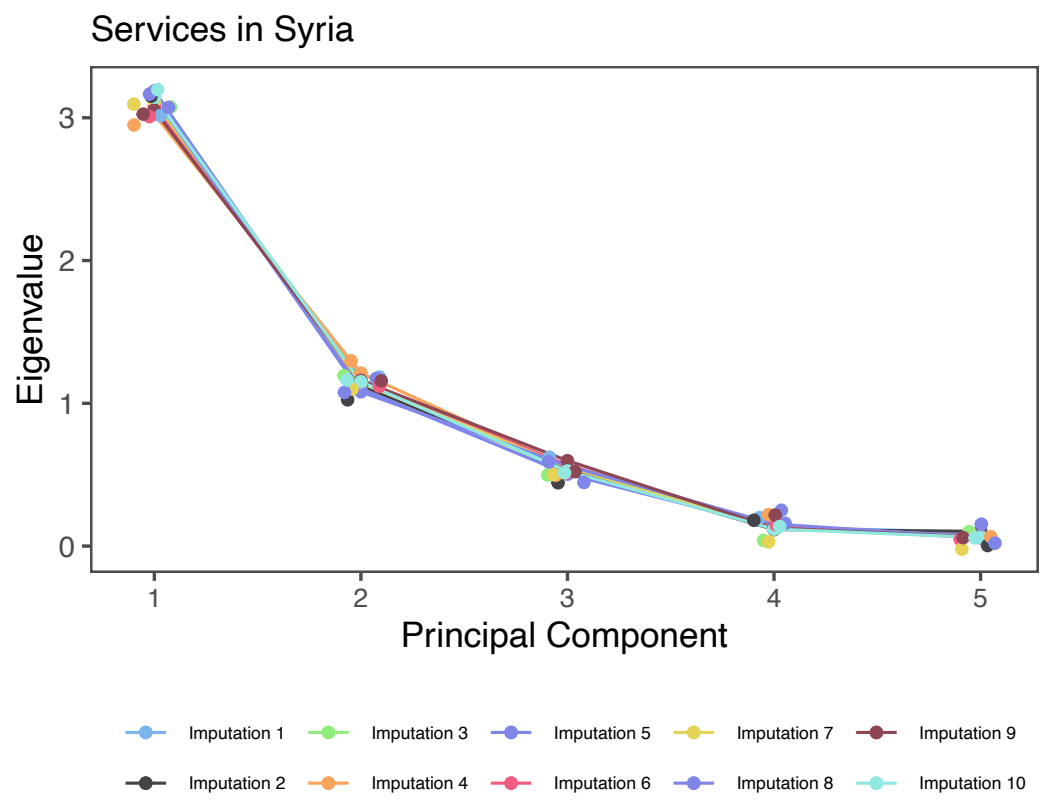

Figure A9: Screeplot for the services in Syria index 


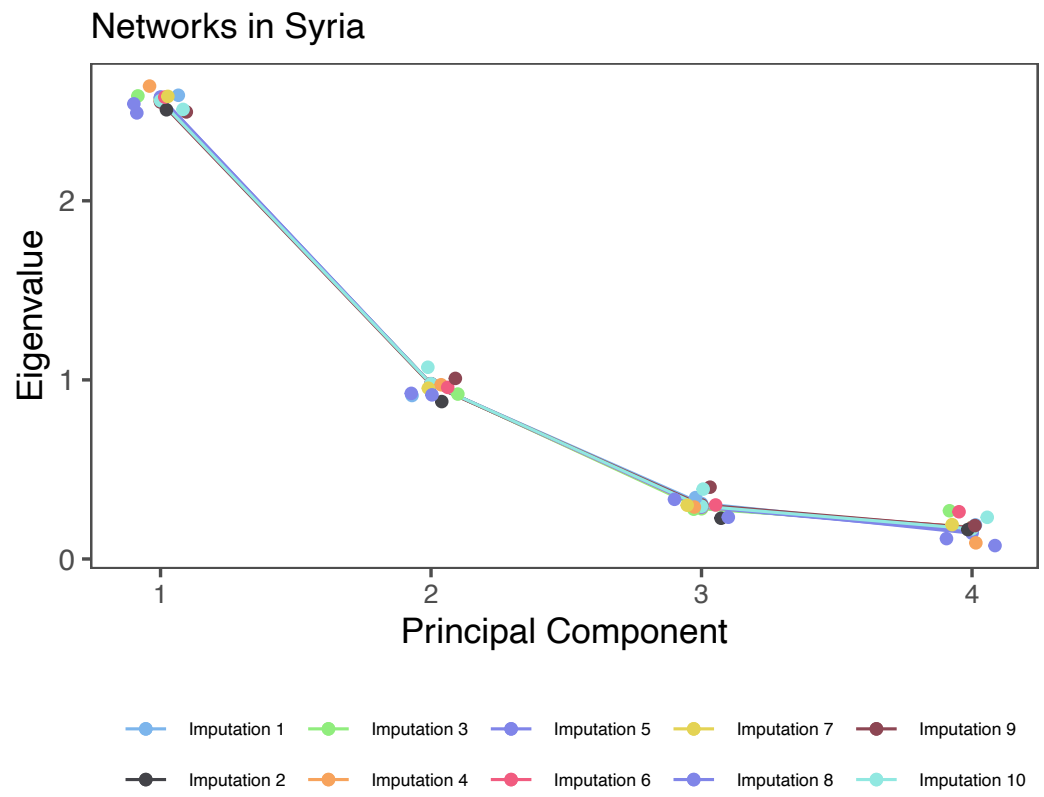

Figure A10: Screeplot for the networks in Syria index

\subsection{Confidence in information}

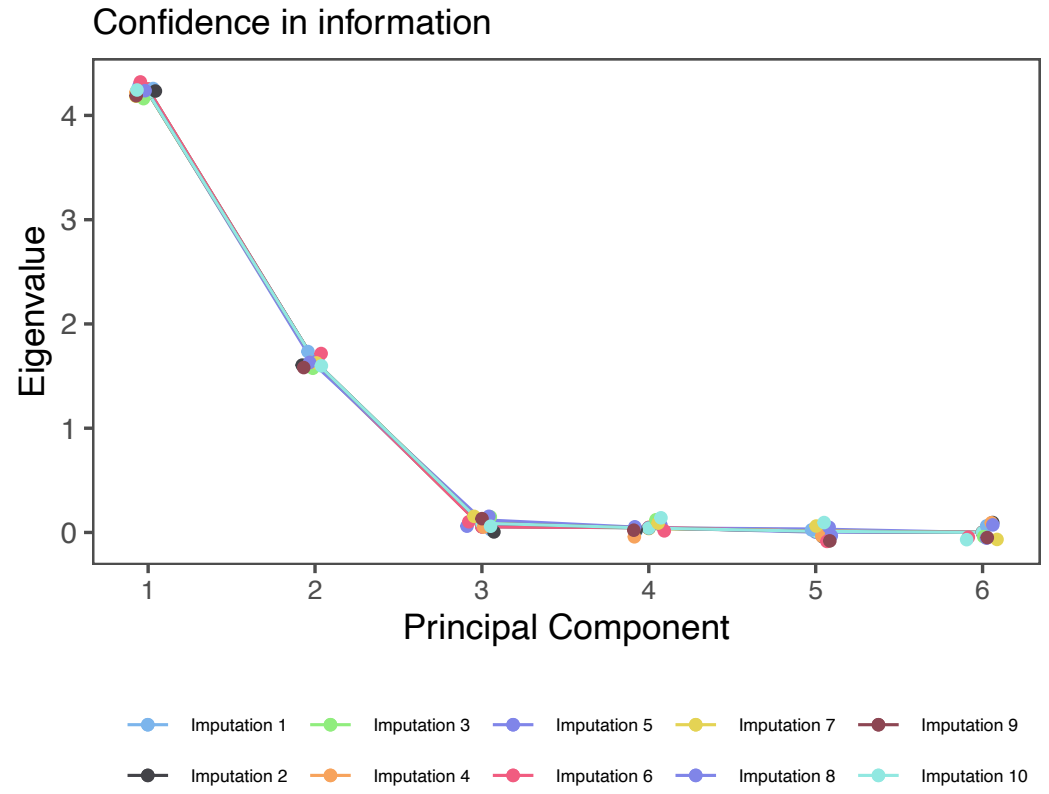

Figure A11: Screeplot for the confidence in information index 


\subsection{Preparation for return}

\section{Prepare to return}

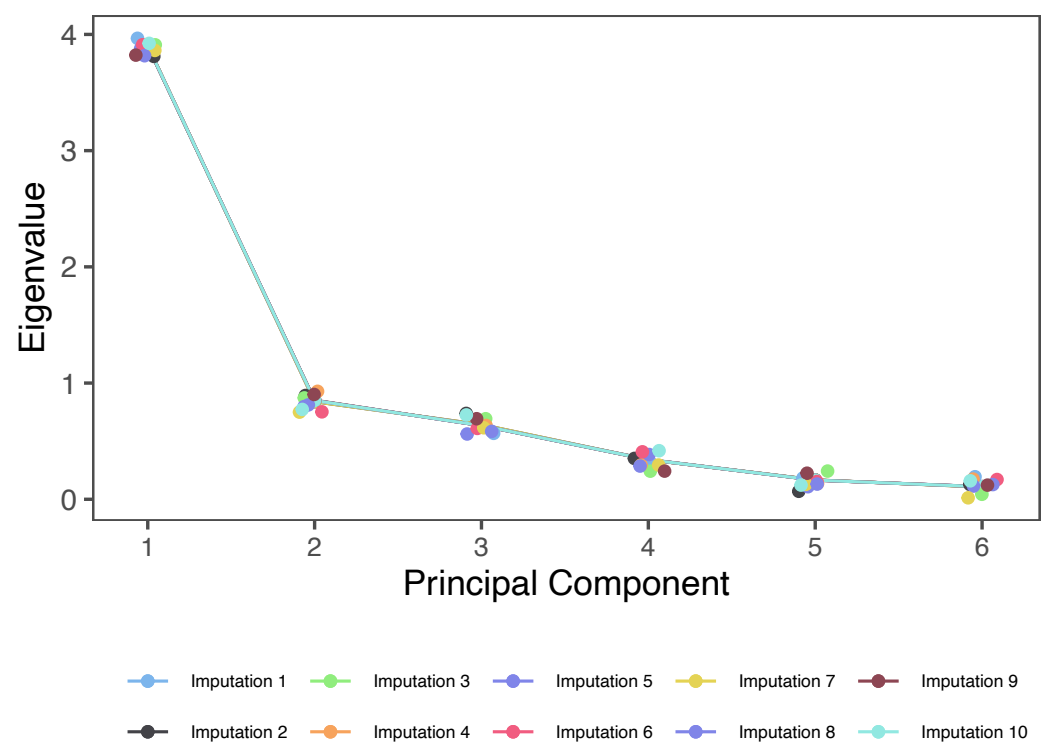

Figure A12: Screeplot for the preparation to return index

\section{Deviations from PAP}

Multicollinearity: In the PAP, we indicated that we would run one regression with all the indices. Because of multicollinearity, we ran separate regressions for each of the indices and also ran the pre-specified regression with a minor adjustment: we did not include the indices measuring safety and services in Syria in the same regression because of their high correlation. In the paper, we present the results results for all the indices where we control for safety. In Section 6.2, we include the results for all the indices where we control for services in Syria.

We made the choice to present an alternative regression after tests of model performance identified multicollinearity in our regression predictors. The first simple test of model performance involved examining the simple pairwise correlations between our predictors. We find that the pairwise correlation between the security index and services index in Syria is high at 0.57.

Of course, simple correlation is not multicollinearity. Therefore, second, we test for an association between predictors conditional on the other variables in the model. The variance inflation factor is a measure to analyze the magnitude of multicollinearity of model terms. Using the performance() package in $\mathrm{R}$, we find that in the pre-specified models we identify very high variance inflation factors for a number of indices, most notably services in Syria and regime control. Evidence of multicollinearity is consistent across multiple tests in the performance() package. 
Analysis without locality fixed effects: We re-ran our main analysis without Lebanese locality fixed effects as a robustness check. This regression can be seen in Figure A24 in Section 6 of the appendix. Furthermore, after submitting the PAP, we realized that it would be misguided to control for Lebanese locality and Syrian locality when analyzing the role of travel distance from Lebanese locality to Syrian locality. Therefore, in regressions with travel distance on the right-hand side, we do not include locality fixed effects.

Predictive analysis: The predictive analyses included in appendix section 6.7 were not prespecified.

PCA inputs: PCA inputs were pre-specified but required a number of ex post modifications for reasons explained below.

Index 1-Economic well being in Lebanon: The PAP mistakenly indicated that a question about someone's former job in Syria would be included in the economic well-being in Lebanon index. This was a typo, and it was removed since it is not a dimension of economic well-being in Lebanon.

Index 2-Social well being in Lebanon: The PAP specifies that we intended to calculate the IPL-12 integration score to use it as an input for PCA. In later revisions to the questionnaire, some questions were modified and no longer matched IPL-12 inputs. We modified this index slightly and now use component questions of IPL-12 as inputs rather than calculating the IPL-12 score. Furthermore, household income in Lebanon was mistakenly included in both index 1 and index 2 . We decided this index fits better in index 1 and removed it from index 2 .

Index 3-services in Lebanon: A question included in the PAP was subsequently cut from the survey: "Have you been forced to move in the last two years, for instance because you were kicked out of your home or your home was deconstructed/demolished?" So we did not include it in the analysis.

Index 5.1 - Safety: First, we separated regime control from safety conditions in Syria. These two concepts were not closely related and we decided to examine territorial control and safety separately. Furthermore, Family deaths in Syria was excluded due to flaw in measurement strategy.

Index 10-Information quality: After submitting the PAP we removed the following ques-

tion: "How confident are you in your knowledge about conditions in [Piped place of origin]?" so we did not include it in the analysis.

\section{Robustness and Additional Tests}




\subsection{Return in two years and ever}

In addition to the return in 12 months and preparation to return outcomes, we have also examined the predictors of expectation to return in two years and intentions to ever return to Syria. In Table A22 the first two models present the regression results for the return ever outcome using one index per regression (Model 1) and using all indices in the same regression (Model 2). Models 3 and 4 show the same analyses for the return in two years outcome.

\begin{tabular}{lcccc}
\hline & Ever (Ind. Indices) & Ever (All Indices) & 2 years (Ind. Indices) & 2 years (All Indices) \\
\hline Safety (Syr.) & $0.038^{* *}$ & $0.039^{* *}$ & $0.049^{* * *}$ & $0.076^{* * *}$ \\
& $(0.016)$ & $(0.014)$ & $(0.017)$ & $(0.017)$ \\
Regime control (Syr.) & 0.004 & -0.014 & 0.006 & -0.021 \\
& $(0.015)$ & $(0.014)$ & $(0.014)$ & $(0.019)$ \\
Economic well-being (Syr.) & $0.033^{* *}$ & $0.061^{* * *}$ & 0.026 & $0.062^{* * *}$ \\
& $(0.013)$ & $(0.013)$ & $(0.021)$ & $(0.016)$ \\
Services (Syr.) & $0.030^{*}$ & 0.018 & 0.023 & $0.052^{* * *}$ \\
& $(0.017)$ & $(0.015)$ & $(0.015)$ & $(0.013)$ \\
Networks (Syr.) & $0.031^{* * *}$ & $0.020^{*}$ & -0.002 & -0.004 \\
Economic well-being (Leb.) & $(0.009)$ & $(0.010)$ & $(0.009)$ & $(0.009)$ \\
& $-0.040^{*}$ & $-0.079^{* * *}$ & -0.019 & -0.055 \\
Services (Leb.) & $(0.020)$ & $(0.020)$ & $(0.015)$ & $(0.035)$ \\
& -0.034 & -0.005 & $0.044^{* * *}$ & 0.030 \\
Networks (Leb.) & $(0.021)$ & $(0.024)$ & $(0.015)$ & $(0.019)$ \\
& -0.017 & $-0.051^{* * *}$ & -0.015 & -0.007 \\
Social well-being (Leb.) & $(0.012)$ & $(0.014)$ & $(0.018)$ & $(0.012)$ \\
& $0.063^{* * *}$ & $0.112^{* * *}$ & 0.004 & 0.029 \\
Legal conditions (Leb.) & $(0.022)$ & $(0.022)$ & $(0.020)$ & $(0.018)$ \\
& 0.001 & 0.011 & $-0.019^{*}$ & -0.012 \\
Log travel distance & $(0.018)$ & $(0.016)$ & $(0.010)$ & $(0.011)$ \\
& $-0.078^{* * *}$ & $-0.056^{* *}$ & 0.002 & 0.020 \\
Log household size & $(0.024)$ & $(0.022)$ & $(0.038)$ & $(0.029)$ \\
& 0.015 & 0.011 & 0.009 & 0.015 \\
Confidence in information & $(0.020)$ & $(0.020)$ & $(0.023)$ & $(0.029)$ \\
& 0.026 & $0.037^{* *}$ & 0.020 & -0.015 \\
& $(0.016)$ & $(0.017)$ & $(0.015)$ & $(0.016)$ \\
\hline$* * * * 01, * *<0.05 * *<0.1$ & & & &
\end{tabular}

Table A22: Regression results using alternative outcomes. The first two models present the regression results for the return ever outcome using one index per regression (model 1) and using all indices in the same regression (model 2). The last two models present the regression results for the return in 2 years outcome using one index per regression (model 3) and using all indices in the same regression (model 4).

\subsection{Safety, services, and additional covariates}

Given the high correlation between safety and services in Syria, we ran a regression that included all the predictors except services in Syria, and then ran a separate regression that included all the predictors except safety in Syria. We reported the results of all the coefficients from the regression that included safety (but not services) in Syria. We then added the single coefficient for services from the second regression. In Models 1 and 2 of Table A23, we do the opposite. We include all the coefficients from the regression that included services (but not safety) in Syria and then add the single coefficient for safety in Syria from the first regression. 
In models 3 and 4 of Table A23, we present the results using all the indices in the regression (including safety and services in Syria) for the return in 12 months outcome (Model 3) and the preparation to return outcome (Model 4). As can be seen here, the two indices (safety and services) get smaller point estimates and are no longer statistically significant. This difference between the individual-index models and the all-indices model aligns with the evidence of correlation and multicollinearity shown in section 5 .

Finally, the main results using individual indices control for a limited set of household covariates because many of the other potential covariates are included in the appendix. Of course, when we include the full list of indices in the same regression (all indices), we control for indices that include a variety of other covariates. In addition to this approach, we also run the main model with the individual indices using a larger set of controls. In addition to the main variables included in the paper, model 5 in Table A23 controls for household income, whether household receives aid, the number of years in Lebanon, the presence of a curfew targeting refugees in the area, whether any household members are school age, and having Lebanese relatives. Note that when one of these variables is included in the index, we do not control for this variable. The full set of variables in each index can be seen in section 3 .

\subsection{Excluding locality fixed effects}

We also test for the robustness of our results by re-running our models, but without controlling for locality fixed effects 11 Model 1 of Table A24 shows the results for the 12 months outcome while Model 2 shows the results for the preparation to return outcome.

\subsection{Return plans for household members and uncertainty about return}

The main paper coded intention to return in 12 months as 1 if heads of households indicated their intentions to return. The last two models in Table A24 present alternative codings of this outcome. The first two models re-run the main analysis without fixed effects for the return in 12 months outcome (Model 1) and for the preparation to return outcome (Model 2). In Model 3, the outcome is whether anyone in the household plans to return in 12 months. In Model 4, the outcome at the head of household level is coded as 1 if the heads of household said they planned to return or were uncertain about return and 0 only if they said that they do not plan to return.

\footnotetext{
${ }^{1}$ This robustness check was not pre-specified.
} 


\begin{tabular}{|c|c|c|c|c|c|}
\hline & 12 months (Services) & Prepare (Services) & 12 months (Safety + Services) & Prepare (Safety + Services) & Return in 12 months \\
\hline Economic well-being (Leb.) & $\begin{array}{l}-0.007 \\
(0.008)\end{array}$ & $0.154^{* * *}$ & $\begin{array}{r}-0.007 \\
(0.008)\end{array}$ & $0.154^{* * *}$ & $\begin{array}{c}0.000 \\
(0.010)\end{array}$ \\
\hline Social well-being (Leb.) & $\begin{array}{c}0.021^{* * *} \\
(0.006)\end{array}$ & $\begin{array}{c}0.020 \\
(0.025)\end{array}$ & $\begin{array}{c}0.020^{* * *} \\
(0.006)\end{array}$ & $\begin{array}{c}0.018 \\
(0.026)\end{array}$ & $\begin{array}{c}0.017^{* * *} \\
(0.006)\end{array}$ \\
\hline Services (Leb.) & $\begin{array}{l}-0.005 \\
(0.007)\end{array}$ & $\begin{array}{l}-0.010 \\
(0.027)\end{array}$ & $\begin{array}{l}-0.006 \\
(0.007)\end{array}$ & $\begin{array}{l}-0.011 \\
(0.028)\end{array}$ & $\begin{array}{l}-0.003 \\
(0.007)\end{array}$ \\
\hline Legal conditions (Leb.) & $\begin{array}{l}-0.003 \\
(0.005)\end{array}$ & $\begin{array}{c}0.000 \\
(0.025)\end{array}$ & $\begin{array}{l}-0.002 \\
(0.005)\end{array}$ & $\begin{array}{c}0.001 \\
(0.025)\end{array}$ & $\begin{array}{l}-0.004 \\
(0.006)\end{array}$ \\
\hline Regime control (Syr.) & $\begin{array}{l}-0.007 \\
(0.006)\end{array}$ & $\begin{array}{l}-0.000 \\
(0.017)\end{array}$ & $\begin{array}{l}-0.009 \\
(0.006)\end{array}$ & $\begin{array}{l}-0.002 \\
(0.018)\end{array}$ & $\begin{array}{l}-0.011 \\
(0.007)\end{array}$ \\
\hline Economic well-being (Syr.) & $\begin{array}{l}0.012^{* *} \\
(0.005)\end{array}$ & $\begin{array}{c}0.013 \\
(0.022)\end{array}$ & $\begin{array}{l}0.013^{* *} \\
(0.005)\end{array}$ & $\begin{array}{c}0.014 \\
(0.022)\end{array}$ & $\begin{array}{l}0.016^{* *} \\
(0.006)\end{array}$ \\
\hline Services (Syr.) & $\begin{array}{l}0.012^{* *} \\
(0.005)\end{array}$ & $\begin{array}{c}0.073^{* * * *} \\
(0.025)\end{array}$ & $\begin{array}{c}0.006 \\
(0.006)\end{array}$ & $\begin{array}{l}0.066^{* *} \\
(0.026)\end{array}$ & $\begin{array}{c}0.018^{* * * *} \\
(0.006)\end{array}$ \\
\hline Networks (Syr.) & $\begin{array}{l}0.012^{*} \\
(0.006)\end{array}$ & $\begin{array}{l}0.077^{*} \\
(0.045)\end{array}$ & $\begin{array}{l}0.012^{*} \\
(0.006)\end{array}$ & $\begin{array}{c}0.077 \\
(0.045)\end{array}$ & $\begin{array}{c}0.017^{* * * *} \\
(0.006)\end{array}$ \\
\hline Networks (Leb.) & $\begin{array}{l}-0.002 \\
(0.006)\end{array}$ & $\begin{array}{c}0.017 \\
(0.024)\end{array}$ & & & \\
\hline Confidence in information & $\begin{array}{l}0.020^{* *} \\
(0.008)\end{array}$ & $\begin{array}{c}0.003 \\
(0.022)\end{array}$ & $\begin{array}{l}0.020^{* *} \\
(0.007)\end{array}$ & $\begin{array}{c}0.003 \\
(0.022)\end{array}$ & $\begin{array}{l}0.019^{* *} \\
(0.009)\end{array}$ \\
\hline Log travel distance & $\begin{array}{c}0.006 \\
(0.009)\end{array}$ & $\begin{array}{l}-0.036 \\
(0.044)\end{array}$ & $\begin{array}{c}0.006 \\
(0.009)\end{array}$ & $\begin{array}{l}-0.036 \\
(0.044)\end{array}$ & $\begin{array}{c}0.002 \\
(0.008)\end{array}$ \\
\hline Log household size & $\begin{array}{c}0.013 \\
(0.010)\end{array}$ & $\begin{array}{l}0.001 \\
(0.049)\end{array}$ & $\begin{array}{c}0.014 \\
(0.010)\end{array}$ & $\begin{array}{c}0.001 \\
(0.049)\end{array}$ & $\begin{array}{c}0.010 \\
(0.011)\end{array}$ \\
\hline Safety (Syr.) & $\begin{array}{l}0.014^{* *} \\
(0.006)\end{array}$ & $\begin{array}{c}0.048^{*} \\
(0.026)\end{array}$ & $\begin{array}{c}0.011 \\
(0.007)\end{array}$ & $\begin{array}{c}0.015 \\
(0.026)\end{array}$ & $\begin{array}{l}0.017^{* *} \\
(0.006)\end{array}$ \\
\hline Networks (Leb.) & & & $\begin{array}{l}-0.003 \\
(0.006)\end{array}$ & $\begin{array}{c}0.016 \\
(0.024)\end{array}$ & $\begin{array}{l}0.010^{*} \\
(0.006)\end{array}$ \\
\hline
\end{tabular}

${ }^{* * *} p<0.01 ;{ }^{* *} p<0.05 ;{ }^{*} p<0.1$

Table A23: Robustness tests. The first two models include the services in Syria index in the all-indices regression (instead of the safety index) for the return in 12 months outcome (model 1) and the preparation to return outcome (model 2). The next two models present the analysis that includes running both the safety and services in Syria indices in the same regression. Note that there is a high correlation between the safety and services in Syria indices. The third model uses the return in 12 months outcome and the fourth model uses the preparation to return outcome. The final model uses the main return in 12 months outcome with individual indices but uses additional covariates. Besides the ones mentioned in the paper, it controls for household income, an indicator for receiving aid, years in Lebanon, an indicator for a curfew in the locality, an indicator for age-school children, and an indicator for Lebanese relatives. Note that these additional controls are included only when the individual index in the regression does not contain any of these variables. The list of variables in each index is included appendix section 3 .

\subsection{Additive indices}

To build indices in the paper, we use the first principal component for the predictors under push factors, pull factors, and information as well as for the preparation to return outcome. In Table A25. we present results using mean effects indices. The first two models in Table A25 present the results using one index per regression for the 12 months return outcome (Model 1) and the preparation to return outcome (Model 2). The last two models present the same analyses but using all the indices in the same regression. 


\begin{tabular}{|c|c|c|c|c|}
\hline & 12 months (No FEs) & Prepare (No FEs) & Household member return & Head of HH return (counting uncertain) \\
\hline \multirow[t]{2}{*}{ Safety (Syr.) } & $0.021^{* * *}$ & $0.084^{* * *}$ & $0.018^{* *}$ & $0.031^{*}$ \\
\hline & $(0.006)$ & $(0.024)$ & $(0.008)$ & $(0.018)$ \\
\hline \multirow[t]{2}{*}{ Regime control (Syr.) } & $-0.013^{*}$ & -0.002 & -0.010 & $-0.042^{*}$ \\
\hline & $(0.007)$ & $(0.021)$ & $(0.007)$ & $(0.021)$ \\
\hline \multirow[t]{2}{*}{ Economic well-being (Syr.) } & $0.018^{* * *}$ & $0.063^{* *}$ & $0.020^{* * *}$ & -0.000 \\
\hline & $(0.005)$ & $(0.030)$ & $(0.007)$ & $(0.011)$ \\
\hline \multirow[t]{2}{*}{ Services (Syr.) } & $0.021^{* * *}$ & $0.115^{* * *}$ & $0.019^{* * *}$ & $0.046^{* *}$ \\
\hline & $(0.005)$ & $(0.028)$ & $(0.006)$ & $(0.017)$ \\
\hline \multirow[t]{2}{*}{ Networks (Syr.) } & $0.019^{* * *}$ & $0.110^{* *}$ & $0.015^{* *}$ & 0.011 \\
\hline & $(0.006)$ & $(0.040)$ & $(0.006)$ & $(0.009)$ \\
\hline \multirow[t]{2}{*}{ Economic well-being (Leb.) } & 0.007 & $0.183^{* * *}$ & -0.001 & 0.043 \\
\hline & $(0.007)$ & $(0.054)$ & $(0.008)$ & $(0.026)$ \\
\hline \multirow[t]{2}{*}{ Services (Leb.) } & -0.001 & 0.011 & -0.009 & 0.000 \\
\hline & $(0.007)$ & $(0.025)$ & $(0.008)$ & $(0.012)$ \\
\hline \multirow[t]{2}{*}{ Networks (Leb.) } & $0.013^{* * *}$ & $0.088^{* * *}$ & & \\
\hline & $(0.004)$ & $(0.021)$ & & \\
\hline \multirow[t]{2}{*}{ Social well-being (Leb.) } & $0.021^{* * *}$ & $0.068^{* * *}$ & $0.020^{* * *}$ & -0.004 \\
\hline & $(0.005)$ & $(0.020)$ & $(0.007)$ & $(0.013)$ \\
\hline \multirow[t]{2}{*}{ Legal conditions (Leb.) } & -0.003 & 0.002 & -0.003 & -0.012 \\
\hline & $(0.006)$ & $(0.020)$ & $(0.005)$ & $(0.011)$ \\
\hline \multirow[t]{2}{*}{ Log travel distance } & 0.002 & $-0.079^{*}$ & 0.007 & 0.019 \\
\hline & $(0.008)$ & $(0.043)$ & $(0.012)$ & $(0.015)$ \\
\hline \multirow[t]{2}{*}{ Log household size } & 0.001 & $-0.103^{* * *}$ & 0.022 & 0.012 \\
\hline & $(0.009)$ & $(0.034)$ & $(0.013)$ & $(0.029)$ \\
\hline \multirow[t]{2}{*}{ Confidence in information } & $0.022^{* * *}$ & $0.050^{*}$ & $0.016^{* *}$ & -0.015 \\
\hline & $(0.008)$ & $(0.027)$ & $(0.007)$ & $(0.015)$ \\
\hline \multirow[t]{2}{*}{ Networks (Leb.) } & & & -0.001 & $0.024^{* *}$ \\
\hline & & & $(0.006)$ & $(0.010)$ \\
\hline
\end{tabular}

${ }^{* * *} p<0.01 ;{ }^{* *} p<0.05 ;{ }^{*} p<0.1$

Table A24: Additional tests. The first two models re-run the main analysis without fixed effects for the return in 12 months outcome (model 1) and for the preparation to return outcome (model 2). The third models uses an alternative dependent variable: household member return intentions. This outcome is

coded as 1 if any household member plans to return and 0 otherwise. The final model uses another outcome. The main return intentions in 12 month is coded as 1 if the respondent indicates their plan to return in 12 months and 0 otherwise. The last model uses the return in 12 months outcome but it is coded as 1 if the respondent indicates either that they plan to return in 12 months or they are uncertain about returning in 12 months and 0 otherwise.

\subsection{Information and return intentions}

To further explore the relationship between information and return, we examine whether information moderates the role of perceived conditions in Syria. Specifically, we examine whether conditions in Syria have a larger effect on people's intentions when they have high levels of confidence in their information about the situation in Syria.

$$
Y_{i}=\alpha+\beta_{1} T_{i}+\beta_{2}\left(T_{i} \times \mathbb{1}\left(I_{i}>0\right)\right)+\gamma X_{i}+\epsilon_{i}
$$

Equation 1 is similar to the "individual indices" specification of Equation 1 in the main paper, but includes a multiplicative interaction term between each index $T$ and confidence in information. The indicator function, $\mathbb{1}\left(I_{i}>0\right)$, denotes whether a respondent $i$ had an index value for infor- 


\begin{tabular}{lcccc}
\hline & 12 months (Ind. Indices) & Prepare (Ind. Indices) & 12 months (All Indices) & Prepare (All Indices) \\
\hline Safety (Syr.) & $0.012^{* *}$ & $0.073^{*}$ & 0.008 & 0.039 \\
& $(0.006)$ & $(0.039)$ & $(0.006)$ & $(0.036)$ \\
Economic well-being (Syr.) & $0.021^{* * *}$ & $0.075^{*}$ & $0.015^{* *}$ & $(0.021$ \\
& $(0.006)$ & $(0.037)$ & $0.010^{*}$ & $(0.024)$ \\
Services (Syr.) & $0.018^{* * *}$ & $0.087^{* * *}$ & $0.005)$ & $(0.026)$ \\
Networks (Syr.) & $(0.006)$ & $(0.030)$ & $(0.005)$ & $0.084^{* *}$ \\
& $0.016^{* *}$ & $0.094^{* *}$ & 0.001 & $(0.040)$ \\
Economic well-being (Leb.) & $(0.006)$ & $(0.039)$ & $(0.008)$ & $0.204^{* *}$ \\
Services (Leb.) & 0.008 & $0.186^{* *}$ & $-0.012^{* *}$ & $(0.082)$ \\
& $(0.008)$ & $(0.074)$ & $(0.006)$ & -0.021 \\
Networks (Leb.) & $-0.010^{*}$ & 0.026 & 0.002 & $(0.018)$ \\
& $(0.005)$ & $(0.020)$ & $(0.006)$ & -0.014 \\
Social well-being (Leb.) & 0.008 & 0.020 & $0.011^{*}$ & $(0.027)$ \\
Legal conditions (Leb.) & $(0.005)$ & $(0.019)$ & $(0.006)$ & -0.004 \\
& 0.004 & 0.033 & -0.003 & $(0.029)$ \\
Log travel distance & $(0.006)$ & $(0.022)$ & $(0.005)$ & -0.013 \\
& -0.003 & 0.004 & 0.007 & $(0.025)$ \\
Log household size & $(0.006)$ & $(0.023)$ & $(0.008)$ & -0.022 \\
& 0.002 & $-0.079^{*}$ & 0.011 & $(0.037)$ \\
Confidence in information & $(0.008)$ & $(0.043)$ & $(0.012)$ & $-0.099^{* *}$ \\
& 0.006 & $-0.066^{*}$ & $(0.046)$ \\
\hline$* * *<0.01 * * *<0.05 * *<0.1$ & $(0.009)$ & $(0.033)$ & $(0.008)$ & 0.016 \\
\end{tabular}

Table A25: Additive indices. While the results in the paper use the first principal component of independent variables, here we construct the independent variables using additive indices. First, we standardize each variable to have zero mean and unit standard deviation. Then we summed these variables and standardized the sum again using the same method. The first two models present the results using one index in each regression for the return in 12 months outcome (model 1) and the preparation to return outcome (model 2). The last two models present the results using all the additive indices in one regression for the return in 12 months outcome (model 3) and the preparation to return outcome (model 4).

mation confidence above the mean. $X$ denotes the same vector of covariates as the main paper's Equation 1. Figure A13 presents regression results, displaying the estimated marginal effect of a one standard deviation change in each index for people with low (below-average) confidence in information compared to high (above-average) confidence in information. To obtain standard errors, we used bootstrapping. The confidence intervals here represent the 97.5th (95th) and the 2.5th (5th) percentiles of coefficients across all bootstraps and imputations.

The results in Figure A13 suggest that the relationship between conditions in Syria and return intentions and preparations is shaped by respondents' confidence in their information sources for some key factors. Specifically, we find evidence that information is a significant moderator for the role of regime control and economic prospects in shaping return intentions. Next, we see a differential relationship between the availability of services in people's hometowns and both return intentions and return preparations. Last, we see a differential relationship between networks in Syria and return preparations depending on information confidence.

An alternative way of obtaining confidence intervals is by finding the empirical variance of 


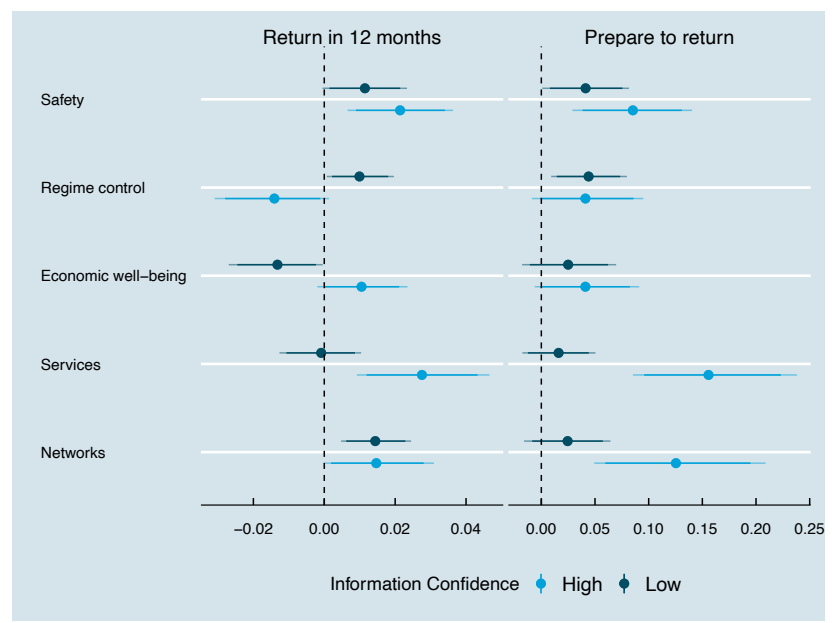

Figure A13: Interactive Effects of Information Confidence on Intentions and Preparations. Estimated marginal effects are presented with the corresponding $90 \%$ and $95 \%$ confidence intervals, with standard errors clustered by locality in Lebanon.

coefficients across bootstraps within each imputation then finding the pooled variance across all imputations using the rules of Rubin (1987). Figure A14 presents results from this approach.

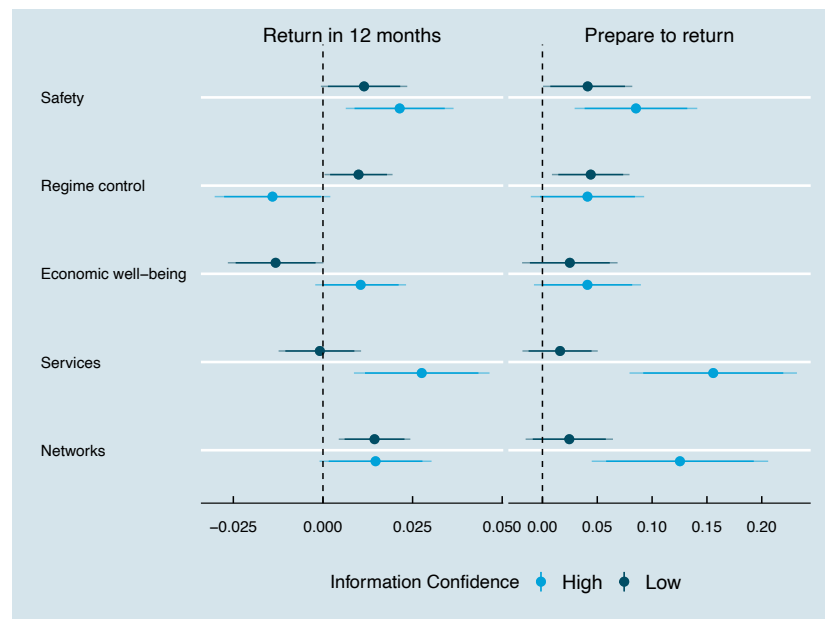

Figure A14: Interactive Effects of Information Confidence on Intentions and Preparations. Estimated marginal effects are presented with the corresponding $90 \%$ and $95 \%$ confidence intervals, with standard errors clustered by locality in Lebanon.

\subsection{Testing the models' predictive power}

As an additional test of the findings in Figure 2 of the main paper, we fit predictive models based on home-country factors and host-country factors using 10-fold cross validation. Below we present prediction plots, including OLS (same models as in the PAP) and lasso, with AUC results for ROC 
and $\mathrm{PR} \mathrm{2}^{2} \mathrm{PR}$ is often as a better performance metric than ROC for predicting rare outcomes. This is due to the fact that the ROC allows for relatively "good" performance by predicting all zeros, which is not the case with PR plots.

Looking at the results in Figures A15 A16, we see that the trends are consistent with our main findings but the differences across models are small. Looking at the ROC plot in the OLS model, we witness a $\sim 2.5$ percentage point increase $(\sim 4 \%)$ comparing the push model to the pull model, and a $\sim 4$ percentage point increase $(\sim 6 \%)$ moving from push to full (i.e., push + pull) ${ }^{3}$ Looking at the PR curve, we see a $\sim 2$ percentage point increase $(\sim 25 \%)$ comparing the push model to the pull model, which is similar to the increase moving from the push model to the full model (i.e., push + pull). The gains in terms of PR AUC are large in percentage terms, although not absolute terms. The results from the lasso model are similar.

The results suggest a few key takeaways about the predictive power of the models presented in the paper. First, the Syria model is a better predictor than the Lebanon model, aligning with our main results. Second, the gains across models are large in percentage terms, but not in absolute terms. Third, overall predictive power is low and prediction is hard in our case, possibly due to studying a rare outcome, but also highlighting that understanding the aggregate drivers of return will not necessarily allow policymakers to make reliable predictions about whether an individual household will return or not.

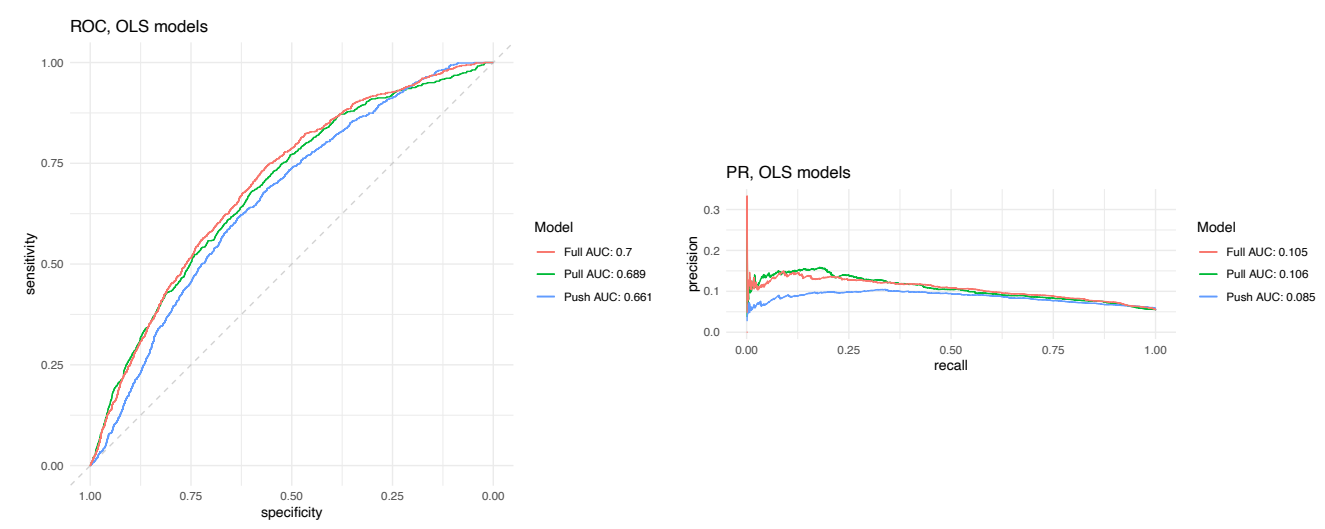

Figure A15: ROC-OLS models with pre-specified inputs of indices as predictors (left) and Principal-response curve - OLS models with pre-specified inputs of indices as predictors (right)

\footnotetext{
${ }^{2}$ We use mean imputation for this analysis.

${ }^{3}$ We indicate that these differences are approximate since their precise magnitudes will vary across different simulations.
} 


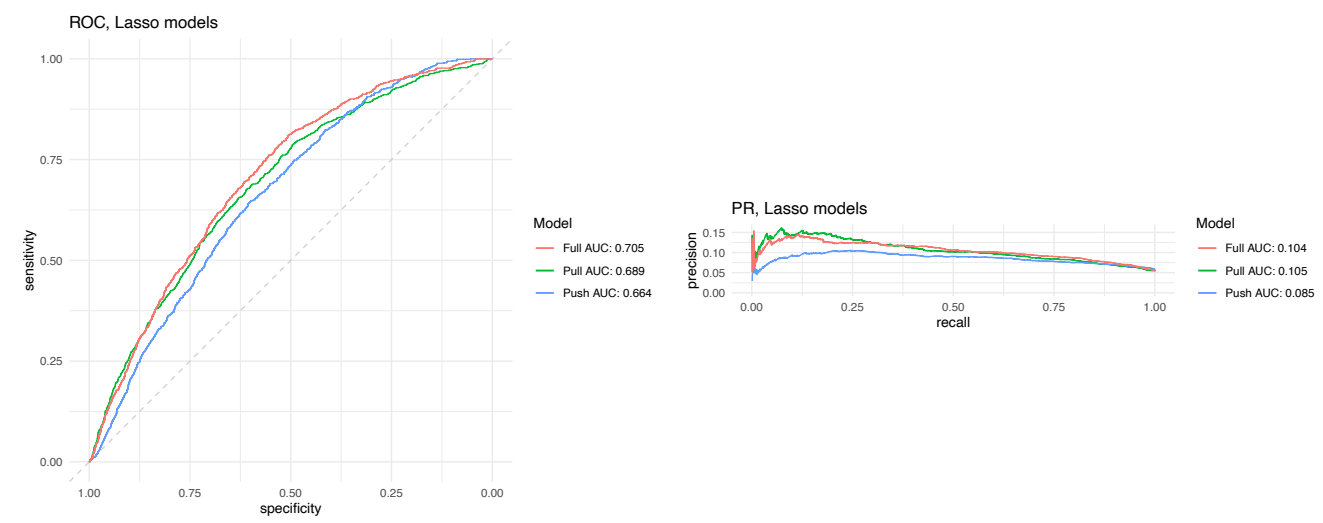

Figure A16: ROC-Lasso models with pre-specified inputs of indices as predictors (left) and Principal-response curve - Lasso models with pre-specified inputs of indices as predictors (right)

\subsection{Map of conditions in Lebanon}

This section further demonstrates the variation in push factors within Lebanon. Using all variables use to measure push factors in Lebanon, we construct a single index for conditions in Lebanon (extracting the first principal component from PCA) 4 Figure A17 shows the weighted average of this index by district. It should be noted that this index was constructed to have zero mean and unit standard deviations, so the variation can be measured in terms of standard deviations. The map in Figure A17 shows that push factors in Lebanon varied substantially across districts. The difference between the district with the worst conditions for respondents (El Minieh-Dennie) and the district with the best conditions for respondents (El-Nabatieh) is about 2.4 standard deviations. This map suggests that variation across districts was associated with a significant change in push factors in our survey. It should be noted that disaggregating results from a nationally representative survey does not produce estimates that are representative of the subnational units (here, districts). Nonetheless, Figure A17 clearly demonstrates that respondents in our sample exhibit significant variation in push factors across Lebanon's different districts.

\footnotetext{
${ }^{4}$ We use mean imputation for this analysis.
} 


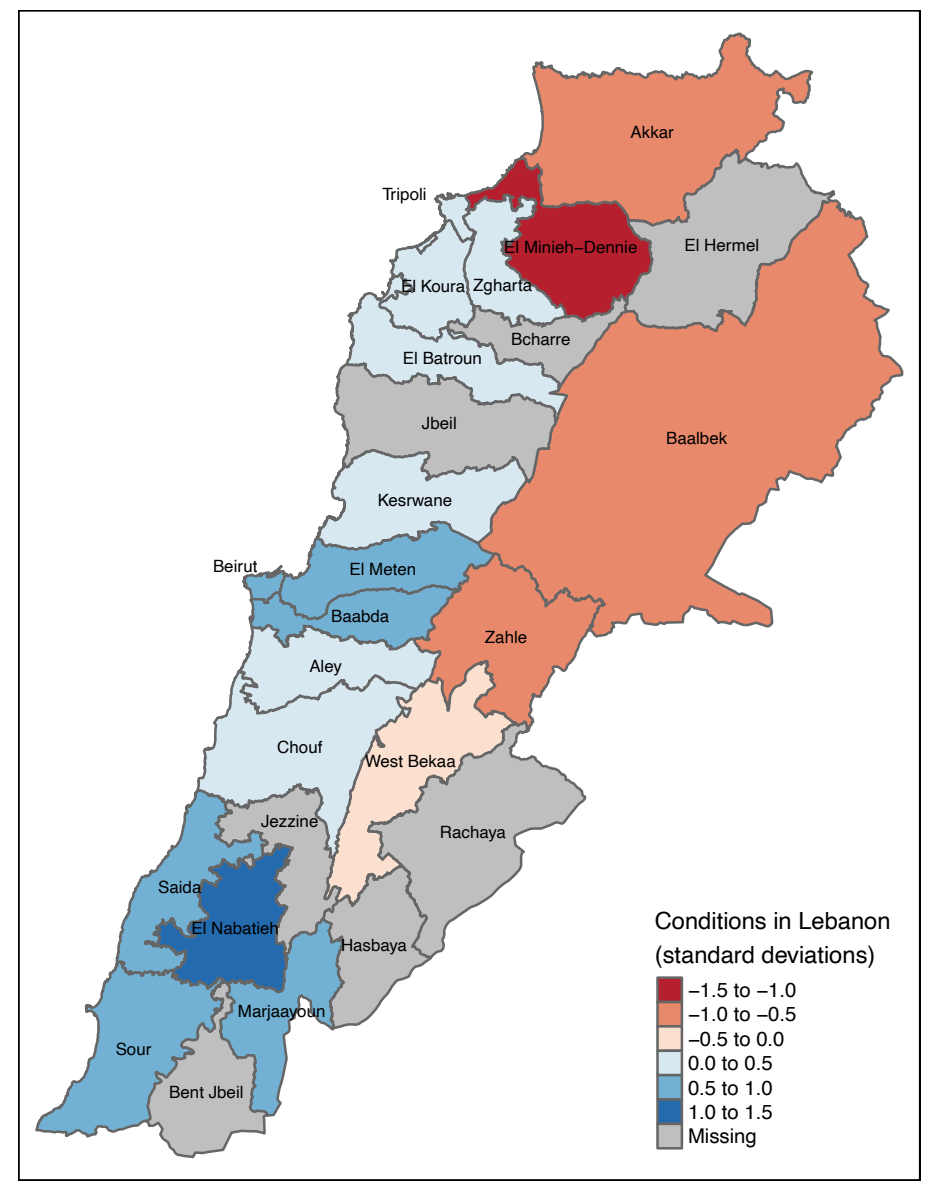

Figure A17: Map of respondents' conditions in Lebanon.

\subsection{Conjoint results}

As many respondents had relatively low literacy levels, the enumerators read them a vignette with the conjoint experiment. To make sure that the vignette was manageable and could be remembered by the respondent, each vignette randomly included either the condition about jobs in Lebanon (Syria) or the condition about public service provision in Lebanon (Syria). We report the regression results for the conjoint in Table A26.

\section{Jordan survey}

In this section, we present the set of questions we used to construct each index from the Jordan survey data. As with the Lebanon indices, we constructed these indices by extracting the first components from PCA of the input variables. Some of the questions differ from the wording used in Lebanon in order to fit the Jordan context. Due to space constraints in the Jordan survey, the 
Table A26: Model 1: Main conjoint results. Model 2: Conjoint results for vignettes that included hometown is not safe AND military conscription remains. Model 3: Conjoint results for vignettes that included (hometown is safe OR all Syria is safe) AND military conscription ended.

\begin{tabular}{lccc}
\hline & Model 1 & Model 2 & Model 3 \\
\hline Intercept & $-0.046(0.012)^{* * *}$ & $0.032(0.012)^{* *}$ & $0.526(0.024)^{* * *}$ \\
Hometown Safe & $0.352(0.010)^{* * *}$ & & \\
All Syria Safe & $0.417(0.011)^{* * *}$ & & \\
Many Jobs in Syria & $0.076(0.011)^{* * *}$ & $0.006(0.014)$ & $0.111(0.022)^{* * *}$ \\
Public Services Available in Syria & $0.077(0.011)^{* * *}$ & $0.006(0.011)$ & $0.126(0.022)^{* * *}$ \\
Conscription Ended & $0.177(0.009)^{* * *}$ & & \\
Good job in Lebanon & $-0.022(0.011)^{*}$ & $-0.008(0.012)$ & $-0.042(0.021)^{*}$ \\
Public Services Available in Lebanon & $-0.028(0.011)^{* *}$ & $-0.012(0.013)$ & $-0.044(0.022)^{*}$ \\
Friends in Lebanon & $-0.001(0.009)$ & $0.021(0.009)^{*}$ & $0.010(0.019)$ \\
Friends in Syria & $0.050(0.010)^{* * *}$ & $0.046(0.011)^{* * *}$ & $0.058(0.019)^{* *}$ \\
\hline Num. obs. & 14728 & 2487 & 4840 \\
RMSE & 7.344 & 3.608 & 8.430 \\
N Clusters & 2998 & 1778 & 2549 \\
\hline
\end{tabular}

${ }^{* * *} p<0.001 ;{ }^{* *} p<0.01 ;{ }^{*} p<0.05$

survey did not contain the full set of questions used in Lebanon.

\begin{tabular}{|c|c|c|c|}
\hline Safety in Syria & Economic well-being in Syria & Services in Syria & Networks in Syria \\
\hline $\begin{array}{l}\text { How would you describe the } \\
\text { risk to civilians physical safety } \\
\text { (such as fighting, kidnapping, } \\
\text { IEDs, crimes) in your place of } \\
\text { origin? }\end{array}$ & $\begin{array}{l}\text { How would you describe the } \\
\text { availability of jobs at present in } \\
\text { your place of origin? }\end{array}$ & $\begin{array}{l}\text { As far as you know, how } \\
\text { many hours per day is there } \\
\text { electricity in your place of } \\
\text { origin? }\end{array}$ & $\begin{array}{l}\text { Approximately how many of } \\
\text { your relatives or friends in } \\
\text { Jordan have gone back to } \\
\text { Syria? (capped at } 15 \text { max) }\end{array}$ \\
\hline $\begin{array}{l}\text { What were the main reasons } \\
\text { for you to leave your home } \\
\text { country } \\
\text { Syria? (Violence/bombardment } \\
\text { selected) }\end{array}$ & & $\begin{array}{l}\text { As far as you know, how many } \\
\text { hours per day is there running } \\
\text { water in your place of origin? }\end{array}$ & $\begin{array}{l}\text { Approximately how many of your } \\
\text { relatives or friends in Jordan have } \\
\text { gone back to your place of } \\
\text { origin in Syria? (capped at } 15 \text { max) }\end{array}$ \\
\hline \multirow[t]{2}{*}{ Conscription eligible $(<42$ male $)$} & & $\begin{array}{l}\text { As far as you know, are schools } \\
\text { operating in your place of } \\
\text { origin? }\end{array}$ & \\
\hline & $\begin{array}{l}\text { As far as you know, are health } \\
\text { centers operating in your place } \\
\text { of origin? }\end{array}$ & & \\
\hline
\end{tabular}

Table A27: Jordan questionnaire: Pull factors in Syria 


\begin{tabular}{|c|c|c|c|c|}
\hline Economic well-being in Jordan & Services in Jordan & Networks in Jordan & Social well-being in Jordan & Legal situation in Jordan \\
\hline $\begin{array}{l}\text { If you think back about the } \\
\text { situation one year ago in terms } \\
\text { of access to assistance, has the } \\
\text { situation improved, stayed the } \\
\text { same, or deteriorated? }\end{array}$ & $\begin{array}{l}\text { On } 24 \text { January }[2019] \text { the Prime Minister's office } \\
\text { signed a decree informing that Syrian refugees in } \\
\text { MOH hospitals and health centers will be requested } \\
\text { to pay directly } 80 \% \text { of the applicable 'foreigners } \\
\text { rate,' whereas from November } 2014 \text {, they were } \\
\text { treated like Jordanians who did not have health } \\
\text { insurance and were able to access health services at } \\
\text { subsidized rates. Has it impacted your ability to } \\
\text { access health services? }\end{array}$ & $\begin{array}{l}\text { In the last } 12 \text { months, how often } \\
\text { did you share a meal with } \\
\text { Jordanians who are not part of } \\
\text { your family? }\end{array}$ & $\begin{array}{l}\text { Does anyone in your family } \\
\text { face verbal or physical } \\
\text { harassment, meaning verbal } \\
\text { or other actions meant to } \\
\text { annoy, threaten, intimidate, } \\
\text { or make someone feel scared } \\
\text { for their safety, in the area } \\
\text { around your house? }\end{array}$ & $\begin{array}{l}\text { Do all your family members } \\
\text { have a valid registration with } \\
\text { UNHCR? }\end{array}$ \\
\hline $\begin{array}{l}\text { Have you received assistance } \\
\text { from [government organizations, } \\
\text { local organizations, NGOs, UN } \\
\text { in the last two months]? }\end{array}$ & Number of school aged children out of school & $\begin{array}{l}\text { Please think about the Jordanians } \\
\text { in your phone contacts. With how } \\
\text { many of them did you have a } \\
\text { conversation-either by phone, } \\
\text { messenger chat, face-to-face, or } \\
\text { text exchange-in the last week? }\end{array}$ & $\begin{array}{l}\text { Would you describe the relations } \\
\text { with your neighbors as mostly } \\
\text { positive/neither positive nor } \\
\text { negative/mostly negative? }\end{array}$ & $\begin{array}{l}\text { Do you have a government } \\
\text { service card, currently called } \\
\text { "MOI Card"? }\end{array}$ \\
\hline Are your currently working? & & $\begin{array}{l}\text { Please think about the Syrians in } \\
\text { Jordan in your phone contacts. } \\
\text { With how many of them did you } \\
\text { have a conversation-either by } \\
\text { phone, messenger chat, face-to- } \\
\text { face, or text exchange-in the last } \\
\text { week? }\end{array}$ & $\begin{array}{l}\text { What is your level of } \\
\text { education? }\end{array}$ & \\
\hline $\begin{array}{l}\text { Is any member of your } \\
\text { household currently working? }\end{array}$ & & & $\begin{array}{l}\text { When did the first member } \\
\text { of your family arrive to } \\
\text { Jordan? }\end{array}$ & \\
\hline $\begin{array}{l}\text { Do you or any of your } \\
\text { household } \\
\text { have a work permit? }\end{array}$ & & & $\begin{array}{l}\text { How connected do you feel } \\
\text { with Jordanian society? }\end{array}$ & \\
\hline $\begin{array}{l}\text { Have you received food } \\
\text { vouchers during the last } \\
\text { month? }\end{array}$ & & & $\begin{array}{l}\text { How often do you feel like } \\
\text { an outsider in Jordan? }\end{array}$ & \\
\hline
\end{tabular}

Table A28: Jordan questionnaire: Push factors from Jordan

\begin{tabular}{|l|l|}
\hline Outcome & Confidence in information \\
\hline \multirow{4}{*}{$\begin{array}{l}\text { Do you think it will ever be possible to return to } \\
\text { your place of origin in Syria? }\end{array}$} & What do you have information about [in Syria]: Respondent selects \\
all that applies. 1 if selected: & (a) Safety/security news \\
& (b) Status of infrastructure in a particular location \\
& (c) News about friends/family in Syria \\
\hline & How confident are you in your knowledge about conditions in your \\
& place of origin? \\
\hline
\end{tabular}

Table A29: Jordan questionnaire: Outcome and confidence in information

\begin{tabular}{lrrrrrl}
\hline Variable & Mean & Std.Dev & Min & Median & Max & Pct.Missing \\
\hline Age (Years) & 38.69 & 11.92 & 18.00 & 37.00 & 85.00 & $0.00 \%$ \\
Female & 0.58 & 0.49 & 0.00 & 1.00 & 1.00 & $0.00 \%$ \\
Female head of household & 0.34 & 0.47 & 0.00 & 0.00 & 1.00 & $0.00 \%$ \\
Household size & 5.06 & 2.32 & 1.00 & 5.00 & 15.00 & $0.00 \%$ \\
Plan to ever return to Syria & 0.04 & 0.19 & 0.00 & 0.00 & 1.00 & $0.00 \%$ \\
\hline
\end{tabular}

Table A30: Summary statistics of the outcome and demographic variables used in the Jordan study 


\begin{tabular}{|c|c|c|c|c|c|c|}
\hline Variable & Mean & Std.Dev & Min & Median & Max & Pct.Missing \\
\hline No. relatives/friends returning to origin (censored at 15$)$ & 1.05 & 3.10 & 0.00 & 0.00 & 15.00 & $0.00 \%$ \\
\hline No. relatives/friends returning to Syria (censored at 15) & 2.24 & 4.65 & 0.00 & 0.00 & 15.00 & $0.00 \%$ \\
\hline Eligible for conscription (male 18-42) & 0.28 & 0.45 & 0.00 & 0.00 & 1.00 & $0.00 \%$ \\
\hline Know about friends and family in Syria & 0.21 & 0.40 & 0.00 & 0.00 & 1.00 & $0.00 \%$ \\
\hline Know about status of infrastructure in Syria & 0.12 & 0.33 & 0.00 & 0.00 & 1.00 & $0.00 \%$ \\
\hline Know about safety and security in Syria & 0.50 & 0.50 & 0.00 & 1.00 & 1.00 & $0.00 \%$ \\
\hline Left Syria because of violence & 0.92 & 0.27 & 0.00 & 1.00 & 1.00 & $0.00 \%$ \\
\hline Hours of electricity in origin ( 0 : none, $4: 24$ hours a day) & 1.69 & 1.24 & 0.00 & 1.00 & 4.00 & $29.47 \%$ \\
\hline Are health centers operating in origin? & 0.55 & 0.50 & 0.00 & 1.00 & 1.00 & $48.83 \%$ \\
\hline Availability of jobs in origin ( 0 : very bad, 3 : very good) & 0.44 & 0.65 & 0.00 & 0.00 & 3.00 & $35.38 \%$ \\
\hline Confidence in info about origin ( 0 : not at all, 4 : very) & 2.21 & 1.19 & 0.00 & 2.00 & 4.00 & $0.00 \%$ \\
\hline Safety in origin (0: very dangerous, 3 : very safe) & 0.44 & 0.70 & 0.00 & 0.00 & 3.00 & $24.26 \%$ \\
\hline Are schools operating in origin? & 0.69 & 0.46 & 0.00 & 1.00 & 1.00 & $41.99 \%$ \\
\hline Hours of water in origin (0: none, $4: 24$ hours a day) & 1.61 & 1.18 & 0.00 & 1.00 & 4.00 & $30.40 \%$ \\
\hline
\end{tabular}

Table A31: Summary statistics of the conditions in Syria used in the Jordan study

\begin{tabular}{|c|c|c|c|c|c|c|}
\hline Variable & Mean & Std.Dev & Min & Median & Max & Pct.Missing \\
\hline Aid change in last year (0: deteriorated, 1 :same, 2 : improved) & 0.41 & 0.58 & 0.00 & 0.00 & 2.00 & $0.00 \%$ \\
\hline Received aid in last 2 months & 0.17 & 0.37 & 0.00 & 0.00 & 1.00 & $0.00 \%$ \\
\hline Education Level (1: no educ, 2: primary, 3: secondary/vocational, 4: higher) & 2.33 & 0.74 & 1.00 & 2.00 & 4.00 & $0.00 \%$ \\
\hline Household member employed & 0.62 & 0.49 & 0.00 & 1.00 & 1.00 & $0.00 \%$ \\
\hline Received food voucher in last month & 0.84 & 0.37 & 0.00 & 1.00 & 1.00 & $0.00 \%$ \\
\hline Household member reported harassment in local area & 0.08 & 0.27 & 0.00 & 0.00 & 1.00 & $0.00 \%$ \\
\hline Lack access to healthcare & 0.56 & 0.50 & 0.00 & 1.00 & 1.00 & $0.00 \%$ \\
\hline Received help from neighbors & 0.17 & 0.38 & 0.00 & 0.00 & 1.00 & $0.00 \%$ \\
\hline Possess Ministry of Interior ID & 0.98 & 0.12 & 0.00 & 1.00 & 1.00 & $0.00 \%$ \\
\hline Share meal with Jordanians (1: Never, 5 : Almost daily) & 2.19 & 1.16 & 1.00 & 2.00 & 5.00 & $0.00 \%$ \\
\hline Conversations with Jordanians in past week (1: $0,5: 15$ or more) & 2.53 & 1.16 & 1.00 & 2.00 & 5.00 & $0.00 \%$ \\
\hline Conversations with Syrians in Jordan in past week (1: $0,5: 15$ or more) & 3.36 & 1.16 & 1.00 & 3.00 & 5.00 & $0.00 \%$ \\
\hline Lack access to school & 0.14 & 0.35 & 0.00 & 0.00 & 1.00 & $0.00 \%$ \\
\hline Relation with neighbords (0: negative, 1 : neither, 2 : positive) & 1.81 & 0.41 & 0.00 & 2.00 & 2.00 & $0.00 \%$ \\
\hline Connection to Jordanian society (1: not at all, 5 : extremely close) & 3.90 & 1.02 & 1.00 & 4.00 & 5.00 & $0.00 \%$ \\
\hline Feel like an outsider (1: always, 5 : never) & 4.12 & 1.05 & 1.00 & 5.00 & 5.00 & $0.00 \%$ \\
\hline All household members registered with UNHCR & 0.98 & 0.14 & 0.00 & 1.00 & 1.00 & $0.00 \%$ \\
\hline Any household member has work permit & 0.25 & 0.44 & 0.00 & 0.00 & 1.00 & $0.00 \%$ \\
\hline No. years since first household member arrived in Jordan & 1.69 & 0.94 & 0.00 & 1.00 & 3.00 & $0.00 \%$ \\
\hline
\end{tabular}

Table A32: Summary statistics of the conditions in Jordan used in the Jordan study 


\section{Ethical Considerations: Survey}

The ethical imperative to do no harm is especially pressing in research with refugees, given their extreme vulnerability (Masterson and Mourad, 2019). We designed this project to reduce potential harm, maximize policy relevance, and increase opportunities for direct benefits to research participants. The achieve the first two goals, the authors drew on exploratory fieldwork, interviews with international and local humanitarian actors, and a research planning workshop with the humanitarian community in Beirut during which we discussed our research plan and questionnaire to minimize potential harm and ensure that the design can provide the humanitarian community with required evidence to fulfill their needs. To address the first and the third goals, the research team partnered with NGOs to provide protection training to enumerators and established a referral mechanism through which research participants in need of humanitarian services were connected to available resources. Below we discuss some of the measures we have taken.

\section{Compensation}

Survey interviews took about 30-40 minutes to complete and we provided survey respondents with $\$ 10$ cash compensation for their time. We decided to compensate respondents following extensive interviews with humanitarian actors, as many humanitarian actors suggested that it is only fair to compensate participants for their time following a somewhat long survey.

\section{Engagement with humanitarian actors}

To strengthen the research contribution, we closely consulted with humanitarian actors at all stages of the project. At the outset, we worked with humanitarian actors to conduct focus groups and meetings with refugees in Lebanon and Jordan. We consulted with humanitarian actors closely on the development of the questionnaire. Prior to data collection, we conducted a workshop with humanitarian actors in Beirut, Lebanon, in March 2019 to present the whole project and get feedback, including on the questionnaire. We then revised the questionnaire based on comments (for instance, we removed questions that directly measured political attitudes, which they suggested were too sensitive for the context). In June 2020, we conducted several online workshops with humanitarian actors in Lebanon to share results and answer questions from humanitarian actors.

\section{Referrals}

When we presented the research design and questionnaire to humanitarian organizations in March 2019, they suggested developing a referral strategy for refugees who require or ask for help. The 
goal of referrals is to help facilitate refugees' access to services by either (1) putting individuals in need of services directly in contact with the service providers or (2) enabling people to seek assistance and support them in receiving assistance. Enumerators and team leaders who participated in data collection received special training from a humanitarian organization in Lebanon on the goals of referrals, when to refer respondents, and how to refer respondents. In addition to the training, enumerators received guidelines that were built using material that is used by humanitarian organizations. Humanitarian organizations in Lebanon collaborate on a centralized referral platform called Referral Information Management System (RIMS), in addition to traditional referral methods (by reaching out directly to the responsible organization). As RIMS was not available for use by researchers (only humanitarian actors could use it), the research team collaborated with a local humanitarian organization to conduct the referrals and compensated them for the time they spent carrying out needed referrals for this project's research participants.

Figure A18 summarizes the referral process and was included in the enumerator guide: 


\section{When and how to do a referral?}

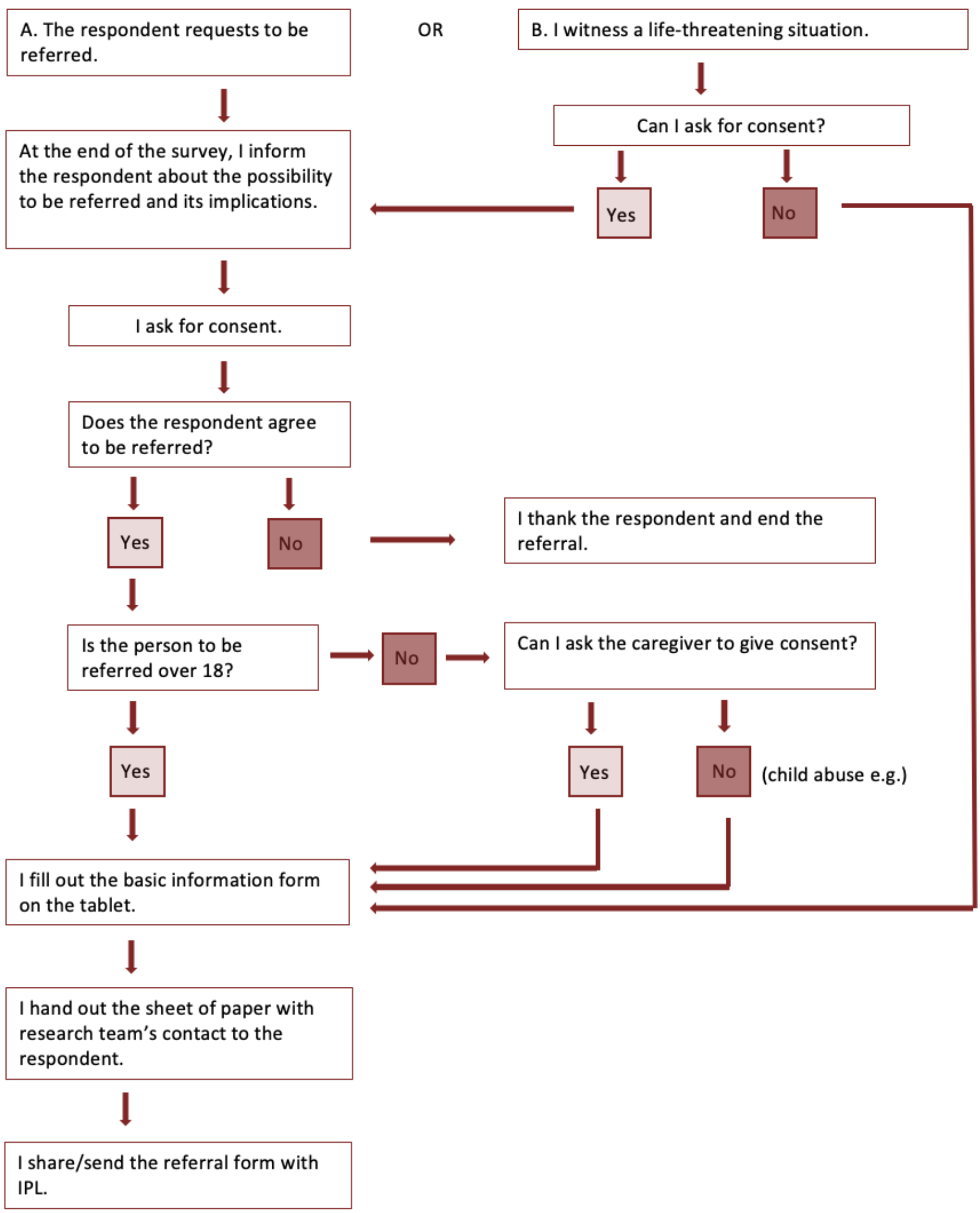

Figure A18: Referral guide summary 


\section{Qualitative Interviews: Details and Ethical Considerations}

In order to complement the quantitative survey, we also conducted repeated in-depth interviews with 20 Syrian families who were in Lebanon as of January 2020. The ethical concerns of these qualitative interviews are distinct from, although we believe no greater than, the quantitative survey. One important aspect of the modification is that the in-depth interviews with 20 participants were audio-recorded and transcribed.

Due to the timing of the beginning of qualitative data collection and the onset of the global Covid-19 pandemic, all qualitative data collection took place through WhatsApp.

Table A33 describes some of the characteristics of the respondents in the qualitative interviews as well as when these interviews took place. 


\begin{tabular}{|c|c|c|c|c|c|c|c|}
\hline ID & Interview Number & Month/year & Residence & Origin & Gender & Age & Comment \\
\hline 1 & 1 & April 2020 & Beirut & Homs & Male & $55-59$ & \\
\hline 1 & 2 & February 2021 & - & - & Male \& Female & - & Wife took over in middle of interview \\
\hline 1 & 3 & May 2021 & - & - & Female & - & Wife answered this interview \\
\hline 2 & 1 & May 2020 & Greater Beirut & Aleppo & Female & $30-34$ & \\
\hline 2 & 2 & June 2020 & - & - & - & - & \\
\hline 2 & 3 & February 2021 & - & - & - & - & \\
\hline 2 & 4 & May 2021 & - & - & - & - & \\
\hline 2 & 5 & August 2021 & - & - & - & - & \\
\hline 3 & 1 & March 2020 & Beirut & Deir Ez-Zor & Female & $35-39$ & \\
\hline 3 & 2 & December 2020 & - & - & - & - & \\
\hline 4 & 1 & April 2020 & Akkar & Hama & Male & $40-44$ & \\
\hline 4 & 2 & December 2020 & - & - & - & - & \\
\hline 4 & 3 & June 2021 & - & - & - & - & \\
\hline 5 & 1 & March 2020 & Akkar & Hama & Male & $30-34$ & \\
\hline 6 & 1 & May 2020 & Beirut & Hassakeh & Female & $25-29$ & \\
\hline 6 & 2 & June 2020 & - & - & - & - & \\
\hline 6 & 3 & June 2021 & - & - & - & - & \\
\hline 7 & 1 & March 2020 & Beirut & Deraa & Male & $40-44$ & \\
\hline 8 & 1 & March \& April 2020 & Beirut & Homs & Female & $25-29$ & \\
\hline 8 & 2 & June 2020 & - & - & - & - & \\
\hline 8 & 3 & February 2021 & - & - & - & - & \\
\hline 8 & 4 & June 2021 & - & - & - & - & \\
\hline 9 & 1 & April 2020 & Mount Lebanon & Hama & Male & $20-24$ & \\
\hline 9 & 2 & November 2020 & - & - & - & - & \\
\hline 9 & 3 & January 2021 & - & - & - & - & \\
\hline 9 & 4 & May 2021 & - & - & - & - & \\
\hline 10 & 1 & February 2020 & Beirut & Aleppo & Female & $55-59$ & \\
\hline 10 & 2 & January 2021 & - & - & - & - & \\
\hline 10 & 3 & June 2021 & - & - & - & - & \\
\hline 11 & 1 & February 2020 & Beirut & Deir Ez-Zor & Female & $40-44$ & \\
\hline 11 & 2 & April 2020 & - & - & Female \& Male & - & Husband took over in middle of interview \\
\hline 11 & 3 & November 2020 & - & - & Male & - & Husband answered this interview \\
\hline 11 & 4 & June 2021 & - & - & Male & - & Husband answered this interview \\
\hline 12 & 1 & February 2020 & Mount Lebanon & Hama & Male & $30-34$ & \\
\hline 12 & 2 & April 2020 & - & - & - & - & \\
\hline 12 & 3 & February 2021 & - & - & - & - & \\
\hline 13 & 1 & May 2020 & Mount Lebanon & Hama & Male & $30-34$ & \\
\hline 14 & 1 & March 2020 & Greater Beirut & Aleppo & Male & $30-34$ & \\
\hline 14 & 2 & January 2021 & - & - & - & - & \\
\hline 14 & 3 & May 2021 & - & - & - & - & \\
\hline 15 & 1 & March 2020 & Akkar & Hama & Male & $30-34$ & \\
\hline
\end{tabular}

Table A33: Qualitative Interview Details

\section{Risks}

As discussed above regarding survey interviews, we do not believe that interview participation is likely to exacerbate risk for Syrians in Lebanon.

Risks from our interviews over WhatsApp calls are minimal. We developed our data collection 
approach through WhatsApp calls through consultation with digital rights groups, and phone-based in-depth interviews avoided sensitive topics.

One potential risk would be that phone calls were monitored or overheard. Monitoring of WhatsApp communication would require that someone's phone be confiscated or they be overheard speaking with us. If someone's phone were confiscated, a phone call record (but not the content of the calls) would be visible. Text message records would be visible. To avoid risk from these situations we did not ask any sensitive questions over text.

If someone were overheard speaking with us by a bystander, that person would hear whatever the interview participant says, but not our questions. Although we deemed these circumstances unlikely, we wanted to take special precaution to reduce this potential threat, especially for anyone in Syria. Therefore, before any interview began, we asked participants a series of questions that gave them the opportunity to not take the call if they were not in a safe position to do so, without needing to say anything that would be suspicious. For instance, "Is now a good time for you to talk?" and "Would it be better if I called back later?" allow people to say simple "yes" and "no" responses if speaking is not safe. Four of the qualitative interview participants moved to Syria during the research time period and two others traveled elsewhere. As a result, those six people were not interviewed.

We designed the study to minimize the risk of a data breach or confidentiality breach. All data is stored on a secure, encrypted, GDPR-compliant server. All contact information and identifying information was stored separately from interview data and is not part of the audio recording but rather filed in a separate document that was password-protected and stored on a secure server. The crosswalk code is encrypted and only available to the research team.

\section{Psychological risks}

Research can create a risk of psychological harm if researchers do not anticipate the risk of retraumatizing people. Such questions could include asking about people's wartime experiences in Syria, their journey to Lebanon and/or things they lost because of the war in Syria. To address these concerns, interview content continually aimed to avoid re-traumatizing participants, which could arise from seeking out information about violence or loss.

The semi-structured nature of baseline interviews and open-ended nature of follow-up interviews allowed participants to bring up their own stories as they choose, telling us only what they feel comfortable discussing. One important goal of the first qualitative interview with each participant was learning about potential sensitivities that they face. We did not elicit discussion of sensitive topics in general, and made specific efforts with each participant to avoid issues that are sensitive 
for them personally.

Additionally, we pilot tested the interview guide to gauge and minimize risks. In the pilot, following each potentially sensitive section and at the end of the interview, the interviewer debriefed with participants about their experience and perception of the interview questions. This was intended to identify questions or sections that provoke negative reactions or anxiety.

The study author carrying out the interviews is well-positioned and trained to address potential protection concerns that may arise during the research. The author is an experienced interviewer who has conducted research work with similarly vulnerable populations in multiple countries and fluently speaks Levantine Arabic. The author has attended several protection trainings, the most recent one delivered by Oxfam in Beirut in July 2019 for enumerators of this study.

If participants needed to be referred to specific NGOs for case management, the team used the referral system described in Appendix Section 8 In the end, no participants in the qualitative interviews were referred to NGOs for support through our referral system.

Although we did not collect data that would put participants at psychological risk if the responses were revealed, we designed the study to minimize the risk of a data breach or confidentiality breach, as discussed directly above.

\section{Privacy and confidentiality}

WhatsApp calls and voice messages facilitate privacy because participants do not need to travel or even leave their homes for data collection, and are always free to refuse to answer a call. As discussed above, we also asked screening questions at the beginning of each qualitative interview that gave people the opportunity to safely decline the interview, if they were not in a good situation to speak on the phone with us.

Data was uploaded from a password-protected audio recording device to MedBox shortly after interviews, and then deleted from the audio recording device.

\section{Informed consent}

The research team obtained verbal consent rather than signed consent. There are two reasons for not asking participants to sign anything. First, many Syrian refugees are semi-literate or illiterate. Asking them to sign a form that they cannot fully understand would likely cause anxiety and mistrust. Second, even among Syrians who can read, asking refugees with precarious legal status to sign formal documents will create anxiety and fear about what exactly the document states and how it will be used. 
Informed consent during the first interview explained the repeated nature of participation in the research study. Semi-structured interviews were only conducted with selected participants if and after they gave consent.

\section{Verbal consent statement}

1. DESCRIPTION: My name is Marine Casalis, I am working on a study with researchers from the universities ETH Zurich, Stanford University, and the University of California, Santa Barbara. We interviewed you .... months ago in ... and you agreed to be re-contacted. As you may remember, our goal is to understand the situation of Syrians living in Lebanon and how they see their future, which will inform the work of humanitarian agencies and the academic community. Your answers will be confidential and will not be shared with anyone outside of the research team. I would like to ask you some questions with the aim of having a better understanding of your living conditions. This interview will be different from the first one you did with us because you will have the opportunity to speak much longer and share your experience with me.

I would like to audio record this interview, only your voice, not taking pictures of you or filming you, so that I can fully focus on what you are telling me and make sure I have an accurate account of what you are sharing with me. This will also allow me when I listen to it again in the coming weeks/months to transcribe truthfully what you told me. I will not use this audio recording beyond the research team without asking you again for consent.

In addition to interviewing you today, we would like to learn about how your situation changes in the future by corresponding with you further in the future, including via WhatsApp and possibly more in-person interviews like today. We will reach in touch with you every 1-3 months, and you are also always free to contact us if you would like to follow-up on anything from the interview.

2. TIME INVOLVEMENT: This is very valuable to us so we thank you for your time. The interview will take roughly 60 minutes but you can stop it at any given time.

3. RISKS AND BENEFITS: Risks include possible loss of confidentiality, and the survey includes questions that you may find upsetting. We cannot and do not guarantee or promise that you will receive any benefits from this study.

We will provide you with approximately $\$ 10$ in phone credit for each long interview.

Your decision whether or not to participate in this study will not affect your eligibility for any services the UN Refugee Agency or any other humanitarian aid provider.

4. PARTICIPANT'S RIGHTS: If you agree to participate in this project, please understand that your participation is voluntary and you have the right to withdraw your consent or discontinue participation at any time without penalty or loss of benefits to which you are otherwise entitled. The 
alternative is not to participate. You have the right to refuse to answer particular questions. The results of this research study may be presented at scientific or professional meetings or published in scientific journals. Your individual privacy will be maintained in all published and written data resulting from the study.

5. Identifiers might be removed from identifiable private information and, after such removal, the information could be used for future research studies or distributed to another investigator for future research studies without additional informed consent from you.

6. CONTACT INFORMATION: a. Questions: If you have any questions, concerns or complaints about this research, its procedures, risks and benefits, contact the Protocol Director at [XXX]. This number is only reachable via WhatsApp and Viber and you can message us or call us this way for free.

b. Independent Contact: If you are not satisfied with how this study is being conducted, or if you have any concerns, complaints, or general questions about the research or your rights as a participant, please contact the Stanford Institutional Review Board (IRB) to speak to someone independent of the research team at (650)-723-2480 or toll free at 1-866-680-2906, or email at IRB2Manager@lists.stanford.edu. You can also write to the Stanford IRB, Stanford University, 3000 El Camino Real, Five Palo Alto Square, 4th Floor, Palo Alto, CA 94306.

Do you have any questions?

Do you agree?

\section{References}

Abadie, Alberto, Susan Athey, Guido W Imbens and Jeffrey Wooldridge. 2017. "When should you adjust standard errors for clustering?".

Hainmueller, Jens, Dominik Hangartner and Giuseppe Pietrantuono. 2017. "Catalyst or crown: Does naturalization promote the long-term social integration of immigrants?" American Political Science Review 111(2):256-276.

Kling, Jeffrey, Jeffrey Liebman and Lawrence Katz. 2007. "Experimental analysis of neighborhood effects." Econometrica 75(1):83-119.

Masterson, Daniel and Lama Mourad. 2019. "The Ethical Challenges of Field Research in the Syrian Refugee Crisis." APSA MENA Politics 2(1).

Rubin, Donald B. 1987. Multiple imputation for nonresponse in surveys. John Wiley \& Sons. 